IFN Working Paper No. 1179, 2017

\title{
Disease and Fertility: Evidence from the 1918 Influenza Pandemic in Sweden
}

Nina Boberg-Fazlić, Maryna Ivets, Martin Karlsson and Therese Nilsson 


\title{
Disease and fertility: Evidence from the 1918 influenza pandemic in Sweden*
}

\author{
Nina Boberg-Fazlić, University of Southern Denmark \\ Maryna Ivets, University of Duisburg-Essen \\ Martin Karlsson, University of Duisburg-Essen \\ Therese Nilsson, Lund University and Research Institute of Industrial Economics
}

\begin{abstract}
This paper studies the effect of the 1918-19 influenza pandemic on fertility using a historical dataset from Sweden. Our results suggest an immediate reduction in fertility driven by morbidity, and additional behavioral effects driven by mortality. We find some evidence of community rebuilding and replacement fertility, but the net long-term effect is fertility reduction. In districts highly affected by the flu there is also an improvement in parental quality: we observe a relative increase in births to married women and better-off city dwellers. Our findings help understand the link between mortality and fertility, one of the central relations in demography, and show that several factors - including disruptions to marriage and labor markets - contribute to fertility reduction in the long term. Our results are consistent with studies that find a positive fertility response following natural disasters, but with high-quality historical data we show that this effect is short-lived.
\end{abstract}

Keywords: 1918-19 influenza pandemic; Influenza and pneumonia mortality; Fertility; Difference-in-Differences.

JEL classifications: I12, J11, J13 .

\footnotetext{
${ }^{*}$ We would like to thank Claudia Andreella, Daniel Avdic, Dave Donaldson, Martin Fischer, Svenn-Erik Mamelund, Stefan Pichler, Claus Pörtner, André Richter as well as the participants at seminars, the Economic Historic Society (EHS) Annual Conference (Cambridge, April 1-3, 2016), Essen Health Conference (Essen, May 27-29, 2016) and the Nordic Health Economists' Study Group (NHESG; Odense, August 17-19, 2016) for their help and suggestions.
} 


\section{Introduction}

A central line of inquiry in economic and demographic research concerns whether, when, and why fertility changes together with mortality. The event of an epidemic can cause major losses to a household and in a globalized world where communicable diseases cause numerous deaths and where epidemics can spread quickly across countries - with the 2002 outbreak of SARS in southern China, the 2006 bird flu in Asia, and the 2014 outbreak of Ebola in West Africa as recent examples - these questions seem especially relevant. Yet, there is a very limited literature on epidemics and fertility 1 Specifically, we lack evidence on the causal effects and knowledge on the dynamics of the fertility response. This paper uses the 1918-19 influenza pandemic in Sweden as a natural experiment to study how a severe morbidity and mortality shock affects subsequent fertility rates.

From a theoretical point of view, the fertility effects of epidemics will vary with mortality and morbidity and depend on the age distribution of the additional deaths. Fertility effects may also vary over different time horizons: the cumulative impact can be decomposed into immediate effects referring to the period of the first gradual increase in morbidity and mortality until the epidemic hits its peak; short-term effects referring to the time period of one to two years right after the peak; and long-term effects referring to the years thereafter.

From a biological perspective, fertility may change if the pandemic disease reduces sexual activity or the possibility to conceive. Pandemic infection may lead to early termination of pregnancy and the death of a spouse naturally reduces fertility prospects. Biological effects will thus reduce fertility and mainly stem from morbidity and adult mortality. Regarding the time horizon, we expect an immediate negative effect that fades out. The only biological effect that may remain in the long term is the death of a spouse, as matching and remarriage may take time.

There may also be behavioral effects driven by conscious decisions to adjust fertility behavior. These effects can be thought of as psychological or economic (where the latter are triggered by changes in relative prices and opportunity costs). The literature on psychological effects distinguishes between postponement and replacement fertility. Postponement fertility refers to fertility decisions being delayed due to uncertainty about survival of children and parents (Lee, 1981; Menken et al., 1981; Castro et al., 2015). Postponement fertility thus stems from morbidity and child or adult mortality. Fertility will decrease during the epidemic and increase right after the peak as couples who would have conceived anyway as well as couples who

\footnotetext{
${ }^{1}$ A growing literature evaluate fertility effects from the HIV/AIDS epidemic (Young, 2005, 2007, KalemliOzcan and Turan, 2011; Juhn et al. 2013; Karlsson and Pichler, 2015; Castro et al., 2015). This is a very different setting compared to the more frequent short-term epidemics as HIV/AIDS has been a problem for more than 20 years and behavior likely adjusts accordingly.
} 
postponed fertility will conceive in the short term. In the long term this positive effect is no longer present.

Replacement fertility stems from mortality inside or outside the family. Couples losing a child might try to conceive again to replace the offspring lost (see Preston, 1978), but replacement can also arise from high adult mortality at the broader community level (see Grimard, 1993, Conning and Udry, 2007; Geertz, 1963; Suri, 2005; Townsend, 1994). High mortality events may trigger a society-wide action to replace those that were lost, leading to new conceptions at the intensive and the extensive margin. This effect could be stronger in rural settings where communities are tighter and closer. In terms of dynamics, replacement fertility increases conceptions in the short-term following the flu, stemming from child or adult mortality $\left.\right|^{2}$

Finally, a major pandemic will impact the economic situation of a family and the broader community leading to economic effects on the fertility decision. Adult mortality within a family likely reduces incomes which may delay fertility as children are costly (Alam and Pörtner. 2016). Moreover, standard economic theory suggests that the death of young adults will increase wages and wealth as labor supply sharply decreases, and fixed factors such as land and capital are shared by fewer people (see Young, 2005; Boucekkine et al., 2009; Herlihy, 1997). The substitution effect associated with this wage increase will reduce fertility as female labor supply likely increases and having children becomes relatively more costly. At the same time the income effect will increase fertility, as agents can afford to have more children (cf. Del Bono et al. 2015) 3 During the short and the long term the economic effects are expected to decrease fertility if mortality stems from adult mortality, and possibly increase fertility if mortality stems from child mortality. ${ }^{4}$

There is a large literature showing that fertility increases as a response to mortality shocks following wars, natural disasters and economic crises (see e.g. Nobles et al. (2015) on the tsunami

\footnotetext{
${ }^{2}$ An alternative view is that increased fertility after a mortality shock is a type of hoarding effect: parents have more children than initially intended because the recent mortality shock instills doubt about their children's survival prospects (Preston, 1978, Rosenzweig and Schultz, 1983, Cohen and Montgomery, 1998, Palloni and Rafalimanana, 1999). This is more pertinent for long-duration events, like wars, the AIDS epidemic, or economic crises, and less pertinent for a short-term mortality shock following a natural disaster or an epidemic. This mechanism would only be relevant in the case of the 1918-19 influenza pandemic if it shifted the expectations of children's future survival over the longer term; for example, if a similar pandemic is expected to strike in the future.

3 Galor and Weil (1996) show that the substitution effect may dominate if women's relative wages increase. Karlsson et al. (2014) find an increase in female labor supply in Sweden after the flu, but no effect on earnings and in fact a positive impact on poverty rates. Despite a null effect on income, the positive effect on female labor supply could indicate a rise in the relative wage of women and thereby a dominating substitution effect. Note, however, that labor supply of women and children here only includes those working in factories. Increasing poverty could actually indicate a negative income effect and thereby predict a negative effect on fertility, but stem from the loss of economically active household members. If these members were children, they may be actively replaced in order to supplement income by which we would note an increase in fertility.

${ }^{4}$ Table A1 in the Appendix presents a graphical summary of the dimensions and time horizons of the predicted fertility effects.
} 
in South-East Asia; Pörtner (2008) on hurricanes in Guatemala; Finlay (2009) on severe earthquakes; Agadjanian and Prata (2002) and Lindstrom and Berhanu (1999) on war). In contrast, only two studies, both focusing on the 1918-19 influenza pandemic, examine fertility responses to transient epidemics. Mamelund (2004) examines the fertility effects in Norway employing a cross-sectional analysis while Donaldson and Keniston (2015) examine the relationship in India. Both studies suggest that birth rates increased significantly in the period after the flu, but provide limited evidence on the causal effect and the dynamics of the fertility response.

The 1918-19 influenza pandemic provides a unique opportunity to study fertility dynamics following a short-term pandemic affecting both morbidity and mortality. The pandemic was unforeseen and characterized by high fatality rates 5 , but also by the fact that it primarily affected fertile men and women from 20 to 40 years old 6

By focusing on Sweden, we have high-quality short- and long-run data to examine changes in fertility in a country that was neutral during WWI. Assembling administrative information from various sources, such as parish records, censuses, reports of chief medical officers and midwife journals, we create a purpose-built historical database. The dataset includes information on the number of deaths from all causes, births, stillbirths, influenza cases and various mother and birth characteristics for about 400 rural and urban areas located within 25 Swedish counties. In some cases, the same information is given in several sources so that they can be directly validated.

Our study makes several distinct contributions to the literature. First, this is the first largescale study of the fertility effects of the 1918-19 influenza pandemic, and of its possible link to the 1920s baby boom. In contrast to most existing studies of mortality shocks, we use data for the entire population, covering hundreds of thousands of births, and rely on highquality administrative information on deaths, births and individual characteristics. Second, compared to existing studies we consider both mortality and morbidity and examine a longer time period, allowing for different mechanisms operating in the immediate, short and long run. We explicitly explore the dynamic structure of the data by employing a difference-in-difference design, allowing us to identify a causal effect. Third, given the broad data sources we can examine several outcomes related to fertility which allow us to analyze effect heterogeneity and a range of mechanisms potentially at work - for example, who actually adjusted their fertility behavior. Finally, the study is also unique in that it explicitly deals with internal migration, which otherwise confounds any analysis on the effects of a mortality shock.

\footnotetext{
${ }^{5}$ Case-fatality rates during regular influenzas are less than $0.1 \%$, while case-fatality rates during the 1918-1919 influenza were more than 2.5\% (Mamelund et al., 2016: Taubenberger and Morens, 2006).

${ }^{6}$ During the influenza period-August 1918 to March $1919-1.45 \%$ of people from 20-40 age group died. More specifically, $1.62 \%$ of males and $1.28 \%$ of females in the $20-40$ age group died during the months of the flu (own calculations).
} 
Focusing on conceptions as our fertility measure, we find that the influenza pandemic was associated with a substantial reduction of fertility rates in the short and long term. Moving from the lowest to the highest quartile of health districts (in terms of adult flu mortality) is associated with a decline in the monthly conception rate by around nine per cent in the long run. Concomitantly, we do not find any evidence of short- or long-term replacement fertility. If anything, an elevated child flu mortality was associated with reductions in fertility. We do however find some evidence of postponement fertility in rural areas: fertility rates here tend to rebound in the period immediately after the pandemic. This positive effect is driven by highquality parents. Married couples, higher socioeconomic groups and mothers who already have at least one child contribute disproportionately to the short-term increase in fertility. In the longer term these temporary increases are swamped by the overall tendency of heavily affected areas to experience lower fertility rates.

Regarding potential mechanisms, we identify a combination of factors contributing to the longterm reduction. The flu period itself appears to trigger disruptions in the marriage market which persistently reduce the proportion of married individuals in the population. Since the number of children to married couples falls more slowly than the general fertility in the aftermath of the crisis, these marriage market disruptions make a large contribution to the drop in fertility rates. Additional effects seem to operate via income effects and changes on the labor market. Thus, when an epidemic turns deadly, consequences for the community will be felt decades after and go far beyond the period of the epidemic itself.

The historical context corresponds to a developed country during the course of the fertility transition 77 This makes our results pertinent to possible epidemics today, which mainly occur in countries which currently are in or recently have gone through the demographic transition. Our findings contribute to the understanding of the link between mortality and fertility and show that the effects go beyond those of direct exposure, but also have implications for the growing and widely cited literature on the fetal origins hypothesis following Barker (1990). Numerous studies show that in utero exposure to a negative health shock will have negative consequences later in life, both in terms of health and socioeconomic status (see, e.g., Almond, 2006). These results, however, rest on the assumption that people conceived during a negative health shock do not differ from those conceived shortly after, other than through exposure. If fertility decisions themselves are affected by the health shock, this assumption may not hold. In line with Brown and Thomas (2011) we find a selection into higher quality parents shortly after the flu.

\footnotetext{
${ }^{7}$ In Sweden, fertility began to decline in the late $19^{\text {th }}$ century (around 1880) when the number of children of married women was above four. The fertility transition to below two children per woman was completed by the mid-1930s (cf. Strulik and Vollmer, 2015). According to Bengtsson and Dribe (2014) fertility started to decline at about the same time for older and younger women. The most common form of birth control at the time was coitus interruptus, but abstinence and illegal abortions were also common methods (Santow, 1993). Contraceptives were sold in pharmacies, but between 1910 and 1938 a law prohibited advertising of contraceptives and speaking publicly about them was not allowed (Charchafche and Nilsson, 2006).
} 
If children conceived shortly after the shock have better predisposition than those conceived during the flu, adverse health and income effects of being in utero during the shock will be overestimated. The same caveat applies to studies of transgenerational effects (cf. Veenendaal et al., 2013) and of parental responses (Almond and Mazumder, 2013).

\section{The Historical Context}

\subsection{The 1918-19 Influenza Pandemic}

The first case of the influenza in Sweden was recorded at the end of June 1918. Initially, the seemingly mild influenza caused little concern, but the situation changed dramatically by the end of the summer. Influenza-related mortality and morbidity were particularly high from August 1918 to February 1919, peaking in October and November. Another less severe wave appeared in March 1919 and a final wave appeared in early 1920. Knowledge about viruses was very limited and many believed that influenza was in fact caused by bacteria. Influenza vaccines were yet to be invented and the only effective measures were rest and basic care, the use of hot blankets, cold compresses for headaches and drinking plenty of water (cf. Mamelund, 2011).

Around $10 \%$ of the Swedish population was infected (Richter and Robling, 2013) and nearly 1\% died from the 1918-19 influenza (Karlsson et al., 2014), but death rates varied considerably across the country. The most heavily affected counties in terms of morbidity and adult mortality were Västernorrland and Jämtland in the north, where the death rates were almost three times higher than in the least affected counties (Åman, 1990), and also child mortality was higher in the northern counties. Despite a clear north/south gradient at the aggregate level there was considerable heterogeneity within each county: Figure 1 shows district influenza morbidity, adult and child mortality rates from all causes for the period August 1918 to March 1919 (per 1,000 inhabitants). 


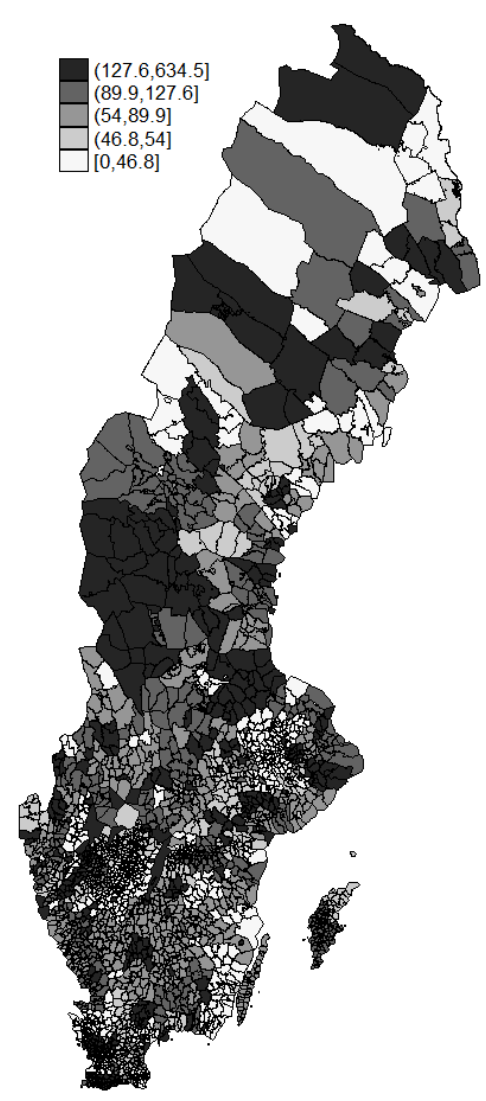

(a) Flu morbidity

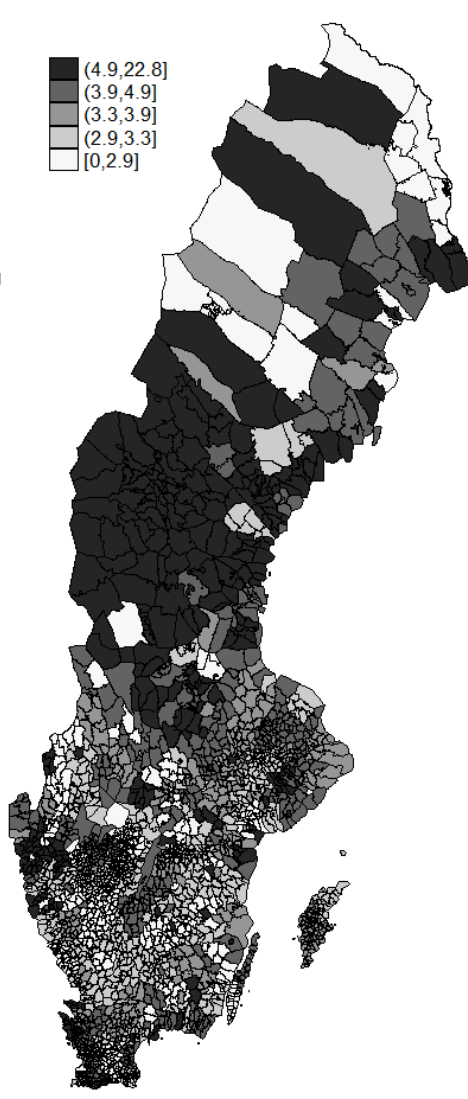

(b) Adult mortality

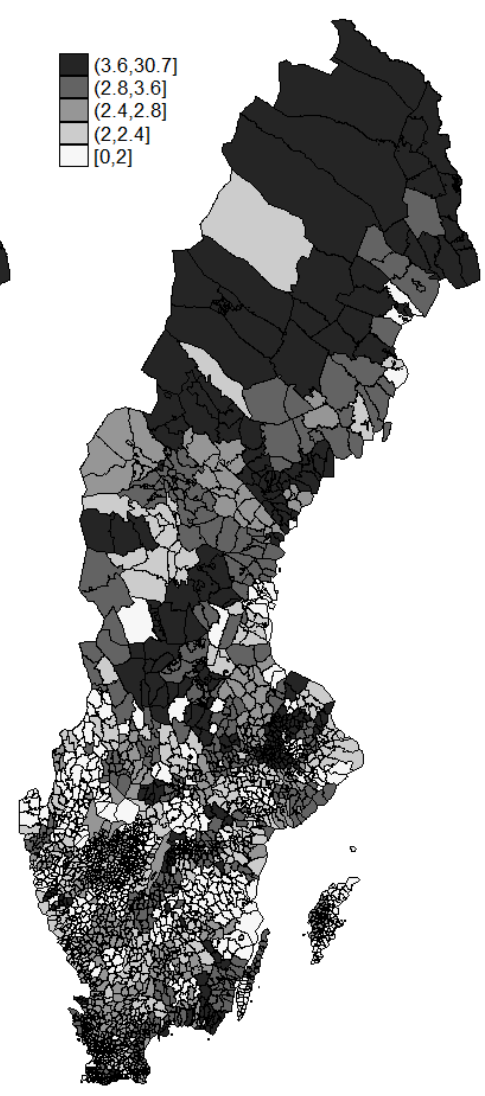

(c) Child mortality

Fig. 1 Influenza and pneumonia morbidity and overall mortality rates in Sweden during August 1918-March 1919 (per 1,000 inhabitants) NOTE: Data is on health district level. Legend categories represent quintiles.

The influenza pandemic had several unique characteristics compared to previous and subsequent flu epidemics. First, in its most virulent form the flu struck swiftly and unexpectedly. Most people died within 6 to 11 days after contracting the illness (Taubenberger and Morens, 2006). Second, the influenza affected bronchus and lungs which induced substantially more pneumonia deaths (Morens and Fauci, 2007). Third, the pandemic was unique in whom it affected as it primarily killed adults aged 20 to 40 . Figure 2 illustrates the fatality cases for Sweden during 1918 as compared to 1917 by age group. Clearly excess deaths for young adults were very high. Research suggests that the reason for this mortality pattern was cytokine shock, an overreaction of the immune system (Kobasa et al., 2007) such that a strong immune system was a liability rather than an asset. 


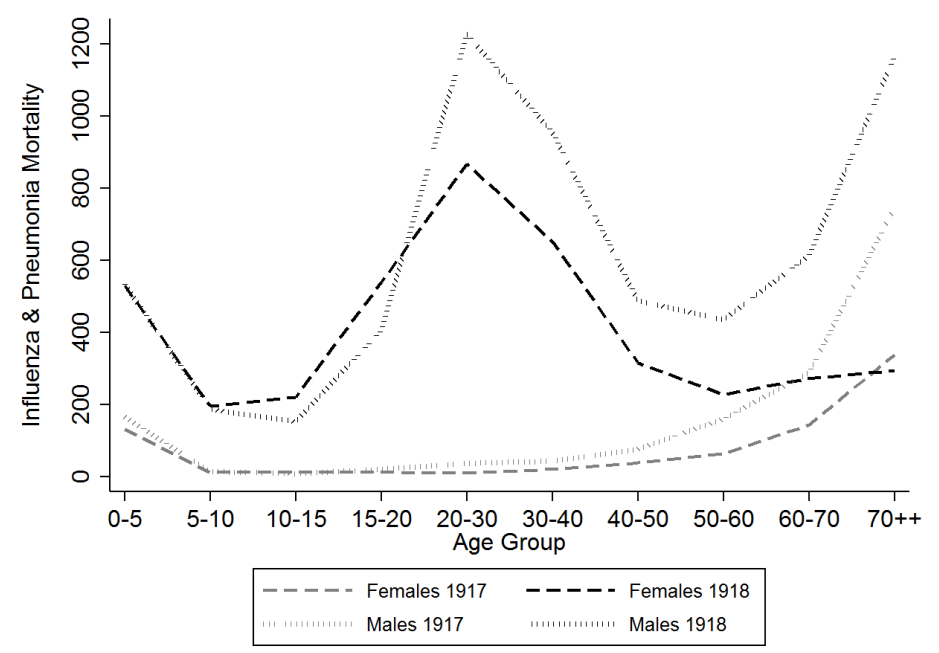

Fig. 2 Age distribution of influenza and pneumonia mortality, Sweden

Figure 3 shows the mortality rates in Sweden during the pandemic and pre/post-pandemic periods for different ages. Here we see that the mortality rates for all ages were higher during the flu period compared to other periods. Also, the share of deaths in 20-40 age group in the total number of deaths was higher during the pandemic (Figure 3b). Additionally, Figure $3 \mathrm{c}$ shows that number of adult deaths was a few times higher than the number of children age 0-5 deaths - which was generally not the case in other years.

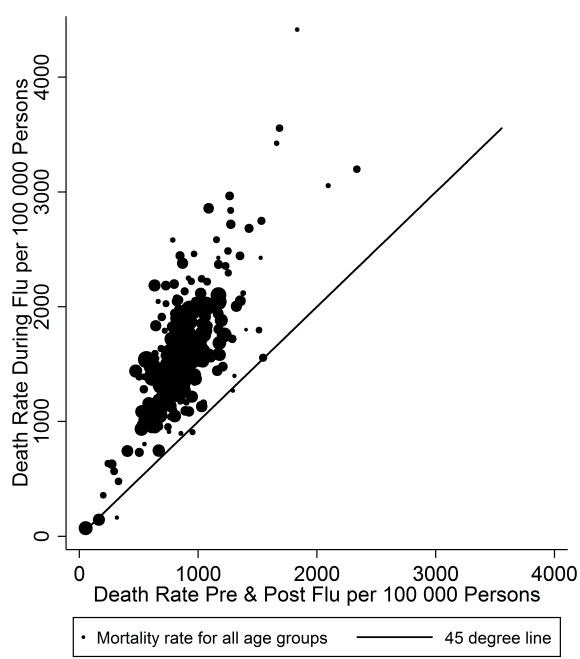

(a) Mortality rate for all ages

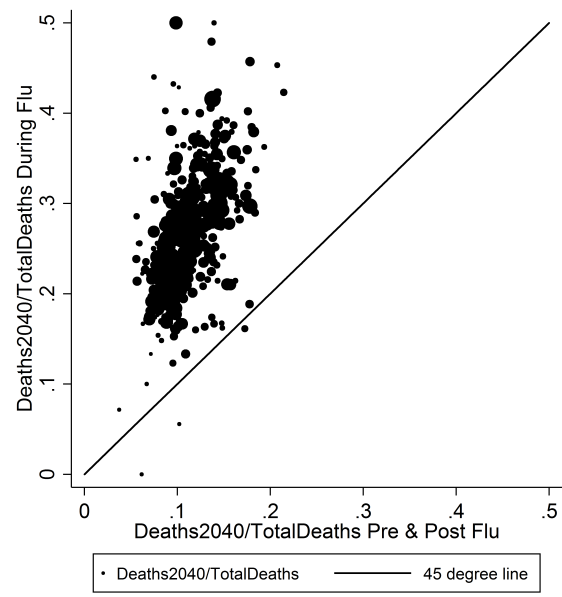

(b) Deaths age 20-40 to total deaths

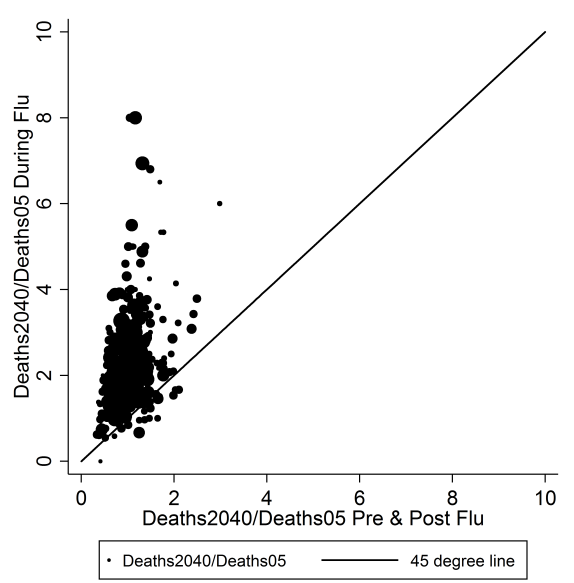

(c) Deaths age 20-40 to deaths age 0-5

Fig. 3 Overall mortality rates in Sweden during the influenza pandemic and pre/post pandemic periods. NOTE: in Figure 3a observations are weighted by the district population.

Given that the most deadly wave of the pandemic was unanticipated and only lasted a few months, it is unlikely that people adjusted fertility behavior prior to the flu. It was also im- 
possible to foresee who would be infected or who was at a higher risk. Men exhibited slightly higher mortality rates than women 8 but some evidence suggests that pregnant women in the last trimester were especially susceptible to the flu often leading to early termination of pregnancy (Bland, 1919; Barry, 2004). 9

Figure 4 presents monthly influenza and pneumonia morbidity and overall mortality from 1915 to 1927. The left panel graphs the number of deaths from all causes and influenza and pneumonia cases, showing a clear spike in deaths and flu incidents in the autumn of 1918. The timing and severity of the increase in deaths in late 1918 suggest that it is reasonable to assume that a majority of the excess deaths in this period were caused by the pandemic. The right panel graphs the number of deaths in different age groups. For all age groups there is a distinct spike during the outbreak, although somewhat less pronounced for infants (age 0-1).

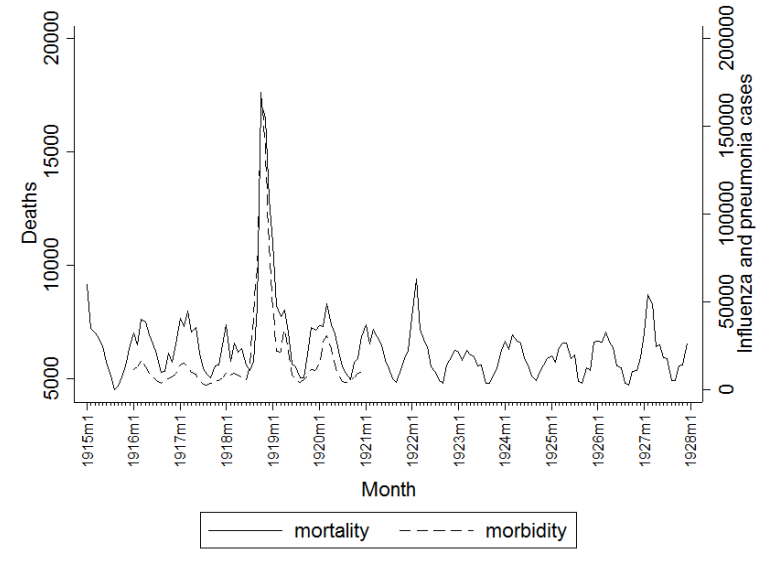

(a) Overall deaths and flu incidents

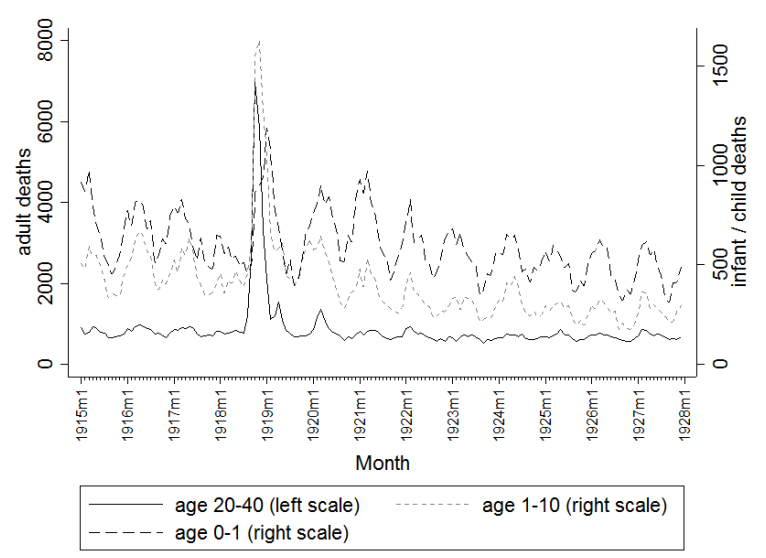

(b) Deaths by age group

Fig. 4 Monthly influenza and pneumonia morbidity (1916-1921) and overall mortality (19151927) in Sweden

Several European countries experienced a baby boom in the 1920s which has commonly been ascribed to the end of WWI. For example, in the U.K. the birth rate jumped from 18.3 births per thousand population in 1918 to more than 23 in 1919. Neutral countries like Sweden and Norway however also exhibited elevated birth rates during these years despite not experiencing any wartime fertility dip (Chesnais, 1992). Swedish fertility rates declined linearly during 1911-19, and WWI neither accelerated nor decelerated this decrease (Statistics Sweden, 1999). The 1920 baby boom has therefore also been linked to the influenza pandemic affecting all European countries (Mamelund, 2004). Figure 5 shows the crude birth rate for Sweden 19151927. Although fertility rates generally declined throughout the entire period, a clear deviation

\footnotetext{
${ }^{8}$ See Table B1 in the Appendix.

${ }^{9}$ This fact should be kept in mind when interpreting the empirical results, especially for the period August 1918 to March 1919 as live birth numbers are likely depressed due to an increased number of stillbirths and miscarriages.
} 
from the trend appears in 1920 and 1921.

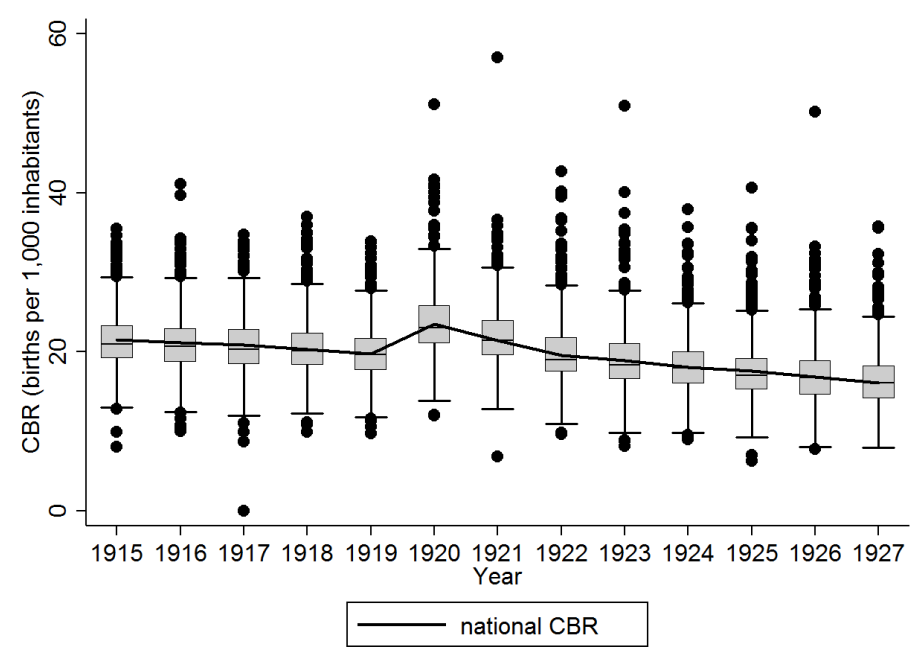

Fig. 5 Crude birth rate, Sweden 1915-1927

\subsection{World War I and Economic Conditions}

Sweden was neutral during WWI. Mortality rates were thus normal in the years prior to the pandemic and morbidity and mortality record keeping was never interrupted. The war nevertheless affected the Swedish economy. The U.K. naval blockade and German naval belligerence hurt the country's import trade (Jörberg and Krantz, 1978); price controls and rationing were introduced. A poor harvest in 1916 led to food shortages in some places and social unrest for a short period, but in general, the wartime period was characterized by adequate food supply (Nyström, 1994).

Some sectors of the economy benefited from the war. Raw material exports to belligerent countries increased significantly and Swedish agriculture did well because of the lack of competitive imports (Schön, 2010), leading to a large trade surplus (Magnusson, 1996). Conversely, there was a downturn for these sectors following the end of the war. Broadly speaking, Sweden was an industrializing nation in the beginning of the $20^{\text {th }}$ century, with about $36 \%$ of the population working in the manufacturing sector by 1930 (Statistics Sweden, 1936). After a period of economic growth, the economy experienced a brief decline in 1920-1921, where GDP dropped by $5 \%$ in one year and unemployment increased, but the country recovered fast (Jörberg and Krantz, 1978). Real wages were also positively affected, which was in part due to the introduction of the 8-hour working day (Jörberg and Krantz, 1978). Brown and Thomas (2011) show that U.S. families with higher socioeconomic status postponed fertility during the entire war period, both because men were stationed outside the U.S. and because of active family planning. Swedish men were not stationed outside the country, but families may still have de- 
cided to delay births following the uncertainty surrounding the war 10 Such behavior would imply depressed birth rates before the influenza pandemic outbreak and possibly a selection into parents of lower socioeconomic status. Since we use the variation in birth rates over time and across districts, this only poses a problem if districts reacting to the threat of war were also those being more affected by the flu. In Section 4.3 , we conduct a robustness check to rule out this possibility. Notably, our estimated effects present a lower bound if birth rates were unusually low prior to the flu.

\section{Data and Empirical Strategy}

We build a unique dataset combining data from several official administrative sources collected from archives and public libraries.11 We combine individual-level data with aggregate information corresponding to three administrative partitions. The smallest unit is a parish, of which there were around 2,500 in Sweden at the time. The next administrative unit is a health district, grouping together several parishes which were served by the same medical personnel, including doctors and midwives. There were about 400 health districts in the country, of varying size both in terms of area and population. In general, districts covered smaller areas in the more densely populated south. 12 The largest administrative level in the dataset is the county level. At the time Sweden was divided into 25 counties 13

\subsection{Sources}

A central source for our study is the parish church books which recorded deaths in Sweden. These records were digitized by the Federation of Swedish Genealogical Societies as the Swedish Death Index, 1901-2013 and include parish location and dates of birth and death for all individuals who died in Sweden between 1901 and 2013. For the cohorts of our interest it generally also includes the civil status at time of death, and in around $50 \%$ of cases the date of the last change in civil status. We use the Death Index to calculate the monthly all-cause death numbers for different age groups and the monthly birth numbers for each district. Since there are people born in the sample who were still alive in 2013 we supplement our data with the information from the 1950 Census to identify the date and parish of birth for people who

\footnotetext{
${ }^{10}$ See Richter and Robling (2013) for a discussion.

${ }^{11}$ Most of the information was scanned from hard copies and digitized by the authors and research assistants.

${ }^{12}$ In terms of population, health districts varied in size from a few hundred to almost half a million inhabitants in the city of Stockholm.

${ }^{13}$ For more details on the administrative partitions in the dataset, please see Appendix B and Bhalotra et al. (2016).
} 
were alive in 1950 but never recorded in the church books. Combining the two sources, we capture more than 95\% of all births in Sweden between 1915 and 1927 (see Figure 6).

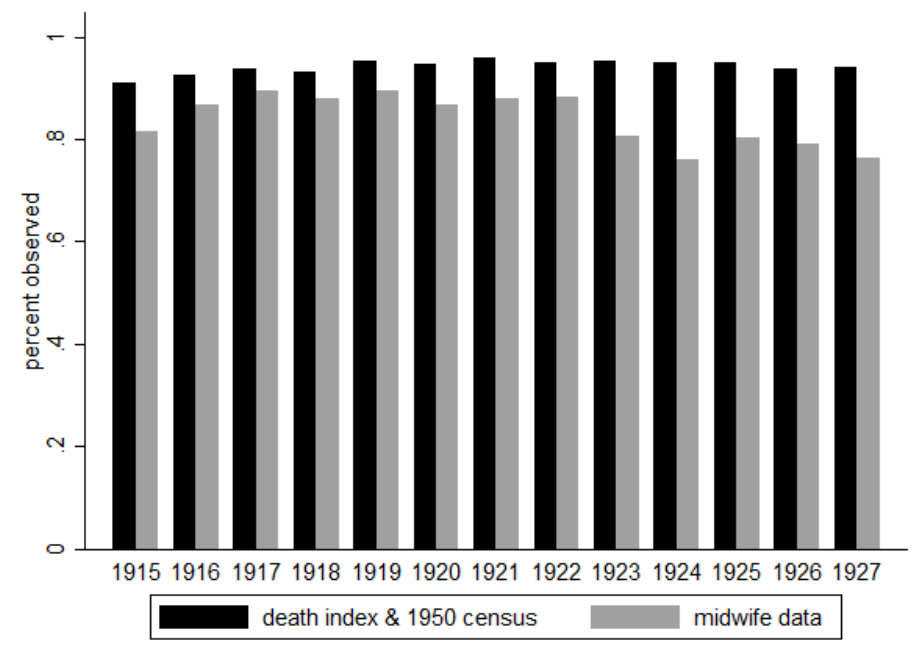

Fig. 6 Birth numbers from different sources compared, as \% of births recorded in official population statistics

We combine the data on births with information from the 'Annual Report of the Chief Medical Officer', collected by the Medical Board (Medicinalstyrelsen), which formally regulated and supervised the health care system. Starting in the mid- $18^{\text {th }}$ century, there was a strong focus on public health and disease prevention in Sweden in order to strengthen population growth (Johannisson, 1994). Health policy was based on the collection of statistics, and district physicians were obliged to compile annual reports on the state of health and health care in their district (Jonsson, 2009). From these reports we digitize demographic information and the number of inhabitants at the beginning of each year in each health district. We combine this information with monthly birth and death numbers to calculate monthly district population figures.

The Swedish system of midwifery was well organized and professionalized very early on. Welltrained midwives attended around $80 \%$ of all births by the turn of the $20^{\text {th }}$ century, while less than $10 \%$ of women gave birth in hospitals (Högberg et al. 1986) 14 Midwives were required to keep diaries on all attended births and to report them annually to the district physician (cf. Bhalotra et al., 2016). In our dataset we include digitized information from the midwife journals for the years 1915 to 1927, which comprise the number of midwives in each district, the type of birth, and several characteristics of the mothers assisted by a midwife. Births are recorded as the number of live births, stillbirths, and miscarriages, and the number of preterm and full

\footnotetext{
${ }^{14}$ By 1711 midwives were required to go through a 2-year training and pass an exam before being allowed to work in the profession. By 1819 , every parish in the country was required to employ a formally trained and licensed midwife. In 1870 the ratio of midwives to doctors was 3.1 in Sweden, compared to 1.4 in the rest of Scandinavia (Romlid, 1997) and 1.2 in France (Thomson, 1997).
} 
term births (in later years also split up by gender and live or stillbirths). The midwife diaries also report mother characteristics including the number of married, unmarried and widowed mothers giving birth and whether the woman was a first time mother.

The Swedish Medical Board also collected monthly data on district morbidity, as reported by local physicians. This variable has been shown to correlate strongly with influenza mortality at the local level in Sweden (Karlsson et al., 2014), but there is an ongoing debate regarding its accuracy in periods of high influenza mortality (Bloom-Feshbach et al., 2012; Mamelund et al. 2016). As the influenza was often misdiagnosed or complicated by pneumonia, we combine information on influenza and pneumonia incidents. We digitize information on a monthly basis for the period January 1916 to December 1921, covering two 'normal' years before the outbreak, the months of the influenza pandemic, and two 'normal' years after the outbreak. Figure 4 a illustrates monthly influenza and pneumonia cases, clearly showing regular seasonal fluctuations in the years before and after the pandemic outbreak and the very pronounced spike in late 1918 and early 1919.

Finally, we add annual information on county poverty rates, income, capital income, and female and children's labor supply. Poverty comes from the annual publication on poor relief (Fattigvården; Statistics Sweden, 1917, 1927a) defined as the share of the population living in public poorhouses, while the remaining variables come from the 'Annual Statistics' (Statistisk Arsbok; Statistics Sweden, 1927b. Income includes all taxable earnings from employment and pensions as reported to the tax authorities. Capital income includes income from asset yields, rents and dividends. Female and children's labor supply is measured as the share of women/children working in factories, either as a share of total population or as a share of the industrial workforce.

With three of our sources including birth numbers, we can check the comparability of different sources. Figure 6 compares the number of births reported in the midwife journals and those calculated from the Swedish Death Index combined with the Census of 1950 as a percentage of the births given in the official population statistics (from Befolkningsrörelsen of Statistisk Arsbok). As expected, the lowest birth numbers are given by the midwife journals, as only births in the presence of a midwife are counted here. Still, the midwife data includes about $80 \%$ of all births.

Appendix Tables B1 and B2 present summary and descriptive statistics for the periods before, during and after the pandemic. There is considerable variation in both mortality and morbidity across districts with an overall mortality rate ranging between 3.85 and 46 deaths per 1,000 inhabitants during the influenza pandemic, and a morbidity rate ranging from 0 to 635 infections per 1,000 inhabitants. It is this variation in the intensity of the pandemic across districts which we explore in the empirical analysis, together with variation over time within districts. 


\subsection{Variable Definitions and Descriptives}

The main analysis is conducted at the health district level, where we examine the effects of the pandemic on subsequent fertility. The aim is to identify biological and behavioral effects and their dynamics over time. Since it is the conditions at the time of conception that matter for the fertility decision we specify the model in terms of conceptions rates. As the true number of conceptions is unobserved we impute the following measure:

$$
\begin{aligned}
& \text { Conceptions }_{i t}= \\
& \qquad \begin{aligned}
\text { DeathIndexBirths }_{i t+9} \quad & +\frac{1}{3} \sum_{\phi=7}^{9}\left[\frac{\text { Stillbirths }_{i T}}{\text { MidwiveBirths }_{i T}} \cdot \frac{\text { DeathIndexBirths }_{i T}}{12}\right]_{i t+\phi} \\
& +\frac{1}{3} \sum_{\theta=4}^{6}\left[\frac{\text { Miscarriages }_{i T}}{\text { MidwiveBirths }_{i T}} \cdot \frac{\text { DeathIndexBirths }_{i T}}{12}\right]_{i t+\theta}
\end{aligned}
\end{aligned}
$$

We thus lag the number of births by nine months and adjust this number for stillbirths and miscarriages. With stillbirths and miscarriages reported annually we assume an equal distribution throughout the year. ${ }^{15}$ Plotting monthly stillbirth rates for 1915-1920 and 1921-1927 in Figure $7 \mathrm{a}$ there is no evidence of any seasonal pattern. Similarly, we do not observe any seasonal pattern when plotting mean differences and confidence intervals in stillbirth rates between counties over time in Figure 7b, further supporting our choice to spread stillbirth numbers equally over 12 months 16

\footnotetext{
${ }^{15}$ Some studies suggest seasonality in stillbirth rates (see, e.g., Auger et al., 2016, Strand et al., 2012, Barnett and Dobson, 2010; Torrey et al., 1993; Keller and Nugent, 1983; Eriksson and Fellman, 2000, Bruckner et al., 2014) with higher stillbirth rates during summer and/or winter when temperatures are at extremes. Existing studies are largely confined to areas exhibiting extreme temperature variations that substantially contrast with Sweden's climate.

${ }^{16}$ The literature on seasonality of miscarriages is inconclusive (see, e.g., Sandahl, 1974; Kovar and Taylor, 1960; Warren et al., 1980). Only one study finds a seasonal pattern in spontaneous abortion rate for pregnancies conceived in June and December (Sandahl, 1974), while others find no seasonal pattern.
} 


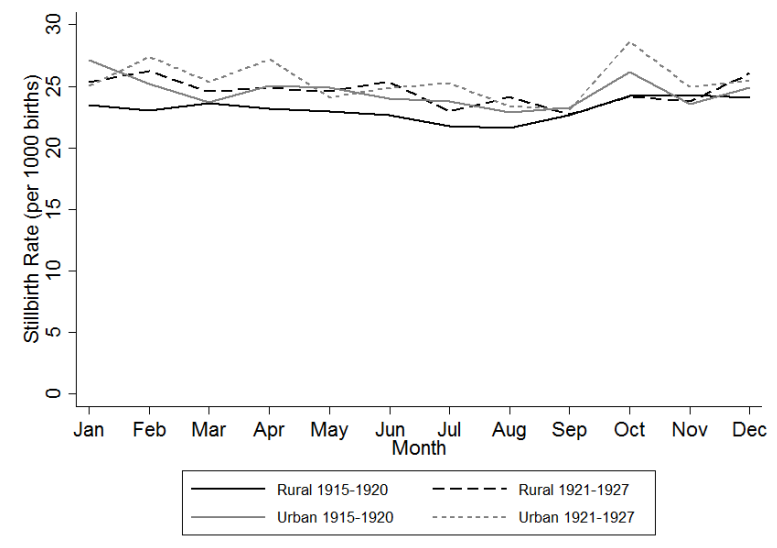

(a) Stillbirth rates 1915-20 and 1921-27.

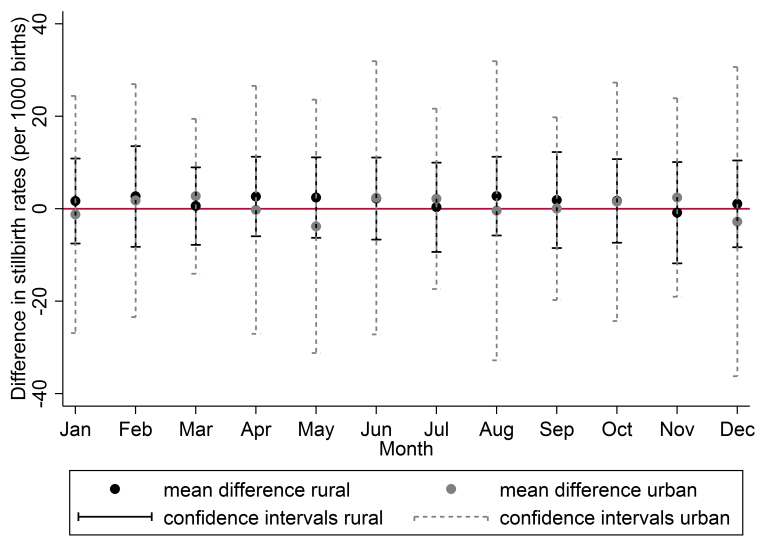

(b) Changes in stillbirth rates from 1911-20 to 1921-27

Fig. 7 Monthly stillbirth rates (per 1,000 births) at the county level

Since these numbers include only stillbirths and miscarriages in the presence of or as reported to a midwife, we assume that we observe the correct share of stillbirths and miscarriages as a share of total births in the midwife data and then calculate the 'true' number of stillbirths and miscarriages by assuming the same share on the number of births observed in the Death Index and the 1950 Census. A miscarriage is a pregnancy loss occurring less than 7 months into the pregnancy but likely only miscarriages after 3 months of pregnancy will take place in the presence of a midwife and thereby appear in the data. ${ }^{17}$ Stillbirths include pregnancy losses in months 7 to 9 . Hence we lag one third of the calculated number of stillbirths occurring in month $t$ by 7 months, one third by 8 months and one third by 9 months. We follow the same procedure for miscarriages, where these are lagged by 4,5 , and 6 months.

The conception rate is calculated by dividing the number of conceptions in district $i$ in month $t$ by the corresponding district population 18

$$
\text { ConceptionRate }_{i t}=\frac{\text { Conceptions }_{i t}}{\text { Population }_{i t}}
$$

We apply an extended difference-in-difference framework, using variation in the severity of the

\footnotetext{
${ }^{17}$ Around 1 in 4 pregnant women experiences a pregnancy loss, with the vast majority occurring well before week 12 of gestation. One could argue that miscarriages are part of the natural process of pregnancy and should not be included in the number of conceptions. In our data, miscarriages constitute on average around $4.1 \%$ of all annual conceptions. Our results do not change when we exclude miscarriages.

${ }^{18}$ Monthly population is calculated by using the population numbers as of January $1^{\text {st }}$ for each year from the demographic data and adding/subtracting the monthly number of births/deaths. Migration is thus attributed to the last month of the year. Ideally the denominator should be women aged 15-49, but without this information we have to assume that the share of women of ages 15-49 remains fairly constant over the period.
} 
pandemic across districts and variation in conception rates over time within districts.

For our influenza intensity variables, the pandemic period is defined as August 1918 to March 1919. In August and September 1918 morbidity and mortality cases were somewhat higher than usual, while the peak occurred in October and November. After that, morbidity and mortality decreased significantly. Our treatment variable FluIntensity is based on a cumulative intensity measure, including influenza and pneumonia cases for morbidity and overall deaths for mortality, up to the moment of conception. Thus, for conceptions in August 1918 only incidents during this specific month matter, whereas the sum of incidents in August and September influence conceptions in September 1918:

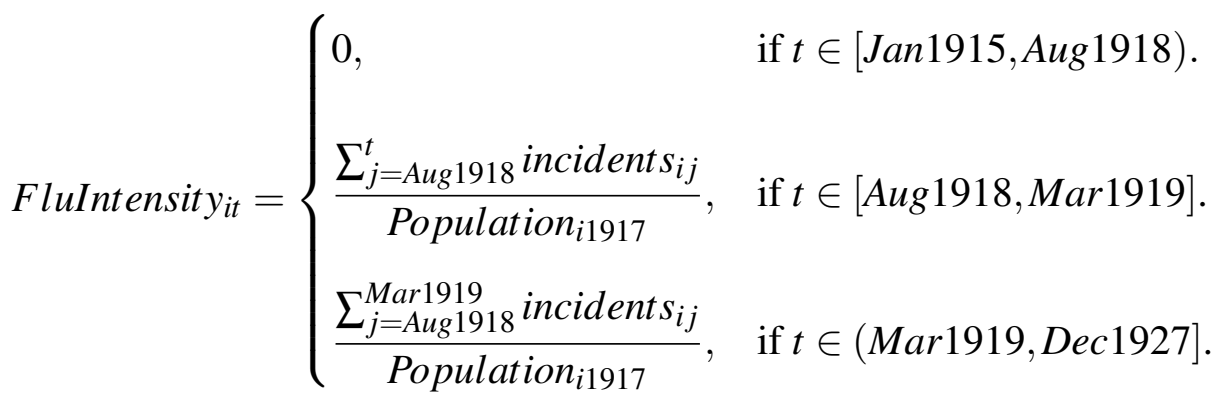

As adult mortality and child mortality may affect the fertility decision differently, we calculate age-specific mortality rates. We define adult mortality as the sum of deaths in the 20-40 age group representing potential parents and child mortality is defined as the sum of deaths in the 0-10 age group. Figure 8 shows the distribution of the peak month of morbidity and child and adult mortality respectively. The peak month is defined as the month with the highest increase in incidents/deaths as compared to the average morbidity/mortality between January 1916 and December 1917 in a district. There is surprisingly little variation in the timing of the pandemic across districts. For the vast majority of districts morbidity and mortality peak in October and November 1918. We are thus confident to capture the pandemic outbreak with our definition of the flu period. 


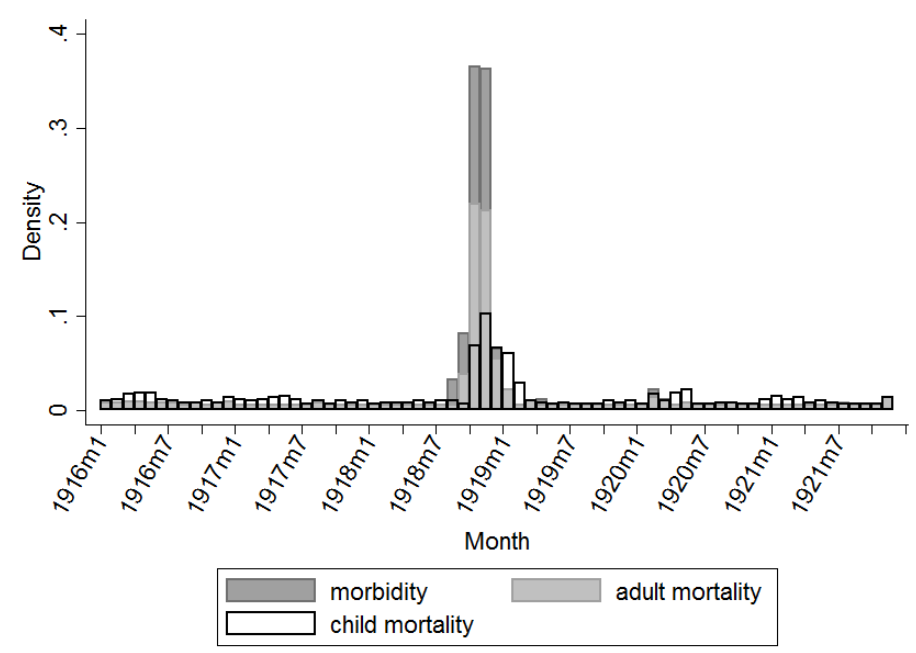

Fig. 8 Density of peak month in morbidity, child and adult mortality

Figure 9 shows how conception rates and the three influenza variables evolve over time. Conception rates were at their lowest in September-November 1918 and seem to drop simultaneously with the increase in mortality and morbidity. Figure $9 b$ further shows that conceptions gradually increased after the peak. As outlined in Section 1, there are different fertility effects at play during different time periods. Our analysis examines the effects for three time intervals: During (August 1918 to November 1918), where we expect a negative effect on conceptions from the beginning of the flu up to its peak due to biological effects and/or postponement fertility; After (December 1918 to December 1920) where we expect an increase in conception rates due to postponement and/or replacement fertility leading to a baby boom in 1920-1921; and Later (1921-27) where we expect a positive or negative effect depending on the interplay between long-term biological and economic effects. 19

\footnotetext{
${ }^{19}$ As mentioned above there was a fourth wave in 1920 (Aman, 1990; Mamelund, 2003). We do not include it in the analysis as it was mild and mostly concentrated in the north of Sweden. Our results do not change when we exclude these districts from the analysis. Moreover flu morbidity and mortality increased already in July in the cities of Stockholm and Gothenburg. Our results also do not change when we exclude them from the analysis or include July into the During period. Similarly results stay qualitatively the same if we redefine our pre-flu reference period and let it last until May 1918.
} 


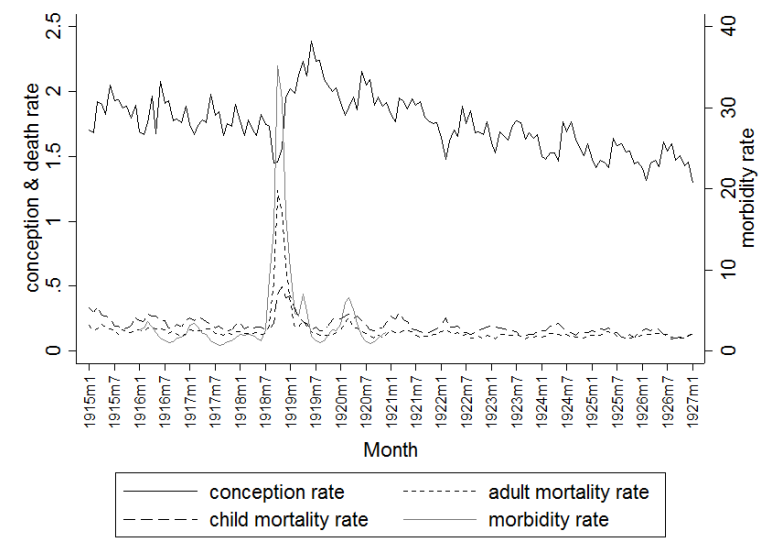

(a) Entire 1915-27 Period

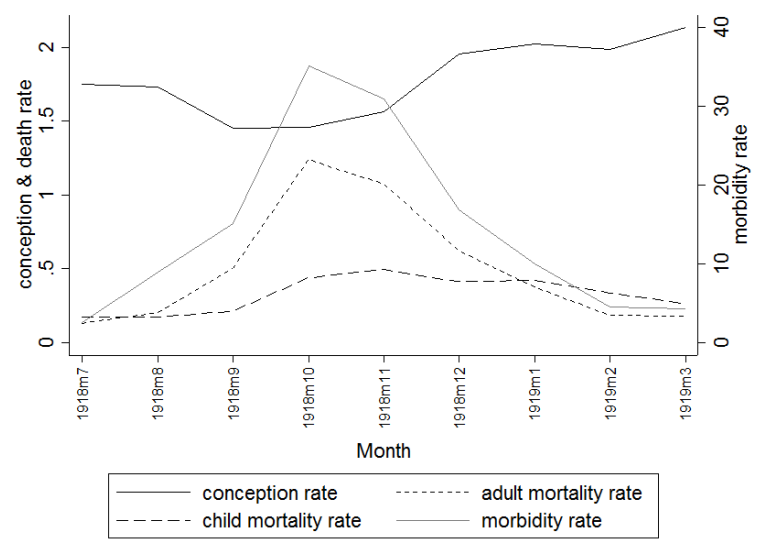

(b) During the Pandemic

Fig. 9 Conception, morbidity and mortality rates

\subsection{Econometric Approach}

For our main analysis, we specify the following model:

$$
\begin{aligned}
& \text { ConceptionRat }_{i t}=\alpha_{i}+\beta_{1} \text { FluIntensity } y_{i t} \cdot D_{\text {During }}+\beta_{2} \text { FluIntensit }_{i t} \cdot D_{\text {After }} \\
& +\beta_{3} \text { FluIntensity }{ }_{i t} \cdot D_{\text {Later }}+\delta_{1} \cdot D_{\text {During }}+\delta_{2} \cdot D_{A f t e r}+\delta_{3} \cdot D_{\text {Later }} \\
& +X_{i t} \Gamma+\lambda_{t}+\varepsilon_{i t}
\end{aligned}
$$

for district $i$ in period $t \in[1915 m 1,1927 m 12]$. FluIntensity $y_{i t}$, representing morbidity or mortality, is constructed according to equation (3). Our main specification includes district fixed effects $\left(\alpha_{i}\right)$ and month-year fixed effects $\left(\lambda_{t}\right)$. The three dummy variables $D_{\text {During }}, D_{A f t e r}$ and $D_{\text {Later }}$ indicate whether period $t$ falls within the influenza peak period, the immediate aftermath of the pandemic, or later years, respectively. The pre-pandemic period ranging from January 1915 until July 1918 is our reference period.

The coefficients of interest are $\beta_{1}$ for the immediate effects during the flu peak, $\beta_{2}$ for short-term effects and $\beta_{3}$ for long-term effects. With treatment defined as the degree of flu exposure and the pre-flu period as our reference, $\beta_{1}$ should be interpreted as the differential effect of greater flu intensity at the district level on conception rates during the flu peak period. Likewise, $\beta_{2}$ is the short-term effect of greater district flu intensity on conception rates after the flu peak, while $\beta_{3}$ corresponds to the longer term effect of greater district flu intensity on conception rates after the flu peak. We consider the overall effect but also split the analysis by rural and urban districts as the fertility dynamics are likely different across these areas. 
As a robustness check, we include a set of control variables $X_{i t}$ and county-specific linear trends. The controls include the mortality environment at the time of conception, per capita earnings and per capita capital income (both normalized by 1917 prices, in logs), the poverty share and the number of female/children factory workers as a share of the total labor force. As a proxy for the medical infrastructure in the districts we also control for the log of the number of midwives ${ }^{20}$ Some of these control variables could be seen as bad controls Angrist and Pischke, 2008) and some caution is required when interpreting estimates from these specifications. We present our results with and without controls.

In a difference-in-difference design the key identifying assumption is that fertility behavior in more and less affected areas would have followed a common time trend in the absence of the pandemic. This assumption is untestable, but having access to 43 months of pre-exposure data we assess its plausibility. Figure 10 plots conception rates in the highest and lowest district quartiles in terms of flu exposure. There is no significant difference in the trends before the flu and a clearly diverging trend thereafter. ${ }^{21}$ Appendix Figures D1 D8 show time trends for the other dependent variables.

To further test the common time trend assumption we perform balancing tests and regress our flu intensity measures on pre-flu values from 1917. If the degree of influenza exposure is predicted by several baseline variables there is a concern that the intensity of the pandemic correlates with relevant unobservables. As seen in Table B3 only the number of midwives and the baseline conception rates are significant for adult mortality. The magnitudes are large for morbidity and are small for adult and child mortality. We conclude that adult mortality appears to be the most reliable indicator of influenza exposure.

\footnotetext{
${ }^{20}$ The flu heavily strained the health care system, hospitals and doctors were overloaded, and financial means to cope with the flu fell short in some districts (Holtenius and Gillman, 2014). This may also have had an impact on the medical care in those districts afterwards, which in turn may influence the decision to have children or not.

${ }^{21}$ It appears that the high mortality districts are adjusting the conception rates already in the spring of 1918 but the confidence intervals are overlapping.
} 


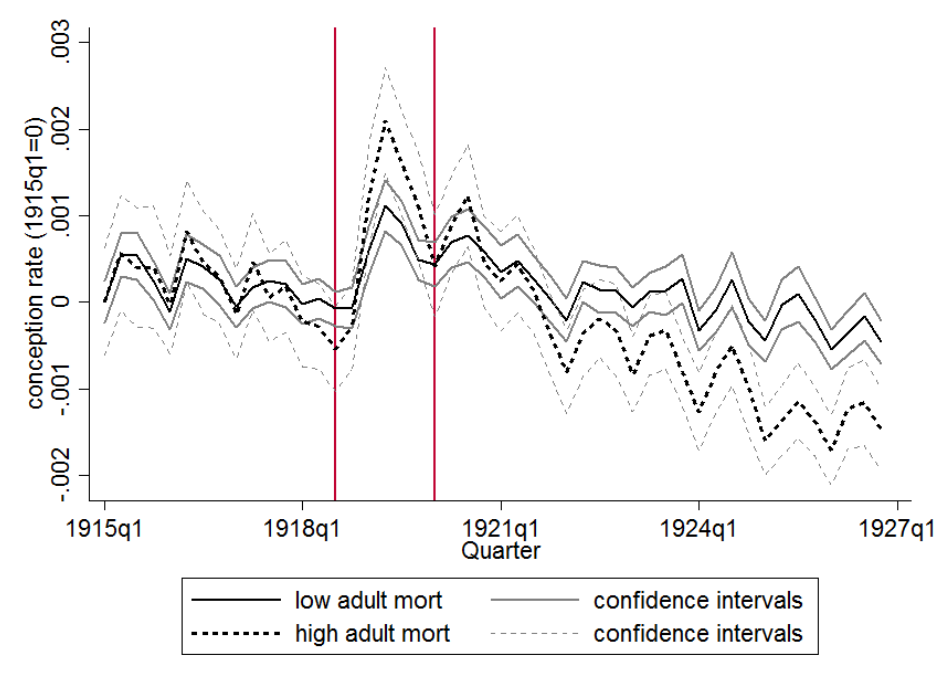

Fig. 10 Time trend for conception rate

\section{Analysis}

In this section, we first present our main estimates of the pandemic's impact on fertility. We then examine various mechanisms which might be driving the results before we turn to a set of robustness checks.

\subsection{Fertility effects}

Table 1 presents estimate of the impact of influenza cases on fertility outcomes for the country as a whole (columns 1-4) and for urban and rural areas separately. We note a small negative effect on conceptions during the flu peak period, which is completely driven by rural areas. This immediate response is indicative of biological effects where women have difficulties conceiving if they or their husbands are ill. However, there are no significant short- and long-term effects for either rural or urban areas and thus no indication of postponement fertility due to high morbidity. The lack of effects in the Later period corroborates the idea that morbidity primarily measures biological effects, mainly expected to be present during the flu peak and for some time afterwards, but less so in the long term.

Turning to adult mortality as a measure of flu intensity, Table 2 presents the main results. Also in this case there is an immediate negative effect on fertility, which in fact applies to both urban and rural areas. After the peak period, fertility bounces back in rural areas so that the net effect turns positive (recall that the influenza peak period is only four months long). However, 
Table 1 Fertility effects from morbidity

\begin{tabular}{|c|c|c|c|c|c|c|c|c|}
\hline & \multicolumn{4}{|c|}{ All } & \multicolumn{2}{|c|}{ Rural } & \multicolumn{2}{|c|}{ Urban } \\
\hline & (1) & (2) & (3) & (4) & (5) & (6) & (7) & (8) \\
\hline During $\times$ morbidity & $\begin{array}{c}-0.0009^{* *} \\
(0.0004)\end{array}$ & $\begin{array}{c}-0.0008^{* *} \\
(0.0004)\end{array}$ & $\begin{array}{c}-0.0012^{* * *} \\
(0.0004)\end{array}$ & $\begin{array}{c}-0.0012^{* * *} \\
(0.0004)\end{array}$ & $\begin{array}{c}-0.0012^{* * *} \\
(0.0004)\end{array}$ & $\begin{array}{c}-0.0012^{* * *} \\
(0.0004)\end{array}$ & $\begin{array}{c}0.0002 \\
(0.0010)\end{array}$ & $\begin{array}{c}0.0001 \\
(0.0010)\end{array}$ \\
\hline After $\times$ morbidity & $\begin{array}{c}0.0003 \\
(0.0002)\end{array}$ & $\begin{array}{c}0.0003 \\
(0.0002)\end{array}$ & $\begin{array}{l}-0.0001 \\
(0.0002)\end{array}$ & $\begin{array}{l}-0.0000 \\
(0.0002)\end{array}$ & $\begin{array}{l}-0.0001 \\
(0.0002)\end{array}$ & $\begin{array}{l}-0.0000 \\
(0.0002)\end{array}$ & $\begin{array}{c}0.0009 \\
(0.0006)\end{array}$ & $\begin{array}{c}0.0009 \\
(0.0007)\end{array}$ \\
\hline Later $\times$ morbidity & $\begin{array}{l}-0.0003 \\
(0.0003)\end{array}$ & $\begin{array}{l}-0.0002 \\
(0.0003)\end{array}$ & $\begin{array}{l}-0.0003 \\
(0.0003)\end{array}$ & $\begin{array}{l}-0.0001 \\
(0.0003)\end{array}$ & $\begin{array}{l}-0.0003 \\
(0.0003)\end{array}$ & $\begin{array}{l}-0.0001 \\
(0.0003)\end{array}$ & $\begin{array}{l}-0.0000 \\
(0.0008)\end{array}$ & $\begin{array}{l}-0.0003 \\
(0.0008)\end{array}$ \\
\hline During $\times$ morbidity $\times$ urban & & & $\begin{array}{c}0.0015 \\
(0.0011)\end{array}$ & $\begin{array}{c}0.0013 \\
(0.0010)\end{array}$ & & & & \\
\hline After $\times$ morbidity $\times$ urban & & & $\begin{array}{c}0.0009 \\
(0.0006)\end{array}$ & $\begin{array}{c}0.0009 \\
(0.0007)\end{array}$ & & & & \\
\hline Later $\times$ morbidity $\times$ urban & & & $\begin{array}{c}0.0003 \\
(0.0009)\end{array}$ & $\begin{array}{l}-0.0002 \\
(0.0008)\end{array}$ & & & & \\
\hline Add. controls & No & Yes & No & Yes & No & Yes & No & Yes \\
\hline County trend & No & Yes & No & Yes & No & Yes & No & Yes \\
\hline $\mathrm{N}$ & 46,861 & 46,861 & 46,861 & 46,861 & 35,200 & 35,200 & 11,661 & 11,661 \\
\hline $\mathrm{N}$ (cluster) & 367 & 367 & 367 & 367 & 270 & 270 & 97 & 97 \\
\hline Baseline & 1.81 & 1.81 & 1.81 & 1.81 & 1.68 & 1.68 & 2.14 & 2.14 \\
\hline
\end{tabular}

Dependent variable: conception rate. All regressions include district and month-year fixed effects. Standard errors in parentheses, clustered at the district level. Additional control variables include the current mortality rate, the log of the number of midwives, the log of earnings and the log of capital income in 1917 prices, the poverty share, the labor supply of women and of children as a share of the labor force. The During period includes August 1918 to November 1918; After includes December 1918 to December 1920; Later includes January 1921 to December 1927. Morbidity and mortality rates are calculated as the cumulative sum of influenza cases/deaths occurring during the flu period, normalized by the district population in 1917. The stars represent significance at the following p-values: * $\mathrm{p}>0.1 * * \mathrm{p}<0.05 * * * \mathrm{p}<0.01$ 
fertility rates are depressed by the pandemic in the long term, so that the cumulative effect of the pandemic is a large reduction in conception rates. This pattern is even more pronounced in urban areas, where no bounceback is observed right after the pandemic peak whereas the immediate and long-term responses are stronger.22

Table 2 Fertility effects from adult mortality

\begin{tabular}{|c|c|c|c|c|c|c|c|c|}
\hline & \multicolumn{4}{|c|}{ All } & \multicolumn{2}{|c|}{ Rural } & \multicolumn{2}{|c|}{ Urban } \\
\hline & (1) & (2) & (3) & (4) & (5) & (6) & (7) & (8) \\
\hline During $\times$ adult mortality & $\begin{array}{c}-0.075^{* * *} \\
(0.019)\end{array}$ & $\begin{array}{c}-0.109^{* * *} \\
(0.033)\end{array}$ & $\begin{array}{c}-0.056^{* *} \\
(0.024)\end{array}$ & $\begin{array}{c}-0.082^{* * *} \\
(0.025)\end{array}$ & $\begin{array}{c}-0.056^{* *} \\
(0.024)\end{array}$ & $\begin{array}{c}-0.062^{* * *} \\
(0.017)\end{array}$ & $\begin{array}{c}-0.094^{* * *} \\
(0.027)\end{array}$ & $\begin{array}{r}-0.147^{* * *} \\
(0.048)\end{array}$ \\
\hline After $\times$ adult mortality & $\begin{array}{c}0.022 \\
(0.024)\end{array}$ & $\begin{array}{c}0.020 \\
(0.023)\end{array}$ & $\begin{array}{c}0.060^{* * *} \\
(0.015)\end{array}$ & $\begin{array}{c}0.053^{* * *} \\
(0.016)\end{array}$ & $\begin{array}{c}0.060^{* * *} \\
(0.015)\end{array}$ & $\begin{array}{c}0.054^{* * *} \\
(0.016)\end{array}$ & $\begin{array}{l}-0.022 \\
(0.036)\end{array}$ & $\begin{array}{l}-0.025 \\
(0.031)\end{array}$ \\
\hline Later $\times$ adult mortality & $\begin{array}{c}-0.090^{* * *} \\
(0.026)\end{array}$ & $\begin{array}{c}-0.094^{* * *} \\
(0.024)\end{array}$ & $\begin{array}{c}-0.079^{* *} \\
(0.031)\end{array}$ & $\begin{array}{c}-0.088^{* * *} \\
(0.027)\end{array}$ & $\begin{array}{c}-0.079^{* *} \\
(0.031)\end{array}$ & $\begin{array}{c}-0.088^{* * *} \\
(0.027)\end{array}$ & $\begin{array}{c}-0.097^{* *} \\
(0.043)\end{array}$ & $\begin{array}{r}-0.106^{* * *} \\
(0.031)\end{array}$ \\
\hline During $\times$ adult mortality $\times$ urban & & & $\begin{array}{l}-0.037 \\
(0.036)\end{array}$ & $\begin{array}{l}-0.038 \\
(0.036)\end{array}$ & & & & \\
\hline After $\times$ adult mortality $\times$ urban & & & $\begin{array}{c}-0.081^{* *} \\
(0.039)\end{array}$ & $\begin{array}{c}-0.079^{* *} \\
(0.035)\end{array}$ & & & & \\
\hline Later $\times$ adult mortality $\times$ urban & & & $\begin{array}{l}-0.018 \\
(0.052)\end{array}$ & $\begin{array}{l}-0.020 \\
(0.042)\end{array}$ & & & & \\
\hline Add. controls & No & Yes & No & Yes & No & Yes & No & Yes \\
\hline County trend & No & Yes & No & Yes & No & Yes & No & Yes \\
\hline $\mathrm{N}$ & 46,861 & 46,861 & 46,861 & 46,861 & 35,200 & 35,200 & 11,661 & 11,661 \\
\hline $\mathrm{N}$ (cluster) & 367 & 367 & 367 & 367 & 270 & 270 & 97 & 97 \\
\hline Baseline & 1.81 & 1.81 & 1.81 & 1.81 & 1.68 & 1.68 & 2.14 & 2.14 \\
\hline
\end{tabular}

Dependent variable: conception rate. All regressions include district and month-year fixed effects. Standard errors in parentheses, clustered at the district level. Additional control variables include the current mortality rate, the log of the number of midwives, the log of earnings and the log of capital income in 1917 prices, the poverty share, the labor supply of women and of children as a share of the labor force. The During period includes August 1918 to November 1918; After includes December 1918 to December 1920; Later includes January 1921 to December 1927. Morbidity and mortality rates are calculated as the cumulative sum of influenza cases/deaths occurring during the flu period, normalized by the district population in 1917 . The stars represent significance at the following $\mathrm{p}$-values: $* \mathrm{p}<0.1 * * \mathrm{p}<0.05 * * * \mathrm{p}<0.01$

The immediate effect is somewhat stronger for child mortality (Table 3), but in the aftermath of the pandemic we note a negative fertility effect in urban areas. According to our estimates, each additional urban child (adult) death per 1,000 people reduced the monthly conception rate in the long-term post flu peak period by 0.133 (0.097). Comparing the $25^{\text {th }}$ and the $75^{\text {th }}$ percentile district, with a child (adult) mortality rate of 0.68 and 1.56 (2.23 and 4.22) per 1,000 people respectively, the difference between these two districts would correspond to a $7.0 \%(9.0 \%)$ reduction in the monthly conception rate.

In the long term, both rural and urban districts exhibiting high adult mortality decreased their fertility compared to districts that were less affected, which is in line with changes in the marriage market due to the loss of spouses and later remarriage, or economic effects including

\footnotetext{
${ }^{22}$ A potential concern for the observed difference between rural and urban areas could be a difference in measurement errors between these districts. As a check we regress the mortality rate on the morbidity rate and an interaction term with the urban dummy. The interaction term is not significant, which indicates that there were no significant differences in reporting influenza and pneumonia cases between rural and urban areas.
} 
Table 3 Fertility effects from child mortality

\begin{tabular}{|c|c|c|c|c|c|c|c|c|}
\hline & \multicolumn{4}{|c|}{ All } & \multicolumn{2}{|c|}{ Rural } & \multicolumn{2}{|c|}{ Urban } \\
\hline & (1) & (2) & (3) & (4) & (5) & (6) & (7) & (8) \\
\hline During $\times$ child mortality & $\begin{array}{c}-0.151^{* * *} \\
(0.026)\end{array}$ & $\begin{array}{c}-0.163^{* * *} \\
(0.024)\end{array}$ & $\begin{array}{c}-0.084^{* *} \\
(0.042)\end{array}$ & $\begin{array}{c}-0.098^{* *} \\
(0.043)\end{array}$ & $\begin{array}{c}-0.084^{* *} \\
(0.042)\end{array}$ & $\begin{array}{c}-0.110^{* * *} \\
(0.042)\end{array}$ & $\begin{array}{c}-0.182^{* * *} \\
(0.021)\end{array}$ & $\begin{array}{c}-0.162^{* * *} \\
(0.040)\end{array}$ \\
\hline After $\times$ child mortality & $\begin{array}{l}-0.024 \\
(0.035)\end{array}$ & $\begin{array}{l}-0.027 \\
(0.035)\end{array}$ & $\begin{array}{c}0.059^{* * *} \\
(0.016)\end{array}$ & $\begin{array}{c}0.054^{* * *} \\
(0.014)\end{array}$ & $\begin{array}{c}0.059^{* * *} \\
(0.016)\end{array}$ & $\begin{array}{c}0.054^{* * *} \\
(0.014)\end{array}$ & $\begin{array}{l}-0.057^{*} \\
(0.031)\end{array}$ & $\begin{array}{l}-0.050^{*} \\
(0.028)\end{array}$ \\
\hline Later $\times$ child mortality & $\begin{array}{c}-0.110^{* * *} \\
(0.023)\end{array}$ & $\begin{array}{c}-0.121^{* * *} \\
(0.022)\end{array}$ & $\begin{array}{l}-0.043^{*} \\
(0.025)\end{array}$ & $\begin{array}{l}-0.064^{*} \\
(0.033)\end{array}$ & $\begin{array}{l}-0.043^{*} \\
(0.025)\end{array}$ & $\begin{array}{l}-0.063^{*} \\
(0.033)\end{array}$ & $\begin{array}{c}-0.133^{* * *} \\
(0.019)\end{array}$ & $\begin{array}{c}-0.122^{* * *} \\
(0.020)\end{array}$ \\
\hline During $\times$ child mortality $\times$ urban & & & $\begin{array}{c}-0.098^{* *} \\
(0.047)\end{array}$ & $\begin{array}{l}-0.079^{*} \\
(0.047)\end{array}$ & & & & \\
\hline After $\times$ child mortality $\times$ urban & & & $\begin{array}{c}-0.116^{* * *} \\
(0.035)\end{array}$ & $\begin{array}{c}-0.104^{* * *} \\
(0.030)\end{array}$ & & & & \\
\hline Later $\times$ child mortality $\times$ urban & & & $\begin{array}{c}-0.090^{* * *} \\
(0.032)\end{array}$ & $\begin{array}{l}-0.056 \\
(0.039)\end{array}$ & & & & \\
\hline Add. controls & No & Yes & No & Yes & No & Yes & No & Yes \\
\hline County trend & No & Yes & No & Yes & No & Yes & No & Yes \\
\hline $\mathrm{N}$ & 46,861 & 46,861 & 46,861 & 46,861 & 35,200 & 35,200 & 11,661 & 11,661 \\
\hline $\mathrm{N}$ (cluster) & 367 & 367 & 367 & 367 & 270 & 270 & 97 & 97 \\
\hline Baseline & 1.81 & 1.81 & 1.81 & 1.81 & 1.68 & 1.68 & 2.14 & 2.14 \\
\hline
\end{tabular}

Dependent variable: conception rate. All regressions include district and month-year fixed effects. Standard errors in parentheses, clustered at the district level. Additional control variables include the current mortality rate, the log of the number of midwives, the log of earnings and the log of capital income in 1917 prices, the poverty share, the labor supply of women and of children as a share of the labor force. The During period includes August 1918 to November 1918; After includes December 1918 to December 1920; Later includes January 1921 to December 1927. Morbidity and mortality rates are calculated as the cumulative sum of influenza cases/deaths occurring during the flu period, normalized by the district population in 1917 . The stars represent significance at the following p-values: * $\mathrm{p}<0.1 * * \mathrm{p}<0.05 * * * \mathrm{p}<0.01$ 
negative income effects or labor market effects. We investigate these mechanisms in greater detail in Section 4.2 .

Some districts may have experienced high morbidity but low mortality, or high adult mortality and low child mortality, or vice versa. In order to gauge the relative importance of the three influenza variables, we also present results for including morbidity and mortality measures together in the Appendix (see Tables E2 and E3). Results do not change when including morbidity and mortality in the same specification. Including adult and child mortality together, however, shows that the effects for rural areas mainly come from adult mortality, while the effects stem from child mortality in urban areas. This pattern would be consistent with the hypothesis regarding different incentives stated above - in the sense that it is the mortality of adults (i.e. workers) that drives results in rural areas.

We also conduct an event study analysis in order to ensure that the estimated results are really due to the pandemic and not some other factor potentially correlated with the influenza. Figures 11 and 12 illustrate an exercise where we estimate $\beta^{\prime} s$ in equation 4 for each month at a time. Clearly, there are no influenza effects before August 1918. The positive effect on conceptions after the influenza peak in rural areas is significant for a period of 19 months, but the estimate in fact stays positive for a total of 31 months. Around 1922 this trend is reversed and the districts most affected by the influenza pandemic exhibit lower conception rates than less affected districts. All together the event study graphs confirm and corroborate the findings of the regression analysis.

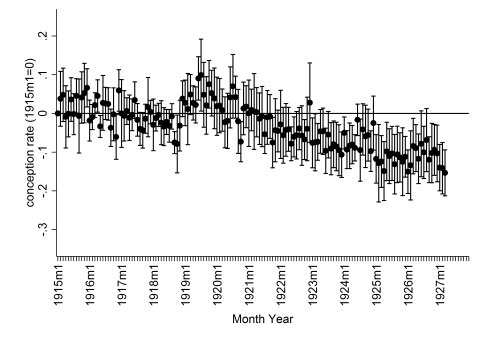

(a) All districts

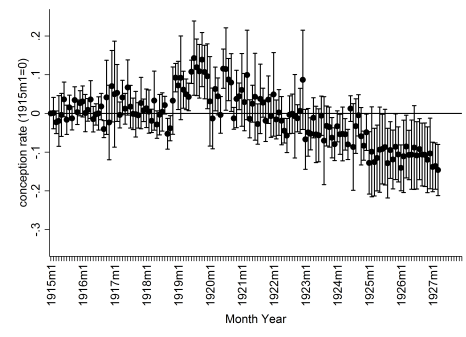

(b) Rural districts

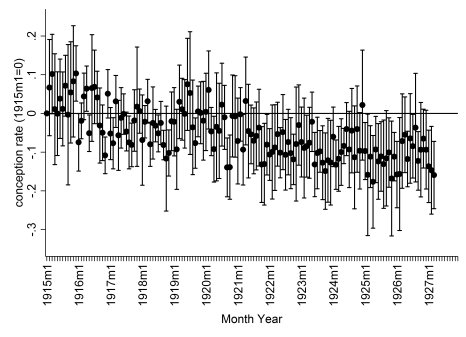

(c) Urban districts

Fig. 11 Fertility effects, adult mortality 


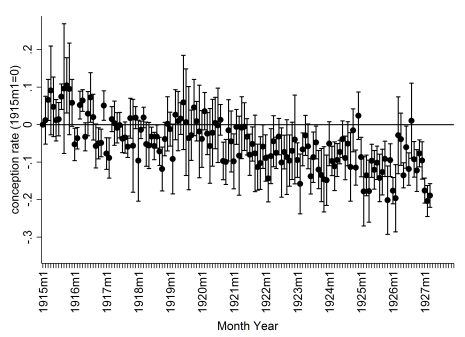

(a) All districts

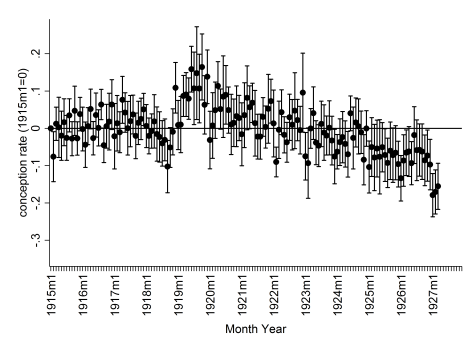

(b) Rural districts

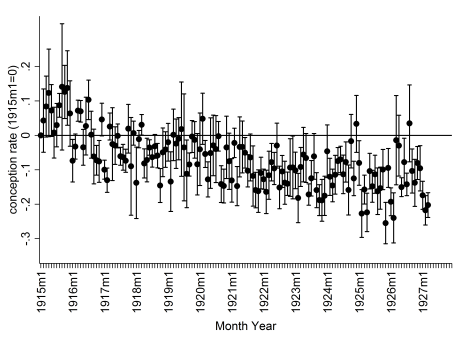

(c) Urban districts

Fig. 12 Fertility effects, child mortality

Additionally, we also graph cumulative fertility effects from the estimations (Figures 13 and 14p. Here we see that for rural areas the short initial decline was offset by the rebound in the medium term followed by the decline. In the urban areas the cumulative effect is always negative.

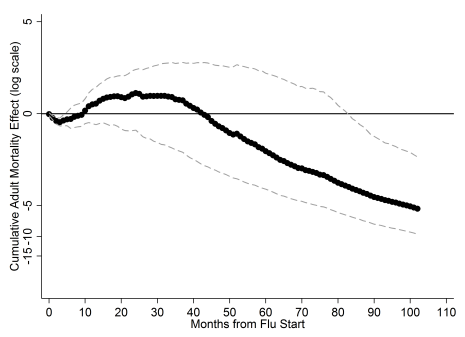

(a) All districts

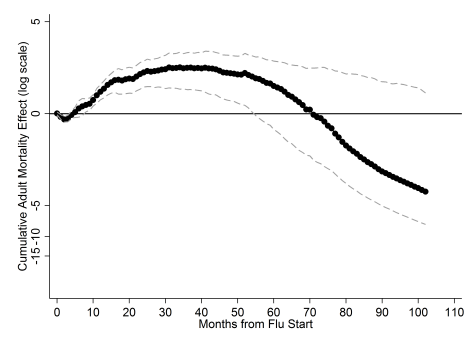

(b) Rural districts

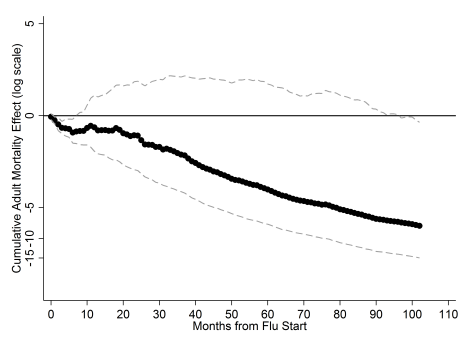

(c) Urban districts

Fig. 13 Cumulative fertility effects, adult mortality

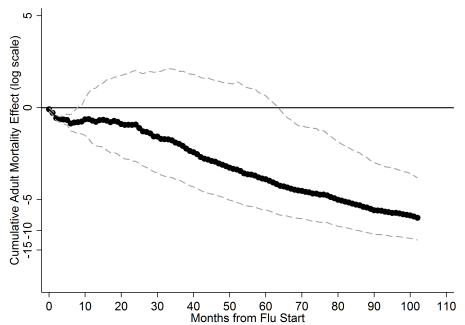

(a) All districts

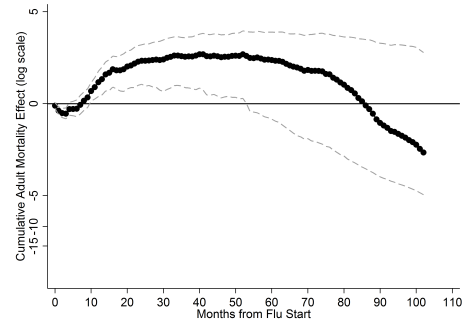

(b) Rural districts

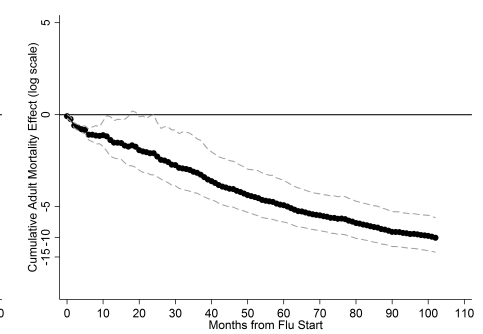

(c) Urban districts

Fig. 14 Cumulative fertility effects, child mortality

\subsection{Mechanisms}

The baseline analysis suggests that the 1918-19 influenza pandemic triggered a reduction in fertility in the immediate and long term, with a bounceback just after the pandemic peak in 
rural areas counteracting the overall decline in this setting.

A fertility increase in the After period (Dec 1918-Dec 1920) can be explained by postponement as couples might have postponed conceptions until the time when mortality decreased. Such effect should however not be unique to rural areas. On the other hand there could be differences across rural and urban contexts regarding replacement fertility. In many respects rural societies were culturally and socially more close-knit than urban Sweden in the early $20^{\text {th }}$ century. For example, agricultural activities implied interdependencies across households during sowing and harvesting periods tightening social ties. Also, divorces were predominantly an urban phenomenon, with Stockholm and Gothenburg counties exhibiting the highest divorce rates (Sandström, 2011). Such knit may have initiated community rebuilding and increasing collective fertility in rural districts that lost many adults.

An alternative explanation to why conception rates in urban districts did not rebound in the same manner as in rural areas is that the incentives to have children differed across these settings. In rural areas children represented an investment good, as they provided labor on the farm and care for the parents during old age and were thus a way to smooth family income and consumption over time, while children were more of a consumption good in urban areas. ${ }^{23}$ This would imply that the cost and the potential pay-off of having children were very different in the two settings, and if the influenza increased uncertainty, the decision to have a child or not could go in opposite directions. In rural areas, benefits would still outweigh the costs as children provided security for the future, while this would not be the case in urban areas.

The long-term decline in fertility may be rationalized with reference to the labor market: if the pandemic pushed up wages it would also increase the opportunity cost of having children. However, Karlsson et al. (2014) did not find a positive effect on earnings. Besides, the rural bounceback is slightly at odds with such a story. In order to shed further light on these issues, we perform some empirical tests related to the labor market in Section 4.2.5. Before this we perform below an empirical analysis of additional possible mechanisms starting with a characterization of the areas driving the results.

\subsubsection{Treatment effect heterogeneity}

In order to examine potential mechanisms driving the results, we first explore whether the impact of the adult mortality on conception rates was different in different district types. We use baseline characteristics of districts in 1917 from official yearbooks to separate districts into categories by splitting the sample at the median value. We generate dummy variables

\footnotetext{
${ }^{23}$ Additionally, urban areas might have access to more formal insurance, while rural areas might not.
} 
indicating whether the district was above the median for a specific variable in 1917 and interact this with our treatment variables. We additionally check whether rural districts with different shares of Sami people responded differently ${ }^{24}$ Table 4 presents the results for rural areas. The immediate effect seems to be driven by districts with low baseline conception rates - which thus reduced conceptions even further. No other baseline characteristic is significantly related to this initial decline. In the medium term, the positive effect is driven by districts with relatively high private property values. Since a big part of rural property values come from farm lands, this may be an indication of replacement fertility. Finally, the long-run decline brought by the pandemic is driven by districts with high initial conception rates, few midwives, many poor in the population, low population density and low taxable income. In other words it appears that in particular under-developed rural areas were likely to reduce long-term fertility in response to the pandemic.

Table 5 presents the results for urban areas. We note that the immediate response is disproportionately large in cities with few midwives, high poverty rates, low private property values, and low population density. These characteristics may be signifying city dwellers facing disproportionately large risks. The absence of a bounceback in the immediate aftermath of the pandemic appears to be attributable to cities with high poverty rates: the other cities have a positive albeit insignificant effect in the medium term. Also the long-run decline in fertility is disproportionately driven by cities with high initial poverty rates.

\subsubsection{Mother Characteristics}

The midwife journals provide information on mother characteristics giving a unique opportunity to investigate who changed their fertility behavior in the years after the pandemic. We look for differences during and after the flu pandemic, as compared to the 'normal' years 1915-1917. We focus on the time of actual birth, as opposed to conception time, as the data is annual. We therefore redefine our four periods in order to account for 9 months of pregnancy as: Before from 1915 to 1917, During from 1918 to 1919, After from 1920 to 1921 and Later from 1922

\footnotetext{
${ }^{24}$ Being an indigenous population, the Sami people can be expected to exhibit divergent fertility behavior. In addition, previous work has shown that the local Sami population was an important predictor of flu mortality in Norway (Mamelund, 2003, 2011).
} 
Table 4 Heterogeneity analysis for rural districts

\begin{tabular}{|c|c|c|c|c|c|c|c|}
\hline & $\begin{array}{c}\text { (1) } \\
\text { concep.rate }\end{array}$ & $\begin{array}{c}\text { (2) } \\
\text { midw.p/birth }\end{array}$ & $\begin{array}{c}\text { (3) } \\
\text { v.pov.rate }\end{array}$ & $\begin{array}{l}\text { (4) } \\
\text { priv.prop }\end{array}$ & $\begin{array}{c}(5) \\
\text { pop.density }\end{array}$ & $\begin{array}{c}(6) \\
\text { tax.inc. }\end{array}$ & $\begin{array}{c}(7) \\
\text { sami share }\end{array}$ \\
\hline $\begin{array}{l}\text { During } \\
\times \text { adult mortality }\end{array}$ & $\begin{array}{c}-0.093^{* * *} \\
(0.023)\end{array}$ & $\begin{array}{l}-0.048 \\
(0.033)\end{array}$ & $\begin{array}{c}-0.093^{* * *} \\
(0.024)\end{array}$ & $\begin{array}{c}-0.070^{* * *} \\
(0.022)\end{array}$ & $\begin{array}{l}-0.052^{*} \\
(0.030)\end{array}$ & $\begin{array}{l}-0.028 \\
(0.036)\end{array}$ & $\begin{array}{l}-0.062^{* *} \\
(0.027)\end{array}$ \\
\hline $\begin{array}{l}\text { After } \\
\times \text { adult mortality }\end{array}$ & $\begin{array}{c}0.036^{* * *} \\
(0.010)\end{array}$ & $\begin{array}{c}0.065^{* * *} \\
(0.016)\end{array}$ & $\begin{array}{c}0.045^{* * *} \\
(0.017)\end{array}$ & $\begin{array}{c}0.028^{* * *} \\
(0.008)\end{array}$ & $\begin{array}{c}0.058^{* * *} \\
(0.017)\end{array}$ & $\begin{array}{c}0.069^{* * *} \\
(0.014)\end{array}$ & $\begin{array}{c}0.062^{* * *} \\
(0.014)\end{array}$ \\
\hline $\begin{array}{l}\text { Later } \\
\times \text { adult mortality }\end{array}$ & $\begin{array}{l}-0.021 \\
(0.016)\end{array}$ & $\begin{array}{c}-0.103^{* * *} \\
(0.032)\end{array}$ & $\begin{array}{l}-0.032^{*} \\
(0.017)\end{array}$ & $\begin{array}{c}-0.041^{* *} \\
(0.016)\end{array}$ & $\begin{array}{c}-0.100^{* * *} \\
(0.029)\end{array}$ & $\begin{array}{c}-0.099^{* * *} \\
(0.034)\end{array}$ & $\begin{array}{c}-0.083^{* * *} \\
(0.031)\end{array}$ \\
\hline $\begin{array}{l}\text { During } \\
\times \text { adult mortality } \times \mathrm{X}\end{array}$ & $\begin{array}{l}0.068^{*} \\
(0.037)\end{array}$ & $\begin{array}{l}-0.022 \\
(0.044)\end{array}$ & $\begin{array}{c}0.058 \\
(0.038)\end{array}$ & $\begin{array}{c}0.028 \\
(0.045)\end{array}$ & $\begin{array}{l}-0.027 \\
(0.036)\end{array}$ & $\begin{array}{l}-0.054 \\
(0.041)\end{array}$ & $\begin{array}{c}0.673 \\
(0.624)\end{array}$ \\
\hline $\begin{array}{l}\text { After } \\
\times \text { adult mortality } \times \mathrm{X}\end{array}$ & $\begin{array}{c}0.027 \\
(0.019)\end{array}$ & $\begin{array}{l}-0.027 \\
(0.018)\end{array}$ & $\begin{array}{c}0.017 \\
(0.023)\end{array}$ & $\begin{array}{c}0.047^{* * *} \\
(0.015)\end{array}$ & $\begin{array}{c}0.005 \\
(0.028)\end{array}$ & $\begin{array}{l}-0.032 \\
(0.020)\end{array}$ & $\begin{array}{l}-0.368 \\
(0.306)\end{array}$ \\
\hline $\begin{array}{l}\text { Later } \\
\times \text { adult mortality } \times \mathrm{X}\end{array}$ & $\begin{array}{l}-0.067^{*} \\
(0.040)\end{array}$ & $\begin{array}{l}0.072^{*} \\
(0.039)\end{array}$ & $\begin{array}{l}-0.068^{*} \\
(0.037)\end{array}$ & $\begin{array}{l}-0.060 \\
(0.037)\end{array}$ & $\begin{array}{c}0.095^{* * *} \\
(0.036)\end{array}$ & $\begin{array}{l}0.071^{*} \\
(0.038)\end{array}$ & $\begin{array}{c}0.452 \\
(0.360)\end{array}$ \\
\hline $\begin{array}{l}\mathrm{N} \\
\mathrm{N} \text { (cluster) } \\
\text { Baseline }\end{array}$ & $\begin{array}{c}35,200 \\
270 \\
1.68\end{array}$ & $\begin{array}{c}35,143 \\
269 \\
1.68\end{array}$ & $\begin{array}{c}35,053 \\
269 \\
1.68\end{array}$ & $\begin{array}{c}35,053 \\
269 \\
1.68\end{array}$ & $\begin{array}{c}35,053 \\
269 \\
1.68\end{array}$ & $\begin{array}{c}35,053 \\
269 \\
1.68\end{array}$ & $\begin{array}{c}34,671 \\
265 \\
1.68\end{array}$ \\
\hline
\end{tabular}

Dependent variable: conception rate. All regressions include district and month-year fixed effects. Standard errors in parentheses, clustered at the district level. During $\times$ adult mortality $\times X$ denotes the interaction with the variable in the column heading. All interaction variables in specifications (1)-(7) are dummy variables taking on the value one for districts above the median in 1917. The Sami share is taken from the 1910 census and since its median equals zero, the actual share is used for interaction. The During period includes August 1918 to November 1918; After includes December 1918 to December 1920; Later includes January 1921 to December 1927. Mortality rates are calculated as the cumulative sum of influenza cases occurring during the flu period, normalized by the district population in 1917. The stars represent significance at the following $\mathrm{p}$-values: $* \mathrm{p}<0.1 * * \mathrm{p}<0.05 * * * \mathrm{p}<0.01$

Table 5 Heterogeneity analysis for urban districts

\begin{tabular}{|c|c|c|c|c|c|c|}
\hline & $\begin{array}{c}\text { (1) } \\
\text { concep.rate }\end{array}$ & $\begin{array}{c}(2) \\
\text { midw.p/birth }\end{array}$ & $\begin{array}{c}\text { (3) } \\
\text { v.pov.rate }\end{array}$ & $\begin{array}{l}\text { (4) } \\
\text { priv.prop }\end{array}$ & $\begin{array}{c}(5) \\
\text { pop.density }\end{array}$ & $\begin{array}{c}(6) \\
\text { tax.inc. }\end{array}$ \\
\hline $\begin{array}{l}\text { During } \\
\times \text { adult mortality }\end{array}$ & $\begin{array}{c}0.024 \\
(0.078)\end{array}$ & $\begin{array}{c}-0.152^{* * *} \\
(0.033)\end{array}$ & $\begin{array}{c}-0.054^{* *} \\
(0.022)\end{array}$ & $\begin{array}{c}-0.111^{* * *} \\
(0.034)\end{array}$ & $\begin{array}{c}-0.141^{* * *} \\
(0.025)\end{array}$ & $\begin{array}{c}-0.123^{* * *} \\
(0.031)\end{array}$ \\
\hline $\begin{array}{l}\text { After } \\
\times \text { adult mortality }\end{array}$ & $\begin{array}{l}-0.035 \\
(0.055)\end{array}$ & $\begin{array}{l}-0.010 \\
(0.057)\end{array}$ & $\begin{array}{c}0.018 \\
(0.033)\end{array}$ & $\begin{array}{l}-0.013 \\
(0.050)\end{array}$ & $\begin{array}{c}0.002 \\
(0.054)\end{array}$ & $\begin{array}{c}0.009 \\
(0.054)\end{array}$ \\
\hline $\begin{array}{l}\text { Later } \\
\times \text { adult mortality }\end{array}$ & $\begin{array}{l}-0.021 \\
(0.037)\end{array}$ & $\begin{array}{l}-0.083 \\
(0.059)\end{array}$ & $\begin{array}{l}-0.049 \\
(0.043)\end{array}$ & $\begin{array}{l}-0.071 \\
(0.053)\end{array}$ & $\begin{array}{l}-0.068 \\
(0.058)\end{array}$ & $\begin{array}{l}-0.074 \\
(0.058)\end{array}$ \\
\hline $\begin{array}{l}\text { During } \\
\times \text { adult mortality } \times \mathrm{X}\end{array}$ & $\begin{array}{l}-0.118 \\
(0.082)\end{array}$ & $\begin{array}{l}0.123^{* *} \\
(0.048)\end{array}$ & $\begin{array}{c}-0.139^{* *} \\
(0.059)\end{array}$ & $\begin{array}{l}0.065^{*} \\
(0.039)\end{array}$ & $\begin{array}{l}0.098^{* *} \\
(0.042)\end{array}$ & $\begin{array}{c}0.063 \\
(0.042)\end{array}$ \\
\hline $\begin{array}{l}\text { After } \\
\times \text { adult mortality } \times \mathrm{X}\end{array}$ & $\begin{array}{c}0.011 \\
(0.069)\end{array}$ & $\begin{array}{l}-0.028 \\
(0.061)\end{array}$ & $\begin{array}{c}-0.144^{* *} \\
(0.063)\end{array}$ & $\begin{array}{l}-0.035 \\
(0.051)\end{array}$ & $\begin{array}{l}-0.058 \\
(0.057)\end{array}$ & $\begin{array}{l}-0.075 \\
(0.057)\end{array}$ \\
\hline $\begin{array}{l}\text { Later } \\
\times \text { adult mortality } \times \mathrm{X}\end{array}$ & $\begin{array}{l}-0.076 \\
(0.061)\end{array}$ & $\begin{array}{l}-0.018 \\
(0.082)\end{array}$ & $\begin{array}{c}-0.164^{* *} \\
(0.081)\end{array}$ & $\begin{array}{l}-0.067 \\
(0.066)\end{array}$ & $\begin{array}{l}-0.059 \\
(0.072)\end{array}$ & $\begin{array}{l}-0.048 \\
(0.073)\end{array}$ \\
\hline $\mathrm{N}$ & 11,661 & 11,586 & 11,661 & 11,661 & 11,661 & 11,661 \\
\hline $\mathrm{N}$ (cluster) & 97 & 96 & 97 & 97 & 97 & 97 \\
\hline Baseline & 2.14 & 2.14 & 2.14 & 2.14 & 2.14 & 2.14 \\
\hline
\end{tabular}

Dependent variable: conception rate. All regressions include district and month-year fixed effects. Standard errors in parentheses, clustered at the district level. During $\times$ adult mortality $\times X$ denotes the interaction with the variable in the column heading. All interaction variables are dummy variables taking on the value one for districts above the median in 1917. Since the share of Sami was virtually zero in all cities it was excluded from the analysis. The During period includes August 1918 to November 1918; After includes December 1918 to December 1920; Later includes January 1921 to December 1927. Mortality rates are calculated as the cumulative sum of influenza cases occurring during the flu period, normalized by the district population in 1917 . The stars represent significance at the following $\mathrm{p}$-values: * $\mathrm{p}<0.1 * * \mathrm{p}<0.05 * * * \mathrm{p}<0.01$ 
to 1927 and specify the following model:

$$
\begin{aligned}
& \ln \left(\text { MotherType }_{i T}\right)=\alpha_{i}+\beta_{1} \ln \left(\text { FluIncident }_{i T}\right) \cdot D_{\text {During }}+\beta_{2} \ln \left(\text { FluIncident }_{i T}\right) \cdot D_{A f t e r} \\
& +\beta_{3} \ln \left(\text { FluIncidents }_{i T}\right) \cdot D_{\text {Later }}+\delta_{1} \cdot D_{\text {During }}+\delta_{2} \cdot D_{\text {After }}+\delta_{3} \cdot D_{\text {Later }}+\gamma \ln \left(\text { births }_{i T}\right) \\
& +\lambda_{T}+\varepsilon_{i T}
\end{aligned}
$$

where $\ln \left(\right.$ MotherTyре $\left._{i T}\right)$ is the natural logarithm of the number of births in year $T$ to married, unmarried, first-time or not first-time mothers. $\ln \left(\right.$ FluIncident $\left._{i}\right)$ is the logarithm of the cumulative number of deaths or number of flu and pneumonia incidents between August 1918 and March 1919. With annual data the dummy variable $D_{\text {During }}$ takes the value one for the years 1918 and 1919, $D_{\text {After }}$ for the years 1920-1921 and $D_{\text {Later }}$ for the years 1922-1927. We also include the $\log$ of the total number of births taking place in district $i$ in year $T, \ln \left(\right.$ birth $\left._{i T}\right)$, in order to account for the fact that fertility was reduced in districts heavily affected by the flu. Here, we thus only examine which types of births were or were not reduced disproportionately to the general fertility decline caused by the flu. We estimate equation (5) using Seemingly Unrelated Regression (SUR) models as the dependent variables represent interdependent states and the standard errors across these regressions will therefore be correlated.

Table 6 suggests that married and single mothers do not contribute disproportionately to the reduction of conceptions during the pandemic: all estimates are insignificant in rural and urban areas. But the increase in the conception rates observed in rural areas after the flu peak (Table 2) was in particular due to more married mothers having children during 1920 and 1921 in high mortality districts ${ }^{25}$ This is in line with the previously discussed postponement fertility, especially by higher-quality parents (Brown and Thomas, 2011; Richter and Robling, 2013), who then decide to have children when the flu was over. In addition, single mothers contribute disproportionately to the long-term reduction in fertility.

The increasing share of married mothers could be driven by an increase in marriage rates - an issue we return to below - but Table 6 shows that the increasing number of married women giving birth in high-mortality rural districts in the years 1920 and 1921 are women who already had children. Thus more stable families were having children during this period, again in line with postponement by high-quality parents. The results for urban areas also indicate a selection into higher-quality mothers as illustrated by relatively fewer first-time births after the flu. In the long term, however, these districts actually experienced lower fertility than districts less

\footnotetext{
${ }^{25}$ As adult and child mortality appear to have similar effects, we only present results for adult mortality. Results for including morbidity and adult mortality jointly can be found in Appendix F
} 
Table 6 Effects by mother type

\begin{tabular}{|c|c|c|c|c|c|c|}
\hline & \multicolumn{2}{|c|}{ All } & \multicolumn{2}{|c|}{ Rural } & \multicolumn{2}{|c|}{ Urban } \\
\hline & $\begin{array}{c}(1) \\
\ln (\text { married })\end{array}$ & $\begin{array}{c}(2) \\
\ln (\text { unmarried) }\end{array}$ & $\begin{array}{c}(3) \\
\ln (\text { married })\end{array}$ & $\begin{array}{c}(4) \\
\ln (\text { unmarried) }\end{array}$ & $\begin{array}{c}(5) \\
\ln (\text { married })\end{array}$ & $\begin{array}{c}(6) \\
\ln (\text { unmarried) }\end{array}$ \\
\hline $\begin{array}{l}\text { During } \\
\times \text { adult mortality }\end{array}$ & $\begin{array}{c}0.007 \\
(0.009)\end{array}$ & $\begin{array}{c}0.004 \\
(0.017)\end{array}$ & $\begin{array}{c}0.012 \\
(0.009)\end{array}$ & $\begin{array}{l}-0.015 \\
(0.019)\end{array}$ & $\begin{array}{l}-0.011 \\
(0.021)\end{array}$ & $\begin{array}{l}-0.010 \\
(0.039)\end{array}$ \\
\hline $\begin{array}{l}\text { After } \\
\times \text { adult mortality }\end{array}$ & $\begin{array}{c}0.026^{* * *} \\
(0.009)\end{array}$ & $\begin{array}{c}0.009 \\
(0.018)\end{array}$ & $\begin{array}{c}0.037^{* * *} \\
(0.009)\end{array}$ & $\begin{array}{c}0.007 \\
(0.019)\end{array}$ & $\begin{array}{l}-0.015 \\
(0.022)\end{array}$ & $\begin{array}{l}-0.039 \\
(0.039)\end{array}$ \\
\hline $\begin{array}{l}\text { Later } \\
\times \text { adult mortality }\end{array}$ & $\begin{array}{l}-0.001 \\
(0.008)\end{array}$ & $\begin{array}{c}-0.039^{* * *} \\
(0.015)\end{array}$ & $\begin{array}{c}0.024^{* * *} \\
(0.007)\end{array}$ & $\begin{array}{l}-0.003 \\
(0.016)\end{array}$ & $\begin{array}{c}-0.082^{* * *} \\
(0.019)\end{array}$ & $\begin{array}{c}-0.154^{* * *} \\
(0.034)\end{array}$ \\
\hline $\begin{array}{l}\mathrm{N} \\
\text { Baseline }\end{array}$ & $\begin{array}{l}4,033 \\
0.890\end{array}$ & 0.106 & $\begin{array}{l}2,996 \\
0.891\end{array}$ & 0.105 & $\begin{array}{l}1,037 \\
0.885\end{array}$ & 0.109 \\
\hline \multirow{2}{*}{ Baseline } & \multicolumn{2}{|c|}{ All } & \multicolumn{2}{|c|}{ Rural } & \multicolumn{2}{|c|}{ Urban } \\
\hline & $\begin{array}{c}(1) \\
\ln (\text { firstbirth) }\end{array}$ & $\begin{array}{c}(2) \\
\ln (\text { notfirst })\end{array}$ & $\begin{array}{c}\text { (3) } \\
\ln (\text { firstbirth) }\end{array}$ & $\begin{array}{c}(4) \\
\ln (\text { notfirst })\end{array}$ & $\begin{array}{c}(5) \\
\ln (\text { firstbirth) }\end{array}$ & $\begin{array}{c}(6) \\
\ln (\text { notfirst })\end{array}$ \\
\hline $\begin{array}{l}\text { During } \\
\times \text { adult mortality }\end{array}$ & $\begin{array}{c}0.028 \\
(0.026)\end{array}$ & $\begin{array}{c}0.047 \\
(0.029)\end{array}$ & $\begin{array}{c}0.041 \\
(0.035)\end{array}$ & $\begin{array}{c}0.059 \\
(0.041)\end{array}$ & $\begin{array}{l}-0.024 \\
(0.031)\end{array}$ & $\begin{array}{l}-0.000 \\
(0.021)\end{array}$ \\
\hline $\begin{array}{l}\text { After } \\
\times \text { adult mortality }\end{array}$ & $\begin{array}{c}0.029 \\
(0.026)\end{array}$ & $\begin{array}{l}0.060^{* *} \\
(0.029)\end{array}$ & $\begin{array}{c}0.048 \\
(0.035)\end{array}$ & $\begin{array}{l}0.071^{*} \\
(0.041)\end{array}$ & $\begin{array}{l}-0.044 \\
(0.031)\end{array}$ & $\begin{array}{l}-0.008 \\
(0.021)\end{array}$ \\
\hline $\begin{array}{l}\text { Later } \\
\times \text { adult mortality }\end{array}$ & $\begin{array}{c}-0.063^{* * *} \\
(0.021)\end{array}$ & $\begin{array}{c}-0.052^{* *} \\
(0.024)\end{array}$ & $\begin{array}{l}-0.041 \\
(0.028)\end{array}$ & $\begin{array}{l}-0.048 \\
(0.033)\end{array}$ & $\begin{array}{c}-0.119^{* * *} \\
(0.027)\end{array}$ & $\begin{array}{c}-0.091^{* * *} \\
(0.019)\end{array}$ \\
\hline $\mathrm{N}$ & 4,187 & & 3,150 & & 1,037 & \\
\hline Baseline & 0.241 & 0.759 & 0.233 & 0.767 & 0.263 & 0.737 \\
\hline
\end{tabular}

Results from estimating SUR models for married/unmarried and first birth/not first birth separately, standard errors in parentheses. All regressions include district and year fixed effects. Additional control variables include the log of the current number of deaths in the age group 20-40 as well as the $\log$ of the total number of births. The During period includes 1918-1919; After includes 1920-1921; Later includes 1922-1927. Morbidity and mortality are calculated as the cumulative sum of influenza cases/deaths occurring during the flu period. The stars represent significance at the following $\mathrm{p}$-values: $* \mathrm{p}<0.1 * * \mathrm{p}<0.05 * * * \mathrm{p}<0.01$ 
affected by the flu. The long-term negative effect on fertility is due to fewer married and fewer unmarried mothers conceiving 26

\subsubsection{Social Gradient}

From individual records in the Death Index and in the census data we can classify individuals into social groups according to their last name and investigate the social gradient in changed fertility behavior. Clark (2014) shows that last names provide a good measure of social position, which is surprisingly constant over very long time periods. We define two social groups: 1 . nobility/high social status (aristocratic and latin names) and bourgeoisie (names including or ending on Lund/-lund, Berg/-berg, Gren/-gren, -quist, -ström) and 2. others (including names ending on -son or -dotter). The vast majority of individuals born during our period (76.4\%) falls into the second category. $22.2 \%$ are born into the category 'bourgeoisie' and the remaining $1.4 \%$ constitute children of nobility/high social status parents. We choose this rather crude division to be sure to really capture characteristics of social status with our names variable. We then create a dummy variable for being born with 'high social status' (HighSES) taking the value one when the last name is 'noble' or 'bourgeoisie', and zero otherwise. We lag the date of birth by nine months in order to approximate the date of conception and estimate a linear probability model (LPM) of the probability of being conceived in a family with high social status in different periods: During, After and Later, as defined by the following equation:27

$$
\begin{aligned}
& \text { HighSES }_{y i t}=\alpha_{i}+\beta_{1} \text { FluIntensity }_{i t} \cdot D_{\text {During }}+\beta_{2} \text { FluIntensity }_{i t} \cdot D_{A f t e r} \\
& +\beta_{3} \text { FluIntensity }_{i t} \cdot D_{\text {Later }}+\delta_{1} \cdot D_{\text {During }}+\delta_{2} \cdot D_{A f t e r}+\delta_{3} \cdot D_{\text {Later }} \\
& +\lambda_{t}+\varepsilon_{i t}
\end{aligned}
$$

where HighSES $S_{y i t}$ indicates whether individual $y$ is born with high social status in district $i$ in period (month-year) $t$. Results can be found in Table 7 below.

From this exercise it appears that even in urban areas there is a selection into higher quality parents in the period just following the peak, with more individuals with high status names being conceived during this period. Consequently economic conditions played a major role when determining fertility decisions after the flu. There is also a long-term effect on the social gradient in conceptions. This could follow from parents of higher social status being less affected by economic conditions and uncertainty and therefore not reducing fertility. Moreover

\footnotetext{
${ }^{26}$ On average $11 \%$ of all births over the period were to unmarried mothers.

${ }^{27}$ A logit model produces similar results.
} 
Table 7 Social gradient in conceptions

\begin{tabular}{|c|c|c|c|}
\hline & All & Rural & Urban \\
\hline & (1) & (2) & (3) \\
\hline During $\times$ adult mortality & $\begin{array}{c}-0.126 \\
(0.158)\end{array}$ & $\begin{array}{l}-0.072 \\
(0.187)\end{array}$ & $\begin{array}{l}-0.236 \\
(0.179)\end{array}$ \\
\hline After $\times$ adult mortality & $\begin{array}{c}0.040 \\
(0.046)\end{array}$ & $\begin{array}{l}-0.009 \\
(0.041)\end{array}$ & $\begin{array}{c}0.159^{* * *} \\
(0.035)\end{array}$ \\
\hline Later $\times$ adult mortality & $\begin{array}{c}0.022 \\
(0.021)\end{array}$ & $\begin{array}{c}0.003 \\
(0.024)\end{array}$ & $\begin{array}{l}0.072^{* *} \\
(0.034)\end{array}$ \\
\hline $\mathrm{N}$ & $1,209,203$ & 771,663 & 437,540 \\
\hline $\mathrm{N}$ (cluster) & 372 & 273 & 99 \\
\hline
\end{tabular}

Dependent variable: dummy variable taking on the value one if born with a surname representing high social status, and 0 otherwise. All regressions include district and month-year fixed effects. Standard errors in parentheses, clustered at the district level. The During period includes August 1918 to November 1918; After includes December 1918 to December 1920; Later includes January 1921 to December 1927. Morbidity and mortality rates are calculated as the cumulative sum of influenza cases/deaths occurring during the flu period, normalized by the district population in 1917. The stars represent significance at the following p-values: $* \mathrm{p}<0.1 * * \mathrm{p}<0.05 * * * \mathrm{p}<0.01$

we do not find significant immediate effects during the flu peak which would be consistent with social neutrality of the influenza pandemic. If mainly lower social status mothers fell ill, we should be able to see this in conceptions during the flu peak period, but the estimates have the opposite signs and remain insignificant across sub-samples.

\subsubsection{Marriage Market}

The fact that long-term negative effects stem from mortality might indicate a change in the marriage market. People may have lost their spouses and, although remarriage was common after the death of a spouse at the end of the $19^{\text {th }}$ century, this process may take time (Lundh, 2007). The protestant church accepted remarriage but imposed a mourning period of six months on men and one year on women. In fact, widows/widowers were not unattractive on the marriage market as they generally could offer an already existing household. Even if not, it was often a necessity for women to remarry in order to support themselves and their children, especially when children were still small. Young widows generally had better prospects of remarriage, but also stronger incentives to remarry as older widows could expect support from their adult children (Lundh, 2007). We would thus expect younger widows and widowers in particular to remarry quickly, which also represents the group of adults who would be expected to have 
additional children 28

From the Swedish Death Index data, we know the last civil status of the deceased person and the date of the last change in civil status. We can thus estimate the number of people getting married or becoming widowed, i.e. changing to the status 'married' or 'widow' for the last time before death, during our period in each district. Several issues should be kept in mind. First, the data come from the Swedish Death Index only. This implies that an increasing number of individuals born late in our sample have not yet died and we cannot observe them or their civil status. Second, we do not know whether a marriage was their first, we only know it was the last marriage before death. Also, we do not know in which parish the marriage/widowhood took place or with whom. We therefore use the parish of birth whenever the date of birth is closer to the date of marriage/widowhood and the parish of death whenever the date of death is closer to this date. Using the overall marriage and widowhood rates to examine possible changes in the marriage market Figure 15 shows that there was a pronounced increase in marriage rates in 1920-1921 and an increase in widowhood rates during the pandemic.

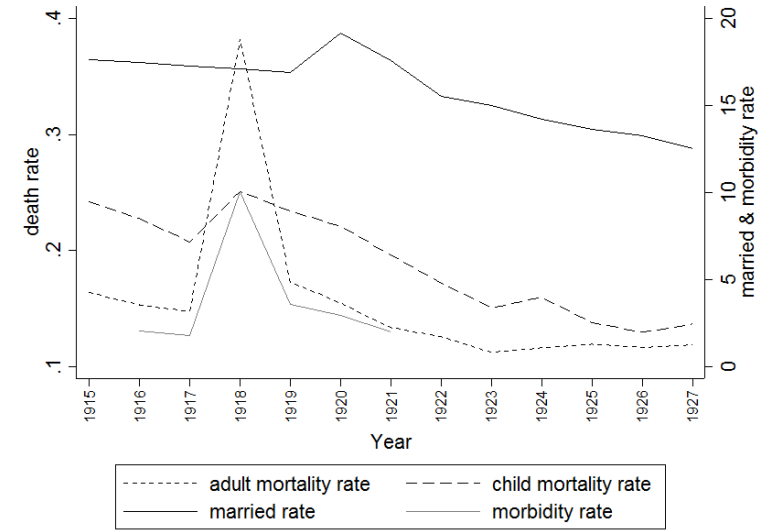

(a) Marriage, morbidity and mortality rates

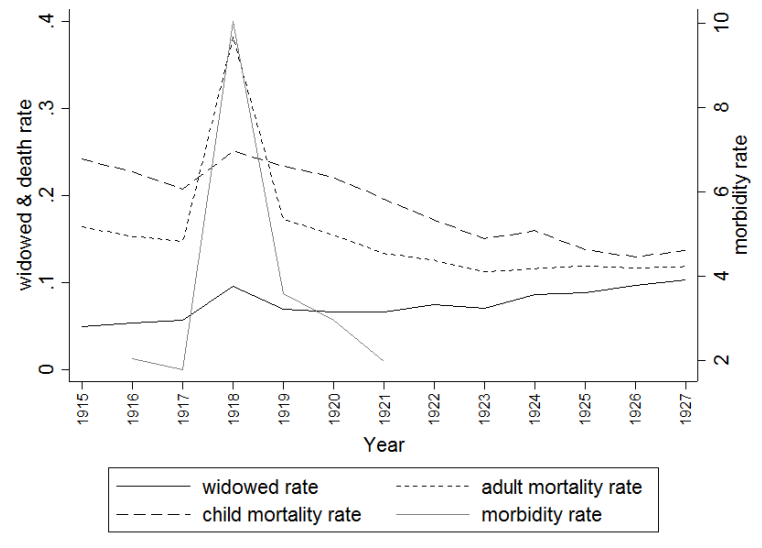

(b) Widowed, morbidity and mortality rates

Fig. 15 Marriage,widowed, morbidity and mortality rates

We then estimate the following model:

$$
\begin{aligned}
& \text { CivilStatusRate }_{i T}=\alpha_{i}+\beta_{1} \text { FluIntensity }_{i T} \cdot D_{\text {During }}+\beta_{2} \text { FluIntensity }_{i T} \cdot D_{A f t e r} \\
& +\beta_{3} \text { FluIntensity }_{i T} \cdot D_{\text {Later }}+\delta_{1} \cdot D_{\text {During }}+\delta_{2} \cdot D_{A f t e r}+\delta_{3} \cdot D_{\text {Later }} \\
& +\lambda_{T}+\varepsilon_{i T}
\end{aligned}
$$

where CivilStatusRate $_{i T}$ is marriage or widowed rate relative to population numbers, in district

\footnotetext{
${ }^{28}$ Although there was a general decline in remarriage rates during the $19^{\text {th }}$ century due to increasing romanticizing of marriage (Lundh, 2007), the group of widows/widowers we are interested in here would be less affected by this trend.
} 
$i$ in period $T \in[1915,1927]$. The rest is as before. Results are displayed in Table 8 , below.

Table 8 Marriage market effects from adult mortality

\begin{tabular}{|c|c|c|c|c|c|c|}
\hline & \multicolumn{2}{|c|}{ All } & \multicolumn{2}{|c|}{ Rural } & \multicolumn{2}{|c|}{ Urban } \\
\hline & $\begin{array}{l}(1) \\
\text { married }\end{array}$ & $\begin{array}{c}(2) \\
\text { widowed }\end{array}$ & $\begin{array}{c}(3) \\
\text { married }\end{array}$ & $\begin{array}{c}\text { (4) } \\
\text { widowed }\end{array}$ & $\begin{array}{c}(5) \\
\text { married }\end{array}$ & $\begin{array}{c}\text { (6) } \\
\text { widowed }\end{array}$ \\
\hline During $\times$ adult mortality & $\begin{array}{c}-0.1545^{* *} \\
(0.0719)\end{array}$ & $\begin{array}{c}0.0374^{* * *} \\
(0.0091)\end{array}$ & $\begin{array}{l}-0.1880^{*} \\
(0.1037)\end{array}$ & $\begin{array}{c}0.0434^{* * *} \\
(0.0143)\end{array}$ & $\begin{array}{l}-0.0819 \\
(0.1034)\end{array}$ & $\begin{array}{l}0.0266^{*} \\
(0.0135)\end{array}$ \\
\hline After $\times$ adult mortality & $\begin{array}{c}-0.0102 \\
(0.1579)\end{array}$ & $\begin{array}{c}0.0673^{* * *} \\
(0.0184)\end{array}$ & $\begin{array}{c}0.0820 \\
(0.2347)\end{array}$ & $\begin{array}{c}0.0659^{* * *} \\
(0.0230)\end{array}$ & $\begin{array}{l}-0.0472 \\
(0.1552)\end{array}$ & $\begin{array}{l}0.0627^{* *} \\
(0.0291)\end{array}$ \\
\hline Later $\times$ adult mortality & $\begin{array}{c}-0.5449^{*} \\
(0.2920)\end{array}$ & $\begin{array}{c}0.0162 \\
(0.0121)\end{array}$ & $\begin{array}{c}-0.8119^{*} \\
(0.4673)\end{array}$ & $\begin{array}{l}-0.0034 \\
(0.0112)\end{array}$ & $\begin{array}{l}-0.1705 \\
(0.1681)\end{array}$ & $\begin{array}{l}0.0259^{*} \\
(0.0151)\end{array}$ \\
\hline $\mathrm{N}$ & 4,097 & 4,097 & 3,086 & 3,086 & 1,011 & 1,011 \\
\hline $\mathrm{N}$ (cluster) & 366 & 366 & 270 & 270 & 96 & 96 \\
\hline
\end{tabular}

Dependent variable: marriage/widow rate. All regressions include district and year fixed effects. Standard errors in parentheses, clustered at the district level. The During period includes 1918-1919; After includes 1920-1921; Later includes 1922-1927. Morbidity and mortality rates are calculated as the cumulative sum of influenza cases/deaths occurring during the flu period, normalized by the district population in 1917. The stars represent significance at the following p-values: $* \mathrm{p}<0.1 * * \mathrm{p}<0.05 * * * \mathrm{p}<0.01$

Separating urban and rural contexts we find lower marriage rates in severely affected rural areas. According to our estimates, each additional adult death per 1,000 people reduced annual marriage rates in the long term by 0.812 . The $25^{\text {th }}$ and the $75^{\text {th }}$ percentile have an adult mortality rate of 1.81 and 3.75 per 1,000 people respectively. The difference between these two rural districts would correspond to a $9.3 \%$ reduction in the annual marriage rate. The long-term decrease in the monthly conception rate in rural areas corresponds to $9.1 \%$ (Table 2) and it thus seems that the observed fertility decrease in rural areas stems from the marriage market.

Lower marriage rates could be induced by the loss of a fiancé, by changes in the population composition (leading to difficulties finding a partner), by negative income effects (people can not afford to get married) or by increased uncertainty after the pandemic (leading to higher reluctance to get married after the pandemic among potential first-time parents). To understand whether large gender distortions, i.e. districts that lost more adult women than adult men and vice versa, had an influence on the marriage market, we use weighted gender distortion as a treatment variable. We calculate an absolute difference between adult male and female deaths normalized by the population in 1917 .

The results in Table 9 show that gender imbalance only mattered in rural areas in the During period and that gender imbalance did not decrease marriage rates in the long term. Rather the decrease was induced by increased uncertainty and/or negative income effect after the pandemic. This is in line with the fact that we find an increasing number of births to married, established mothers in the years just after the flu in rural areas, but fewer first-time mothers in 
the long-run. The fact that this effect only appears in rural areas indicates that the marriage market was more severely affected, possibly due to a less dynamic marriage market in these areas.

Table 9 Marriage market effects from adult gender distortion

\begin{tabular}{|c|c|c|c|c|c|c|}
\hline & \multicolumn{2}{|c|}{ All } & \multicolumn{2}{|c|}{ Rural } & \multicolumn{2}{|c|}{ Urban } \\
\hline & $\begin{array}{c}(1) \\
\text { married }\end{array}$ & $\begin{array}{c}(2) \\
\text { widowed }\end{array}$ & $\begin{array}{c}\text { (3) } \\
\text { married }\end{array}$ & $\begin{array}{c}\text { (4) } \\
\text { widowed }\end{array}$ & $\begin{array}{c}(5) \\
\text { married }\end{array}$ & $\begin{array}{c}\text { (6) } \\
\text { widowed }\end{array}$ \\
\hline During $\times$ gender distortion & $\begin{array}{l}-0.2978 \\
(0.2507)\end{array}$ & $\begin{array}{c}0.0850^{* *} \\
(0.0353)\end{array}$ & $\begin{array}{l}-0.4543^{*} \\
(0.2718)\end{array}$ & $\begin{array}{c}0.0995^{* * *} \\
(0.0287)\end{array}$ & $\begin{array}{c}0.0121 \\
(0.4542)\end{array}$ & $\begin{array}{c}0.0583 \\
(0.0710)\end{array}$ \\
\hline After $\times$ gender distortion & $\begin{array}{l}-0.3260 \\
(0.3560)\end{array}$ & $\begin{array}{c}0.0669^{*} \\
(0.0397)\end{array}$ & $\begin{array}{l}-0.5002 \\
(0.3682)\end{array}$ & $\begin{array}{c}0.0481 \\
(0.0396)\end{array}$ & $\begin{array}{c}0.0699 \\
(0.6794)\end{array}$ & $\begin{array}{c}0.0714 \\
(0.0785)\end{array}$ \\
\hline Later $\times$ gender distortion & $\begin{array}{c}0.0010 \\
(0.3160)\end{array}$ & $\begin{array}{c}0.0122 \\
(0.0261)\end{array}$ & $\begin{array}{l}-0.0872 \\
(0.3750)\end{array}$ & $\begin{array}{c}0.0095 \\
(0.0320)\end{array}$ & $\begin{array}{c}0.3831 \\
(0.5549)\end{array}$ & $\begin{array}{l}-0.0114 \\
(0.0446)\end{array}$ \\
\hline $\begin{array}{l}\mathrm{N} \\
\mathrm{N} \text { (cluster) }\end{array}$ & $\begin{array}{c}4,097 \\
366\end{array}$ & $\begin{array}{c}4,097 \\
366\end{array}$ & $\begin{array}{c}3,086 \\
270\end{array}$ & $\begin{array}{c}3,086 \\
270\end{array}$ & $\begin{array}{c}1,011 \\
96\end{array}$ & $\begin{array}{c}1,011 \\
96\end{array}$ \\
\hline
\end{tabular}

Dependent variable: marriage/widow rate. All regressions include district and year fixed effects. Standard errors in parentheses, clustered at the district level. The During period includes 1918-1919; After includes 1920-1921; Later includes 1922-1927. Gender distortion is calculated as the absolute difference between male and female deaths in the flu period, normalized by the district population in 1917. The stars represent significance at the following p-values: * $\mathrm{p}<0.1 * * \mathrm{p}<0.05 * * * \mathrm{p}<0.01$

\subsubsection{Labor Market}

Theoretically the decrease in fertility after the flu could also be linked to changes on the labor market. If women's relative wages increased or if the flu killed a husband/father in the household, women and/or children would potentially have to enter the labor market to earn an income. We would expect this effect to appear in regions that lost relatively more adult males than females. Using information on county factory labor supply we run the following regression to examine whether there were labor supply adjustments after the flu:

$$
\begin{aligned}
& \text { LaborSupply }_{c T}=\alpha_{c}+\beta_{1} \text { FluAdultMaleMort }_{c T} \cdot D_{\text {During }}+\beta_{2} \text { FluAdultMaleMort }_{c T} \cdot D_{A f t e r} \\
& +\beta_{3} \text { FluAdultMaleMort }_{c T} \cdot D_{\text {Later }}+\delta_{1} \cdot D_{\text {During }}+\delta_{2} \cdot D_{\text {After }}+\delta_{3} \cdot D_{\text {Later }}+X_{c T} \Gamma \\
& +\lambda_{T}+\varepsilon_{i T}
\end{aligned}
$$

for county $c$ in period $T \in[1915,1927]$. LaborSupply $c T$ is the labor supply of females, minors or males in factories (as a share of total population). FluAdultMaleMort c $_{c}$ is the number of 
adult male deaths in the county over the number of adult female deaths during the flu period. $X_{c T}^{\prime}$ includes the relative population share of females, minors or males respectively and regional time trends. Table 10 suggests that the labor supply of women indeed increased in the short term after the flu in regions that lost more adult males than females, while no such effect took place for minors and adult males. In the long run the positive effect on female labor supply however loses significance. Consequently the observed negative fertility effects seem mainly to follow from the marriage market and not the labor market.

The data on labor supply corresponds to workers in factories likely located in urban areas. If the short-term positive effect on female labor supply mainly took place in urban areas, this explains why there is no short-term positive effect on conceptions in these areas. Moreover the increase in the relative number of children born to high social status parents in urban areas likely reflects that these parents were not affected economically to the extent that women would have to enter the labor market.

Table 10 Labor market effects from higher adult male mortality

\begin{tabular}{|c|c|c|c|}
\hline & Females & Minors & Males \\
\hline & (1) & (2) & (3) \\
\hline During $\times$ adult male mortality & $\begin{array}{c}0.1849 \\
(0.1453)\end{array}$ & $\begin{array}{c}-0.1086 \\
(0.1331)\end{array}$ & $\begin{array}{c}-0.1687 \\
(0.2709)\end{array}$ \\
\hline After $\times$ adult male mortality & $\begin{array}{c}0.2952^{* *} \\
(0.1155)\end{array}$ & $\begin{array}{c}-0.1542 \\
(0.1689)\end{array}$ & $\begin{array}{l}-0.1362 \\
(0.6508)\end{array}$ \\
\hline Later $\times$ adult male mortality & $\begin{array}{c}0.3226 \\
(0.2355)\end{array}$ & $\begin{array}{c}-0.1110 \\
(0.2866)\end{array}$ & $\begin{array}{c}0.2832 \\
(1.2215)\end{array}$ \\
\hline Add. controls & Yes & Yes & Yes \\
\hline Region trend & Yes & Yes & Yes \\
\hline $\mathrm{N}$ & 324 & 324 & 324 \\
\hline $\mathrm{N}$ (cluster) & 25 & 25 & 25 \\
\hline
\end{tabular}

Dependent variable: labor supply of females, minors and
males (as a share of total population). All regressions include
year dummies, regional time trends and the relative popula-
tion share of females, minors and males respectively which
are not displayed. Standard errors in parentheses. Standard
errors are clustered at the county level. The During period in-
cludes 1918-1919; After includes $1920-1921 ;$ Later includes
1922-1927. The stars represent significance at the following
p-values: $*$ p $<0.1 * * \mathrm{p}<0.05 * * * \mathrm{p}<0.01$

\subsection{Robustness Checks}

To address potential concerns we run a set of robustness tests. First, negative fertility effects may be due to migration. If life became more difficult in districts hard hit by the flu, people 
might choose to move away. Although we are looking at conception rates it might be that especially young people in their fertile age have the possibility to migrate which would bias our measure of conception rates downwards. One way that we account for the age structure in the district is by including the current age-specific mortality rate as a control variable. Assuming that, in the absence of unusual events such as the influenza, a constant share of a specific age group dies every month, this measure will reflect the share of that age group living in the district. In order to minimize possible bias due to migration, we nevertheless conduct a robustness check using larger regions, i.e. we repeat the analysis of equation 4 on the county level, reducing the number of geographical units from 367 to 25. Table G1 in the Appendix presents the results. The estimates during the peak and in the long term are very similar to the ones obtained on the district level.

An alternative way to account for migration is to exclude the counties with the highest outmigration. During our period, the regions Blekinge, Västmanland, and Kronoberg lose most inhabitants. Table G2 shows the results when excluding these three counties. Again, the results are similar to Tables 1, 2 and 3. Yet another robustness check for whether migration is driving our results on the long-term parameters is to calculate the net migration rate for every district using population numbers, number of deaths, and number of births. For every year the residual provides a measure of how many people moved in or out of the district, subject to random measurement error. From this we calculate the net migration rate by dividing the residual by the total population of the district at the beginning of the year. We then estimate whether the net migration rate correlates with our measure of flu intensity. Table G3 shows that the only significant effect is a positive effect on migration in urban areas during the flu period and a borderline effect in rural areas after 1920. This actually implies that there was inmigration to heavily affected areas. ${ }^{29}$ We do not know who actually moved into the parishes, but it seems unlikely that only older or very young people outside fertile age would move on their own thereby depressing the conception rates. All together our results do not seem to be driven by migration.

Another potential concern is World War I being a confounding factor. If those areas most affected by the flu were also areas most affected by the war, our findings might mirror the end of the war. We therefore conduct a robustness check excluding the areas potentially more affected by the war. Sweden was neutral but issued several declarations to Germany and Great Britain that it would never fight on the side of Russia. There was a general fear of Russia going back to Russia's seizure of Finland in 1809 and a belief that Russia might invade northern Sweden, specifically the areas neighboring Finland that was under Russian rule, in order to gain access to the Atlantic (Siney, 1975). Repeating the analysis excluding the two most northern counties, Norrbotten and Västerbotten, and the island Gotland which was exposed due to its position on

\footnotetext{
${ }^{29} \mathrm{We}$ leave the issue of reverse causation aside here, as it is beyond the scope of this paper.
} 
the Baltic sea, the effects are qualitatively unchanged, see Table G4.

In addition to these concerns, it is difficult to determine for how long the biological effects reducing fertility are present. The literature does not have a clear answer to how long women, and possibly also men, are negatively affected in their ability to conceive (Wiwanitkit, 2010). We study a period of ten years after the flu, and it could still be that couples had difficulties in conceiving. However, the positive effect on marital fertility in 1920 and 1921 strongly contradicts this notion. Also, possible negative health effects would concern women who were infected but survived the infection, therefore, we would expect such effect to stem from morbidity, not mortality. Table 1 illustrates that this is not the case.

Finally, as mentioned in Appendix C, some health districts changed their boundaries over time and we aggregate these to 'super districts' with stable borders during our period. Table G5 in the Appendix presents results where we include dummy variables indicating a change in the district border and show that this does not influence our main results.

\section{Conclusion}

We show that a large morbidity and mortality shock such as the 1918-19 influenza pandemic influences fertility rates not only in the short term but even a decade later. Every year seasonal influenza causes 250,000 to 500,000 deaths worldwide (WHO, 2014), underlining the importance and relevance of the study of past pandemics for today. There is still a sizeable world population that lives in conditions similar to Sweden in 1918-1919. If a virus with similar power to the influenza pandemic appeared today, the ease and speed of modern travel in our globalized world would produce a devastating death toll. It is therefore important to examine how societies respond in the short and long term to these types of events.

We find evidence for postponement fertility, especially for high quality parents, as the increase in fertility rates in rural areas in the years immediately following the flu peak is driven by married women with previous children giving birth during the baby boom of the $1920 \mathrm{~s}$. We also find a selection into parents of higher social status in urban areas following a decrease of conceptions during the flu. In contrast to previous research we are able to also study longer term effects of the shock. We find that the positive trend reverses, such that fertility rates are in fact lower in districts which were highly affected by the flu when examined over a ten year period. Investigating potential mechanisms shows that this is due to a combination of negative income effects, changes on the marriage market as well as changes on the labor market. The negative fertility response is driven by poor areas and marriage rates are depressed even in the long term. Additionally, we find that female labor supply increases immediately after the 
pandemic in regions that lost more adult men than women. All together it is evident that if an epidemic turns deadly, fertility effects go far beyond the period of infection itself and will be felt for decades after.

\section{Conflict of Interest Statement}

The authors declare that they have no conflict of interest. 


\section{References}

Agadjanian, V. and N. Prata (2002). War, peace, and fertility in Angola. Demography 39(2), $215-231$.

Alam, S. A. and C. C. Pörtner (2016). Income shocks, contraceptive use, and timing of fertility. Contraceptive Use, and Timing of Fertility (May 2, 2016).

Almond, D. (2006). Is the 1918 influenza pandemic over? Long-term effects of in utero influenza exposure in the post-1940 U.S. population. J POLIT ECON 114, 672-712.

Almond, D. and B. Mazumder (2013). Fetal origins and parental responses. In Annual Review of Economics. Citeseer.

Åman, M. (1990). Spanska sjukan: den svenska epidemin 1918-1920 och dess internationella bakgrund.

Angrist, J. D. and J.-S. Pischke (2008). Mostly harmless econometrics: An empiricist's companion. Princeton university press.

Auger, N., W. D. Fraser, A. Smargiassi, M. Bilodeau-Bertrand, and T. Kosatsky (2016). Elevated outdoor temperatures and risk of stillbirth. INT J EPIDEMIOL, 1-6.

Barker, D. J. (1990, November). The fetal and infant origins of adult disease. BRIT MED $J$ 301(6761), 1111.

Barnett, A. G. and A. J. Dobson (2010). Analysing seasonal health data, Volume 30. Springer.

Barry, J. M. (2004). The great influenza: the epic story of the greatest plague in history. Viking Penguin, New York.

Bengtsson, T. and M. Dribe (2014). The historical fertility transition at the micro level: Southern sweden 1815-1939. DEMOGR RES.

Bhalotra, S., M. Karlsson, and T. Nilsson (2016). Life expectancy and mother-baby interventions: Evidence from a historical trial. Working Paper Series 1124, Research Institute of Industrial Economics.

Bland, P. B. (1919). Influenza in its relation to pregnancy and labor. American Journal of Obstetrics 79(184), 97.

Bloom-Feshbach, K., L. Simonsen, C. Viboud, K. Mølbak, M. A. Miller, M. Gottfredsson, and V. Andreasen (2012). Reply to mamelund. J INFECT DIS 206(1), 141-143.

Boucekkine, R., R. Desbordes, and H. Latzer (2009, June). How do epidemics induce behavioral changes? J ECON GROWTH 14(3), 233-264. 
Brown, R. and D. Thomas (2011). On the long term effecs of the 1918 U.S. influenza pandemic. Unpublished Manuscript.

Bruckner, T. A. ., B. Modin, and D. Vågerö (2014). Cold ambient temperature in utero and birth outcomes in Uppsala, Sweden, 1915-1929. ANN EPIDEMIOL 24(2), 116-121.

Castro, R., J. R. Behrman, and H.-P. Kohler (2015). Perception of HIV risk and the quantity and quality of children: the case of rural Malawi. J POPUL ECON 28(1), 113-132.

Charchafche, H. and P. Nilsson (2006). [the women and the right to contraceptives]. Svensk medicinhistorisk tidskrift 11(1), 139-150.

Chesnais, J.-C. (1992). The demographic transition: Stages, patterns, and economic implications. A longitudinal study of sixty-seven countries covering the period 1720-1984. OUP Catalogue.

Clark, G. (2014). The son also rises: Surnames and the history of social mobility. Princeton University Press.

Cohen, B. and M. R. Montgomery (Eds.) (1998). From death to birth: Mortality decline and reproductive change. National Academies Press.

Conning, J. and C. Udry (2007). Rural financial markets in developing countries. Handbook of Agricultural Economics 3, 2857-2908.

Del Bono, E., A. Weber, and R. Winter-Ebmer (2015). Fertility and economic instability: the role of unemployment and job displacement. J POPUL ECON 28(2), 463-478.

Donaldson, D. and D. Keniston (2015). How positive was the positive check? Investment and fertility in the aftermath of the 1918 influenza in India.

Eriksson, A. W. and J. Fellman (2000). Seasonal variation of livebirths, stillbirths, extramarital births and twin maternities in Switzerland. TWIN RES 3(4), 189-201.

Finlay, J. (2009). Fertility response to natural disasters: the case of three high mortality earthquakes. World Bank Policy Research Working Paper Series (4338).

Galor, O. and D. N. Weil (1996). The gender gap, fertility, and growth. AM ECON REV 86(3), 374-387.

Geertz, C. (1963). Agricultural involution: the process of ecological change in Indonesia, Volume 11. University of California Press.

Grimard, F. (1993). Household consumption smoothing through ethnic ties: evidence from Cote d'Ivoire. J DEV ECON 53(2), 391-422. 
Herlihy, D. (1997). The Black Death and the transformation of the West. Harvard University Press.

Högberg, U., S. Wall, and G. Broström (1986). The impact of early medical technology on maternal mortality in late 19th century Sweden. INT J GYNECOL OBSTET 24(4), 251-261.

Holtenius, J. and A. Gillman (2014). The Spanish flu in Uppsala, clinical and epidemiological impact of the influenza pandemic 1918-1919 on a Swedish county. Infection Ecology \& Epidemiology 4.

Johannisson, K. (1994). The people's health: Public health policies in Sweden. Clio Medica 26, $165-182$.

Jonsson, E. (2009). History of health technology assessment in Sweden. INT J TECHNOL ASSESS 25(1), 42-52.

Jörberg, L. and O. Krantz (1978). Ekonomisk och social politik i Sverige, 1850-1939. Ekonomisk-historiska institutionen, Lunds Universitet.

Juhn, C., S. Kalemli-Ozcan, and B. Turan (2013). HIV and fertility in Africa: first evidence from population-based surveys. J POPUL ECON 26(3), 835-853.

Kalemli-Ozcan, S. and B. Turan (2011). HIV and fertility revisited. J DEV ECON 96(1), $61-65$.

Karlsson, M., T. Nilsson, and S. Pichler (2014). The impact of the 1918 Spanish flu epidemic on economic performance in Sweden: An investigation into the consequences of an extraordinary mortality shock. J HEALTH ECON 36, 1-19.

Karlsson, M. and S. Pichler (2015). Demographic consequences of HIV. J POPUL ECON 4, $1097-1135$.

Keller, C. A. and R. P. Nugent (1983). Seasonal patterns in perinatal mortality and preterm delivery. AM J EPIDEMIOL 118(5), 689-698.

Kobasa, D., S. M. Jones, K. Shinya, J. C. Kash, J. Copps, H. Ebihara, Y. Hatta, J. H. Kim, P. Halfmann, M. Hatta, F. Feldmann, J. B. Alimonti, L. Fernando, Y. Li, M. G. Katze, H. Feldmann, and Y. Kawaoka (2007, January). Aberrant innate immune response in lethal infection of macaques with the 1918 influenza virus. Nature 445(7125), 319-323.

Kovar, R. W. and R. J. Taylor (1960). Is spontaneous abortion a seasonal problem? Obstetrics \& Gynecology 16(3), 350-353.

Lee, R. (1981). Short-term variation: vital rates, prices and weather. in, The population history of England, 1541-1871. E.A. Wrigley and R.S. Schofield, eds. 
Lindstrom, D. P. and B. Berhanu (1999). The impact of war, famine, and economic decline on marital fertility in Ethiopia. Demography 36(2), 247-261.

Lundh, C. (2007). Remarriage, gender and social: A longitudinal study of remarriage in Southern Sweden, 1766-1894. CONTINUITY CHANGE 22(3), 373-406.

Magnusson, L. (1996). Sveriges ekonomiska historia. Raben Prisma.

Mamelund, S.-E. (2003). Spanish influenza mortality of ethnic minorities in Norway 19181919. EUR J POPUL 19(1), 83-102.

Mamelund, S.-E. (2004). Can the Spanish influenza pandemic of 1918 explain the baby boom of 1920 in neutral Norway? Population 59(2), 229-260.

Mamelund, S.-E. (2011). Geography may explain adult mortality from the 1918-20 influenza pandemic. Epidemics 3(1), 46-60.

Mamelund, S.-E., B. Haneberg, and S. Mjaaland (2016). A missed summer wave of the 19181919 influenza pandemic: Evidence from household surveys in the united states and norway. In Open forum infectious diseases, Volume 3, pp. ofw040. Oxford University Press.

Menken, J., J. Trussell, and S. Watkins (1981). The nutrition fertility link: An evaluation of the evidence. The Journal of Interdisciplinary History 11(3), 425-441.

Morens, D. M. and A. S. Fauci (2007). The 1918 influenza pandemic: insights for the 21st century. J INFECT DIS 195(7), 1018-1028.

Nobles, J., E. Frankenberg, and D. Thomas (2015). The effects of mortality on fertility: population dynamics after a natural disaster. Demography 52(1), 15-38.

Nyström, H. (1994). Hungerupproret 1917. Zelos.

Palloni, A. and H. Rafalimanana (1999). The effects of infant mortality on fertility revisited: New evidence from Latin America. Demography 36(1), 41-58.

Pörtner, C. (2008). Gone with the wind? Hurricane risk, fertility and education. Working Papers UWEC-2006-19-R, University of Washington, Department of Economics.

Preston, S. H. (1978). The effects of infant and child mortality on fertility. New York: Academic Press.

Richter, A. and P. O. Robling (2013). Multigenerational effects of the 1918-19 influenza pandemic in Sweden. Swedish Institute for Social Research 5. 
Romlid, C. (1997). Midwives, society and childbirth: Debates and controversies in the modern period, Chapter Swedish midwives and their instruments in the eighteenth and nineteenth centuries, pp. 38-60. London, England: Routledge.

Rosenzweig, M. R. and T. P. Schultz (1983). Consumer demand and household production: the relationship between fertility and child mortality. AM ECON REV 73(2), 38-42.

Sandahl, B. (1974). A study of seasonal and secular trends in incidence of stillbirths and spontaneous abortions in sweden. Acta obstetricia et gynecologica Scandinavica 53(3), 251257.

Sandström, G. (2011). Time-space trends in swedish divorce behaviour 1911-1974. SCAND J HIST 36(1), 65-90.

Santow, G. (1993). Coitus interruptus in the twentieth century. POPUL DEV REV, 767-792.

Schön, L. (2010). Sweden's road to modernity: An economic history. SNS förlag.

Siney, M. C. (1975). Swedish neutrality and the economic warfare in World War I. Conspectus of History 1(2), 13-28.

Statistics Sweden (1911-1917). Sveriges officiella statistik. Kommunernas Fattigvård och Finanser. Stockholm: Kungl. Statistiska Centralbyrån.

Statistics Sweden (1915-1927b). Statistisk årsbok för Sverige. Stockholm: Kungl. Statistiska Centralbyrån.

Statistics Sweden (1918-1927a). Fattigvården. Stockholm: Kungl. Statistiska Centralbyrån.

Statistics Sweden (1936). Folkräkningen den 31 December 1930. Stockholm: Kungl. StatistiskaCentralbyrån, Stockholm.

Statistics Sweden (1999). Befolkningsutvecklingen under 250 år. Historisk statistik för Sverige 1999.

Strand, L. B., A. G. Barnett, and S. Tong (2012). Maternal exposure to ambient temperature and the risks of preterm birth and stillbirth in brisbane, australia. AM J EPIDEMIOL 175(2), 99-107.

Strulik, H. and S. Vollmer (2015). The fertility transition around the world. J POPUL ECON 28(1), 31-44.

Suri, T. (2005). Spillovers in village consumption: Testing the extent of partial insurance. New Haven, Conn.: Yale University. mimeo. 
Taubenberger, J. K. and D. M. Morens (2006). 1918 influenza: the mother of all pandemics. EMERG INFECT DIS 12(1), 15-22.

Thomson, A. (1997). Midwives, society and childbirth: debates and controversies in the modern period, Chapter European midwifery in the inter-war years, pp. 20-37. London, England: Routledge.

Torrey, E. F., A. E. Bowler, R. Rawlings, and A. Terrazas (1993). Seasonality of schizophrenia and stillbirths. SCHIZOPHRENIA BULL 19(3), 557-562.

Townsend, R. M. (1994). Risk and insurance in village India. Econometrica: Journal of the Econometric Society, 539-591.

Veenendaal, M. V., R. C. Painter, S. Rooij, P. M. Bossuyt, J. Post, P. D. Gluckman, M. A. Hanson, and T. J. Roseboom (2013). Transgenerational effects of prenatal exposure to the 194445 dutch famine. BJOG: An International Journal of Obstetrics \& Gynaecology 120(5), $548-554$.

Warren, C. W., J. Gold, C. W. Tyler Jr, J. C. Smith, and A. L. Paris (1980). Seasonal variation in spontaneous abortions. AM J PUBLIC HEALTH 70(12), 1297-1299.

WHO (2014, March). Influenza (seasonal). Web. Accessed: 2016-07-24.

Wiwanitkit, V. (2010). Influenza, swine flu, sperm quality and infertility: A story. Journal of human reproductive sciences $3(2), 116$.

Young, A. (2005, May). The gift of the dying: The tragedy of AIDS and the welfare of future African generations. The Quaterly Journal of Economics 120(2), 423-466.

Young, A. (2007). In sorrow to bring forth children: fertility amidst the plague of HIV. $J$ ECON GROWTH 12(4), 283-327. 


\section{Appendix}

\section{A Theoretical Predictions}

Table A1 presents a graphical summary of the dimensions and time horizons of the predicted fertility effects. Here, the time of conception is considered. Previous empirical studies generally find positive fertility effects after mortality shocks, but these studies only consider the short-term effects and do not separate between adult and child mortality.

Table A1 Summary of Theoretical Predictions

\begin{tabular}{|c|c|c|c|}
\hline & \multicolumn{3}{|c|}{ Time Period } \\
\hline & $\begin{array}{c}\text { During } \\
(08 / 1918-11 / 1918)\end{array}$ & $\begin{array}{c}\text { After } \\
(12 / 1918-12 / 1920)\end{array}$ & $\begin{array}{c}\text { Later } \\
(1 / 1921-12 / 1927)\end{array}$ \\
\hline \multicolumn{4}{|l|}{ Biological Effects } \\
\hline Morbidity & - & - & $(-)$ \\
\hline Adult Mortality & - & - & -1 \\
\hline Child Mortality & 0 & 0 & 0 \\
\hline \multicolumn{4}{|c|}{ Psychological Effects } \\
\hline Morbidity & - & $+^{2}$ & 0 \\
\hline Adult Mortality & - & $+^{3}$ & - \\
\hline Child Mortality & - & $+^{3}$ & 0 \\
\hline \multicolumn{4}{|l|}{ Economic Effects } \\
\hline Morbidity & 0 & 0 & 0 \\
\hline Adult Mortality & 0 & -4 & -4 \\
\hline Child Mortality & 0 & $+^{5}$ & $+^{5}$ \\
\hline $\begin{array}{l}{ }^{1} \text { Marriage market ef } \\
{ }^{2} \text { Postponement fertil } \\
{ }^{3} \text { Postponement and/ } \\
{ }^{4} \text { Negative income ef } \\
{ }^{5} \text { Replacement due to }\end{array}$ & $\begin{array}{l}\text { ect. } \\
\text { ty. } \\
\text { r replacement fertility } \\
\text { ect/labor market effect } \\
\text { labor market effects }\end{array}$ & & \\
\hline
\end{tabular}




\section{B Summary Statistics}

Table B1 Descriptive Statistics.

\begin{tabular}{|c|c|c|c|c|c|c|c|c|c|}
\hline & \multicolumn{5}{|c|}{ All Periods } & \multicolumn{4}{|c|}{ Specific Periods } \\
\hline & $\mathrm{N}$ & Min & Max & Mean & SD & Before & During & After & Later \\
\hline \multicolumn{10}{|l|}{ All } \\
\hline Conception Rate & 53,719 & 0 & 20.48 & 1.74 & 1.14 & 1.81 & 1.55 & 2.04 & 1.61 \\
\hline Morbidity Rate* & 31,831 & 0 & 392.28 & 3.12 & 8.77 & 4.79 & 22.57 & 3.82 & 2.01 \\
\hline Death Rate (20-40) & 57,296 & 0 & 9.03 & 0.15 & 0.26 & 0.15 & 0.77 & 0.18 & 0.12 \\
\hline Male Death Rate (20-40) & 57,296 & 0 & 4.65 & 0.08 & 0.16 & 0.08 & 0.43 & 0.10 & 0.06 \\
\hline Female Death Rate (20-40) & 57,296 & 0 & 5.80 & 0.07 & 0.15 & 0.07 & 0.34 & 0.08 & 0.06 \\
\hline Children Death Rate (0-10) & 57,296 & 0 & 5.69 & 0.19 & 0.25 & 0.22 & 0.33 & 0.24 & 0.16 \\
\hline High SES** & $1,296,073$ & 0 & 1 & 0.24 & 0.42 & 0.24 & 0.24 & 0.24 & 0.23 \\
\hline \multicolumn{10}{|l|}{ Rural } \\
\hline Conception Rate & 38,981 & 0 & 12.39 & 1.63 & 0.86 & 1.68 & 1.45 & 1.90 & 1.51 \\
\hline Morbidity Rate* & 24,702 & 0 & 392.28 & 2.61 & 8.05 & 4.26 & 20.21 & 3.44 & 1.79 \\
\hline Death Rate (20-40) & 41,526 & 0 & 7.61 & 0.15 & 0.22 & 0.14 & 0.72 & 0.17 & 0.12 \\
\hline Male Death Rate (20-40) & 41,526 & 0 & 4.65 & 0.08 & 0.14 & 0.07 & 0.41 & 0.09 & 0.06 \\
\hline Female Death Rate (20-40) & 41,526 & 0 & 3.51 & 0.07 & 0.12 & 0.07 & 0.31 & 0.08 & 0.06 \\
\hline Children Death Rate (0-10) & 41,526 & 0 & 4.34 & 0.19 & 0.21 & 0.21 & 0.38 & 0.24 & 0.16 \\
\hline High SES** & 831,749 & 0 & 1 & 0.23 & 0.42 & 0.23 & 0.23 & 0.23 & 0.22 \\
\hline \multicolumn{10}{|l|}{ Urban } \\
\hline Conception Rate & 14,738 & 0 & 20.48 & 2.06 & 1.61 & 2.14 & 1.81 & 2.40 & 1.90 \\
\hline Morbidity Rate* & 7,129 & 0 & 310.26 & 4.91 & 10.74 & 6.25 & 28.91 & 4.85 & 2.67 \\
\hline Death Rate (20-40) & 15,770 & 0 & 9.36 & 0.18 & 0.33 & 0.18 & 0.83 & 0.21 & 0.14 \\
\hline Male Death Rate (20-40) & 15,770 & 0 & 3.76 & 0.09 & 0.20 & 0.09 & 0.45 & 0.11 & 0.07 \\
\hline Female Death Rate (20-40) & 15,770 & 0 & 6.02 & 0.09 & 0.19 & 0.09 & 0.38 & 0.10 & 0.07 \\
\hline Children Death Rate (0-10) & 15,770 & 0 & 5.69 & 0.19 & 0.34 & 0.23 & 0.34 & 0.23 & 0.15 \\
\hline High SES** & 464,324 & 0 & 1 & 0.25 & 0.44 & 0.26 & 0.25 & 0.26 & 0.25 \\
\hline
\end{tabular}

The table shows the descriptive statistics for the variables, and shows means of the variables for $B e$ fore ( $t \geq$ January $1915 \& t<$ August 1918), During ( $t \geq$ August $1918 \& t \leq$ November 1918), After ( $t>$ November $1918 \& t \leq$ November 1920) and Later $(t>$ November $1920 \& t \leq$ December 1927$)$ of the 1918-19 flu pandemic. The above variables are available on a health district level, monthly basis and per 1,000 people. ${ }^{*}$ - morbidity data is only available from 1916 through $1921 .{ }^{* *}$ - individual-level data. 
Table B2 Descriptive Statistics: Mother and Birth Characteristics.

\begin{tabular}{|c|c|c|c|c|c|c|c|c|c|}
\hline & \multicolumn{5}{|c|}{ All Periods } & \multicolumn{4}{|c|}{ Specific Periods } \\
\hline & $\mathrm{N}$ & Min & Max & Mean & SD & Before & During & After & Later \\
\hline \multicolumn{10}{|l|}{ COUNTY-LEVEL VARIABLES } \\
\hline Poverty share (\%) & 324 & 2.08 & 8.89 & 4.51 & 1.32 & 4.23 & 4.10 & 3.99 & 4.99 \\
\hline Female labor supply & 324 & 0.02 & 2.99 & 0.75 & 0.68 & 0.75 & 0.71 & 0.74 & 0.78 \\
\hline Child labor supply & 324 & 0.07 & 1.36 & 0.65 & 0.29 & 0.80 & 0.73 & 0.63 & 0.55 \\
\hline Male labor supply & 324 & 1.63 & 8.17 & 4.52 & 1.50 & 4.66 & 4.70 & 4.42 & 4.41 \\
\hline Earnings (SEK/capita) & 324 & 138.46 & 1592.76 & 412.93 & 170.71 & 265.81 & 287.95 & 419.83 & 524.20 \\
\hline Capital income (SEK/capita) & 324 & 4.17 & 274.43 & 38.85 & 27.29 & 18.31 & 24.70 & 49.85 & 49.94 \\
\hline \multicolumn{10}{|l|}{ HEALTH-DistRICT LEVEL VARIABLES } \\
\hline \multicolumn{10}{|l|}{ All } \\
\hline Married mothers & 4,214 & 0 & 1,117 & 205.41 & 170.72 & 217.39 & 217.84 & 238.69 & 182.22 \\
\hline Unmarried mothers & 4,214 & 0 & 339 & 26.86 & 27.08 & 26.31 & 25.28 & 33.13 & 25.40 \\
\hline First time mothers & 4,214 & 0 & 443 & 60.89 & 52.32 & 58.54 & 64.52 & 75.89 & 55.16 \\
\hline Not first time mothers & 4,214 & 0 & 930 & 172.56 & 144.21 & 186.17 & 180.28 & 197.27 & 153.50 \\
\hline Marriage Rate* & 4,098 & 0 & 88.17 & 16.12 & 6.81 & 17.53 & 17.08 & 18.53 & 14.06 \\
\hline Widowed Rate* & 4,812 & 0 & 6.79 & 0.60 & 0.55 & 0.40 & 0.65 & 0.56 & 0.69 \\
\hline Still births rate (per 1,000 births) & 4,003 & 0 & 157.89 & 22.77 & 15.44 & 24.42 & 22.40 & 21.82 & 22.41 \\
\hline Miscarriage rate (per 1,000 births) & 3,785 & 0 & 363.64 & 41.25 & 26.16 & 37.72 & 42.73 & 37.40 & 44.01 \\
\hline \multicolumn{10}{|l|}{ Rural } \\
\hline Married mothers & 3,177 & 0 & 1,117 & 225.58 & 178 & 238.06 & 237.63 & 262.32 & 201.35 \\
\hline Unmarried mothers & 3,177 & 0 & 339 & 28.90 & 27.84 & 28.22 & 27.39 & 35.58 & 27.35 \\
\hline First time mothers & 3,177 & 0 & 443 & 64.35 & 52.28 & 62.16 & 68.38 & 80.47 & 58.05 \\
\hline Not first time mothers & 3,177 & 0 & 930 & 191.42 & 150.97 & 205.23 & 198.44 & 218.99 & 171.72 \\
\hline Marriage Rate* & 3,086 & 0 & 88.17 & 15.93 & 6.66 & 16.98 & 16.79 & 18.35 & 14.12 \\
\hline Widowed Rate* & 3,479 & 0 & 6.11 & 0.55 & 0.44 & 0.38 & 0.63 & 0.51 & 0.62 \\
\hline Still births rate (per 1,000 births) & 2,977 & 0 & 138.89 & 22.00 & 13.51 & 24.26 & 21.77 & 20.73 & 21.39 \\
\hline Miscarriage rate (per 1,000 births) & 2,866 & 0 & 200 & 37.96 & 20.69 & 34.03 & 37.65 & 35.59 & 40.97 \\
\hline \multicolumn{10}{|l|}{ Urban } \\
\hline Married mothers & 1,037 & 6 & 833 & 143.59 & 127.76 & 155.05 & 159.36 & 168.31 & 121.66 \\
\hline Unmarried mothers & 1,037 & 0 & 164 & 20.62 & 23.55 & 20.53 & 19.05 & 25.83 & 19.24 \\
\hline First time mothers & 1,037 & 0 & 358 & 50.31 & 51.02 & 47.59 & 53.10 & 62.23 & 46.00 \\
\hline Not first time mothers & 1,037 & 0 & 604 & 114.80 & 101.31 & 128.66 & 126.64 & 132.61 & 95.82 \\
\hline Marriage Rate* & 1,012 & 0.40 & 67.37 & 16.70 & 7.23 & 19.20 & 17.92 & 19.05 & 13.87 \\
\hline Widowed Rate* & 1,333 & 0 & 6.79 & 0.72 & 0.76 & 0.43 & 0.71 & 0.67 & 0.89 \\
\hline Still births rate (per 1,000 births) & 1,026 & 0 & 157.89 & 25.01 & 19.86 & 24.88 & 24.18 & 24.99 & 25.41 \\
\hline Miscarriage rate (per 1,000 births) & 919 & 0 & 363.64 & 51.53 & 36.67 & 49.01 & 57.74 & 42.75 & 54.01 \\
\hline
\end{tabular}

The table shows the descriptive statistics for the variables, and shows means of the variables for Before $(t \geq 1915$ $\& t<1918)$, During $(t \geq 1918 \& t \leq 1919)$, After $(t \geq 1920 \& t \leq 1921)$ and Later $(t \geq 1922 \& t \leq 1927)$ of the 1918-19 flu pandemic. The above variables are available on a health district level, monthly basis and per 1,000 people. ${ }^{*}$ - rate per 1,000 people. 
Table B3 Balancing test

\begin{tabular}{lccc}
\hline & $(1)$ & $(2)$ & $(3)$ \\
& flu morbidity & adult flu mortality & child flu mortality \\
\hline $\ln ($ midwives) & $-33.109^{* * *}$ & $-0.778^{* * *}$ & $-0.399^{* *}$ \\
& $(6.979)$ & $(0.189)$ & $(0.166)$ \\
population density & -1.028 & -0.015 & -0.031 \\
& $(1.219)$ & $(0.033)$ & $(0.028)$ \\
poverty rate & 0.474 & 0.048 & 0.014 \\
& $(1.049)$ & $(0.029)$ & $(0.025)$ \\
private property & -7.302 & 0.054 & -0.101 \\
value & $(8.060)$ & $(0.218)$ & $(0.185)$ \\
taxable income & -17.009 & 0.086 & -0.280 \\
& $(10.602)$ & $(0.287)$ & $(0.244)$ \\
conception rate & $0.867^{* *}$ & $0.136^{* * *}$ & $0.123^{* * *}$ \\
sami share & $(0.394)$ & $(0.008)$ & $(0.006)$ \\
high ses share & -0.106 & 0.002 & $0.015^{* *}$ \\
& $(0.277)$ & $(0.008)$ & $(0.006)$ \\
& -0.003 & -0.002 & $-0.002^{*}$ \\
Standard errors & $(0.047)$ & $(0.001)$ & $(0.001)$ \\
\hline
\end{tabular}

Standard errors in parentheses. The stars represent significance at the following p-values: $* \mathrm{p}<0.1 * * \mathrm{p}<0.05 * * * \mathrm{p}<0.01$ 


\section{Data Description}

The Medical Board classified health districts into four groups: extra provincial, provincial, municipal district, and city. The distinction between extra provincial and provincial was usually one of timing, where a newly formed district would start as an extra provincial district which was later turned into a provincial district if the separation proved viable. Likewise a municipal district was often given the status of a city later on. We use this classification to divide health districts into rural and urban districts, where we group extra provincial and provincial districts into rural districts and municipalities and cities into urban districts. We do this as fertility dynamics might potentially be very different between rural and urban areas.

We know the corresponding county for all health districts and all parishes, as it is given in the data. However, data on the parish level, namely the Swedish Death Index which is described in more detail in the following, does not include information on the health district level. As we conduct the analysis on the health district level, we need to map parishes to health districts in order to combine the different sources. We do this based on the official list from 1930. Often, parishes changed health district over time as new districts were formed and others were dissolved. We use information from royal decrees in order to track these changes. Also, the royal decrees sometimes report full lists of allocations for certain counties in a particular year. This helps us to verify the allocation from 1930 back to our study period. In some cases, parishes that we observe in the Swedish Death Index were not included in the list nor the royal decrees. These parishes are allocated manually using information on parish changes and the corresponding municipality ${ }^{30}$ (kommun) as well as individual web searches. For the analysis we group health districts together into super-district whenever boundaries changed, in order to use geographical units with stable boundaries over time. This leaves us with a total of 396 districts (although all data is not always available for all districts) including 65 super-districts.

\footnotetext{
${ }^{30}$ This information can be conveniently found at http://sara.moricz.se/Kommungränskonverterare/
} 


\section{Time Trends}

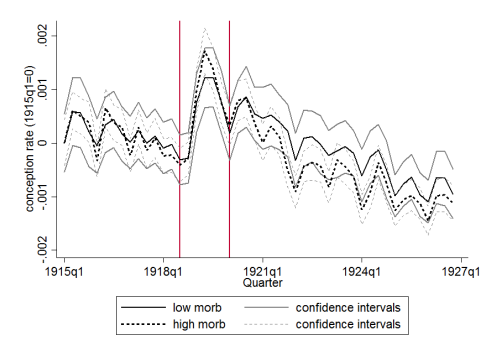

(a) Morbidity

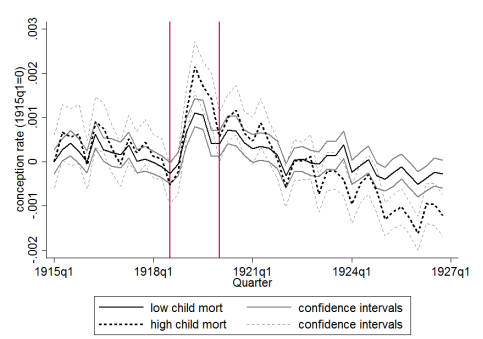

(b) Child mortality

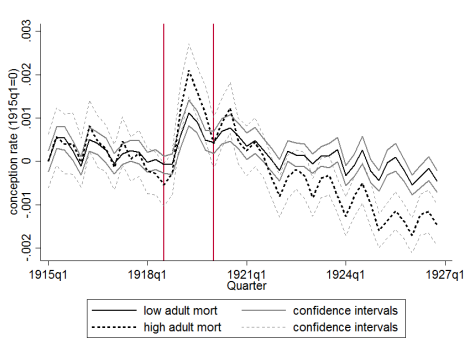

(c) Adult mortality

Fig. D1 Time trend for conception rate

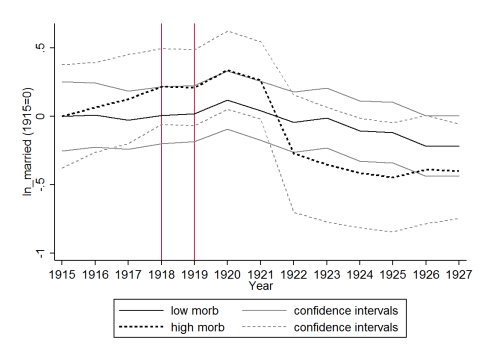

(a) Morbidity

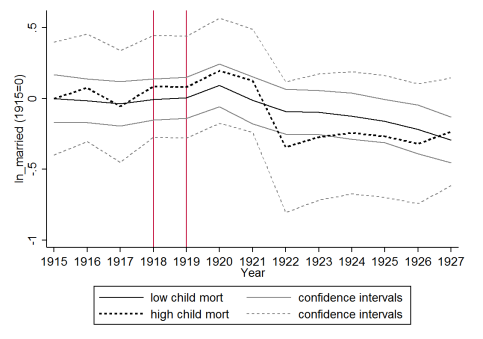

(b) Child mortality

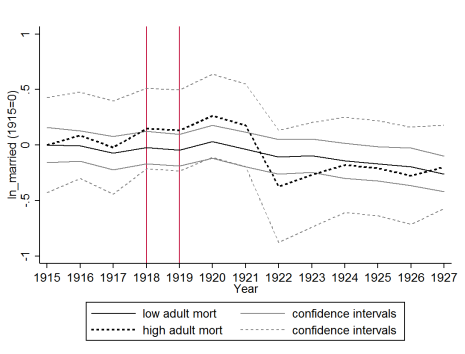

(c) Adult mortality

Fig. D2 Time trend for $\ln$ (married)

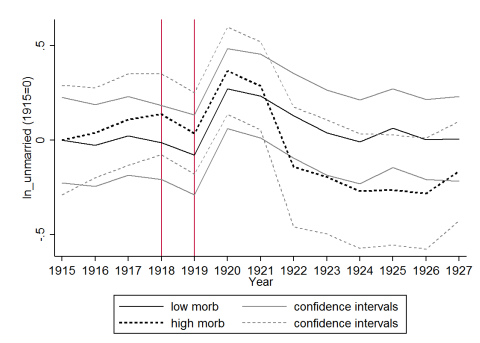

(a) Morbidity

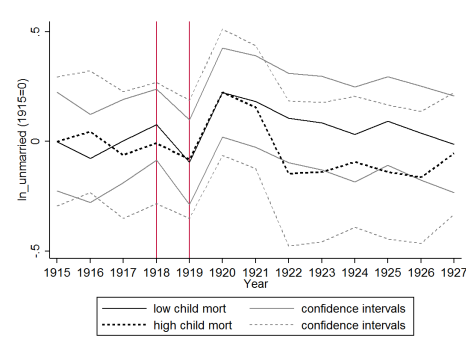

(b) Child mortality

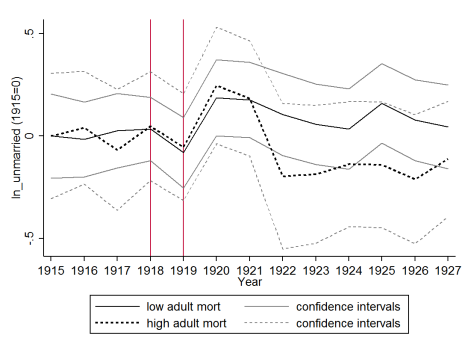

(c) Adult mortality

Fig. D3 Time trend for $\ln$ (unmarried)

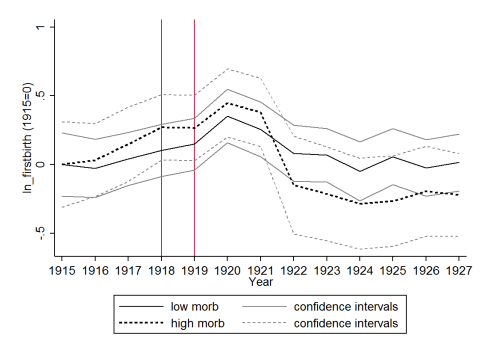

(a) Morbidity

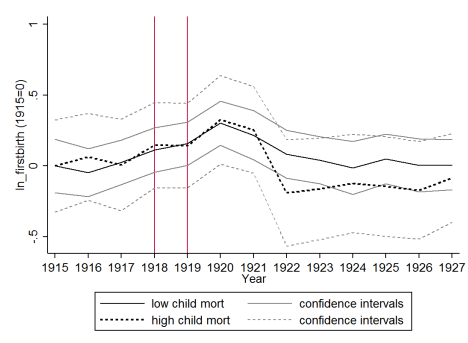

(b) Child mortality

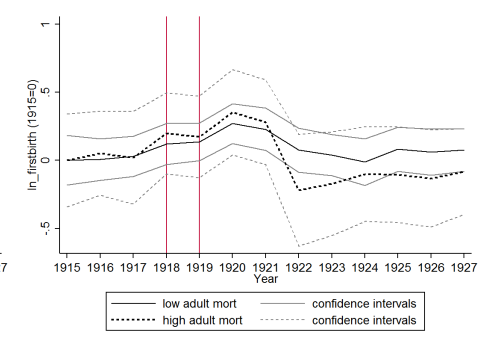

(c) Adult mortality

Fig. D4 Time trend for $\ln ($ firstbirth) 


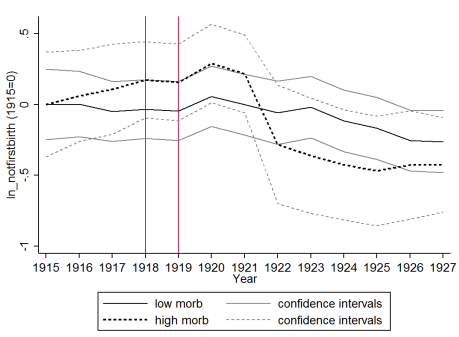

(a) Morbidity

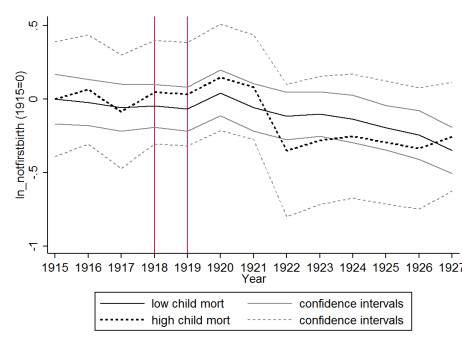

(b) Child mortality

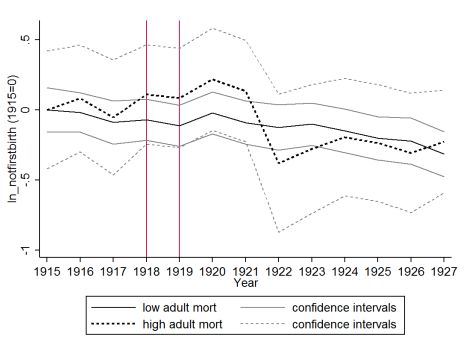

(c) Adult mortality

Fig. D5 Time trend for $\ln$ (notfirstbirth)

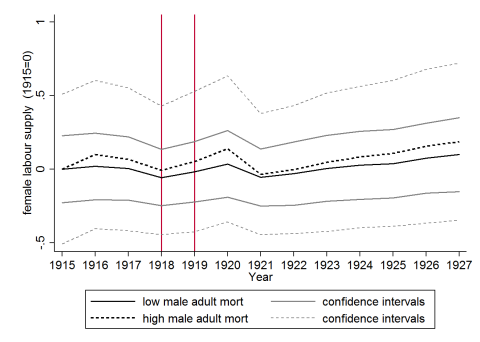

(a) Females

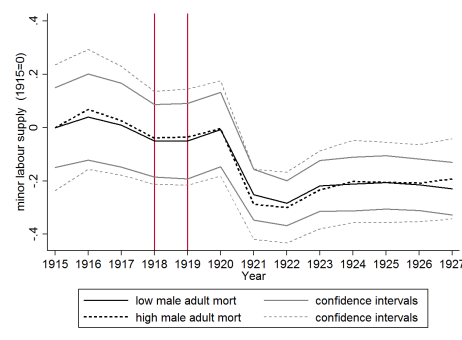

(b) Minors

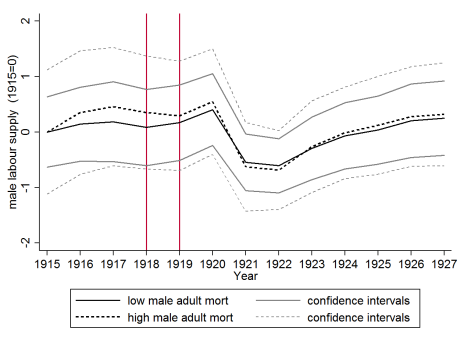

(c) Males

Fig. D6 Time trend for female, minor and male labor supplies

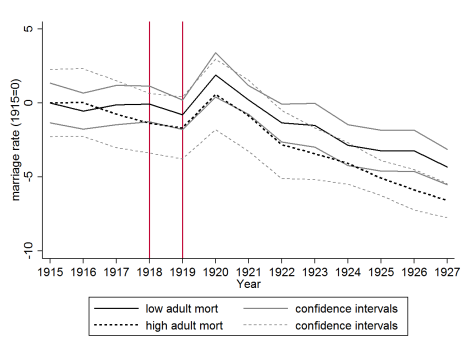

(a) Marriage rate

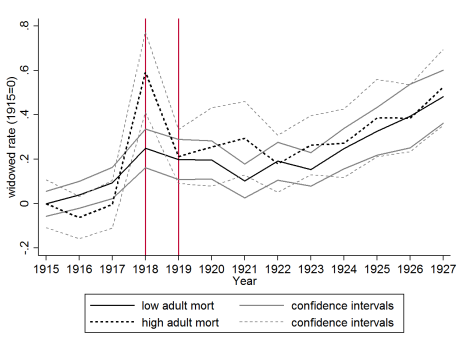

(b) Widowed rate

Fig. D7 Time trend for marriage and widowed rate with respect to adult mortality

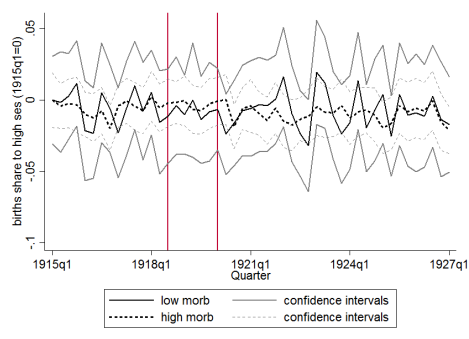

(a) Morbidity

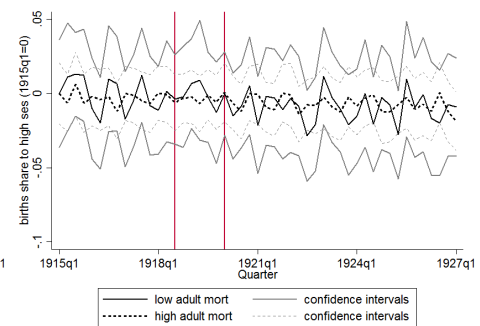

(b) Adult mortality

Fig. D8 Time trend for births to high SES parents 


\section{E Fertility Effects}

Table E1 Fertility effects from morbidity and mortality

\begin{tabular}{|c|c|c|c|c|c|c|c|c|}
\hline & \multicolumn{8}{|c|}{ All } \\
\hline & (1) & (2) & (3) & (4) & (5) & (6) & (7) & (8) \\
\hline During $\times$ morbidity & $\begin{array}{l}-0.0004 \\
(0.0004)\end{array}$ & $\begin{array}{l}-0.0005 \\
(0.0005)\end{array}$ & $\begin{array}{l}-0.0007^{*} \\
(0.0003)\end{array}$ & $\begin{array}{l}-0.0006^{*} \\
(0.0004)\end{array}$ & & & $\begin{array}{l}-0.0005 \\
(0.0004)\end{array}$ & $\begin{array}{l}-0.0006 \\
(0.0004)\end{array}$ \\
\hline After $\times$ morbidity & $\begin{array}{c}0.0002 \\
(0.0002)\end{array}$ & $\begin{array}{c}0.0002 \\
(0.0002)\end{array}$ & $\begin{array}{c}0.0003 \\
(0.0002)\end{array}$ & $\begin{array}{c}0.0003 \\
(0.0002)\end{array}$ & & & $\begin{array}{c}0.0001 \\
(0.0002)\end{array}$ & $\begin{array}{c}0.0001 \\
(0.0002)\end{array}$ \\
\hline Later $\times$ morbidity & $\begin{array}{c}0.0000 \\
(0.0004)\end{array}$ & $\begin{array}{c}0.0001 \\
(0.0003)\end{array}$ & $\begin{array}{l}-0.0002 \\
(0.0003)\end{array}$ & $\begin{array}{l}-0.0001 \\
(0.0003)\end{array}$ & & & $\begin{array}{l}-0.0000 \\
(0.0004)\end{array}$ & $\begin{array}{l}-0.0000 \\
(0.0003)\end{array}$ \\
\hline During $\times$ adult mortality & $\begin{array}{c}-0.0708^{* * *} \\
(0.0213)\end{array}$ & $\begin{array}{c}-0.1040^{* * *} \\
(0.0341)\end{array}$ & & & $\begin{array}{l}-0.0351 \\
(0.0239)\end{array}$ & $\begin{array}{c}-0.0602^{* *} \\
(0.0270)\end{array}$ & $\begin{array}{l}-0.0282 \\
(0.0254)\end{array}$ & $\begin{array}{l}-0.0533^{*} \\
(0.0274)\end{array}$ \\
\hline After $\times$ adult mortality & $\begin{array}{c}0.0212 \\
(0.0245)\end{array}$ & $\begin{array}{c}0.0186 \\
(0.0243)\end{array}$ & & & $\begin{array}{c}0.0607^{* * *} \\
(0.0194)\end{array}$ & $\begin{array}{c}0.0583^{* * *} \\
(0.0200)\end{array}$ & $\begin{array}{c}0.0598^{* * *} \\
(0.0201)\end{array}$ & $\begin{array}{c}0.0574^{* * *} \\
(0.0209)\end{array}$ \\
\hline Later $\times$ adult mortality & $\begin{array}{c}-0.0899^{* * *} \\
(0.0267)\end{array}$ & $\begin{array}{c}-0.0940^{* * *} \\
(0.0247)\end{array}$ & & & $\begin{array}{l}-0.0536^{*} \\
(0.0321)\end{array}$ & $\begin{array}{l}-0.0532^{*} \\
(0.0283)\end{array}$ & $\begin{array}{l}-0.0532 \\
(0.0333)\end{array}$ & $\begin{array}{l}-0.0531^{*} \\
(0.0286)\end{array}$ \\
\hline During $\times$ child mortality & & & $\begin{array}{c}-0.1449^{* * *} \\
(0.0280)\end{array}$ & $\begin{array}{c}-0.1573^{* * *} \\
(0.0238)\end{array}$ & $\begin{array}{c}-0.1135^{\text {*** }} \\
(0.0405)\end{array}$ & $\begin{array}{c}-0.1148^{* * *} \\
(0.0392)\end{array}$ & $\begin{array}{c}-0.1169^{* * *} \\
(0.0417)\end{array}$ & $\begin{array}{r}-0.1184^{* * *} \\
(0.0398)\end{array}$ \\
\hline After $\times$ child mortality & & & $\begin{array}{l}-0.0239 \\
(0.0349)\end{array}$ & $\begin{array}{l}-0.0272 \\
(0.0345)\end{array}$ & $\begin{array}{c}-0.0739^{* *} \\
(0.0326)\end{array}$ & $\begin{array}{c}-0.0750^{* *} \\
(0.0317)\end{array}$ & $\begin{array}{c}-0.0733^{* *} \\
(0.0326)\end{array}$ & $\begin{array}{c}-0.0743^{* *} \\
(0.0318)\end{array}$ \\
\hline Later $\times$ child mortality & & & $\begin{array}{c}-0.1099^{* * *} \\
(0.0231)\end{array}$ & $\begin{array}{c}-0.1208^{* * *} \\
(0.0223)\end{array}$ & $\begin{array}{l}-0.0686^{*} \\
(0.0374)\end{array}$ & $\begin{array}{c}-0.0773^{* *} \\
(0.0331)\end{array}$ & $\begin{array}{l}-0.0688^{*} \\
(0.0377)\end{array}$ & $\begin{array}{c}-0.0773^{* *} \\
(0.0331)\end{array}$ \\
\hline Add. controls & No & Yes & No & Yes & No & Yes & No & Yes \\
\hline County trend & No & Yes & No & Yes & No & Yes & No & Yes \\
\hline $\mathrm{N}$ & 46,861 & 46,861 & 46,861 & 46,861 & 46,861 & 46,861 & 46,861 & 46,861 \\
\hline $\mathrm{N}$ (cluster) & 367 & 367 & 367 & 367 & 367 & 367 & 367 & 367 \\
\hline Baseline & 1.81 & 1.81 & 1.81 & 1.81 & 1.81 & 1.81 & 1.81 & 1.81 \\
\hline
\end{tabular}

Dependent variable: conception rate. All regressions include district and month-year fixed effects. Standard errors in parentheses, clustered at the district level. Additional control variables include the current mortality rate, the log of the number of midwives, the log of earnings and the log of capital income in 1917 prices, the poverty share, and the labor supply of women and of children as a share of the labor force. The During period includes August 1918 to November 1918; After includes December 1918 to December 1920; Later includes January 1921 to December 1927. Morbidity and mortality rates are calculated as the cumulative sum of influenza cases/deaths occurring during the flu period, normalized by the district population in 1917. The stars represent significance at the following $\mathrm{p}$-values: $* \mathrm{p}<0.1 * * \mathrm{p}<0.05 * * * \mathrm{p}<0.01$ 
Table E2 Fertility effects from morbidity and mortality

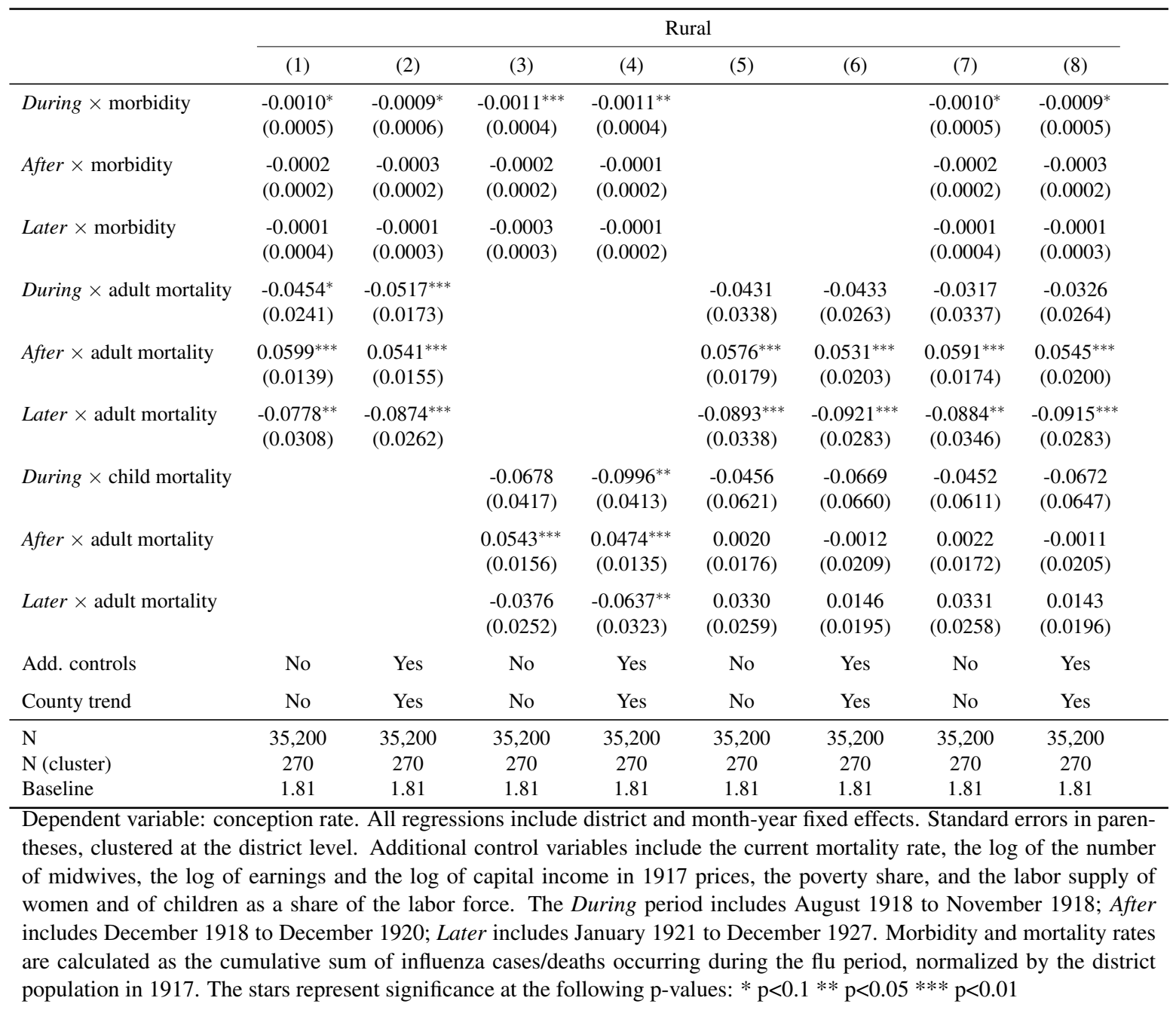


Table E3 Fertility effects from morbidity and mortality

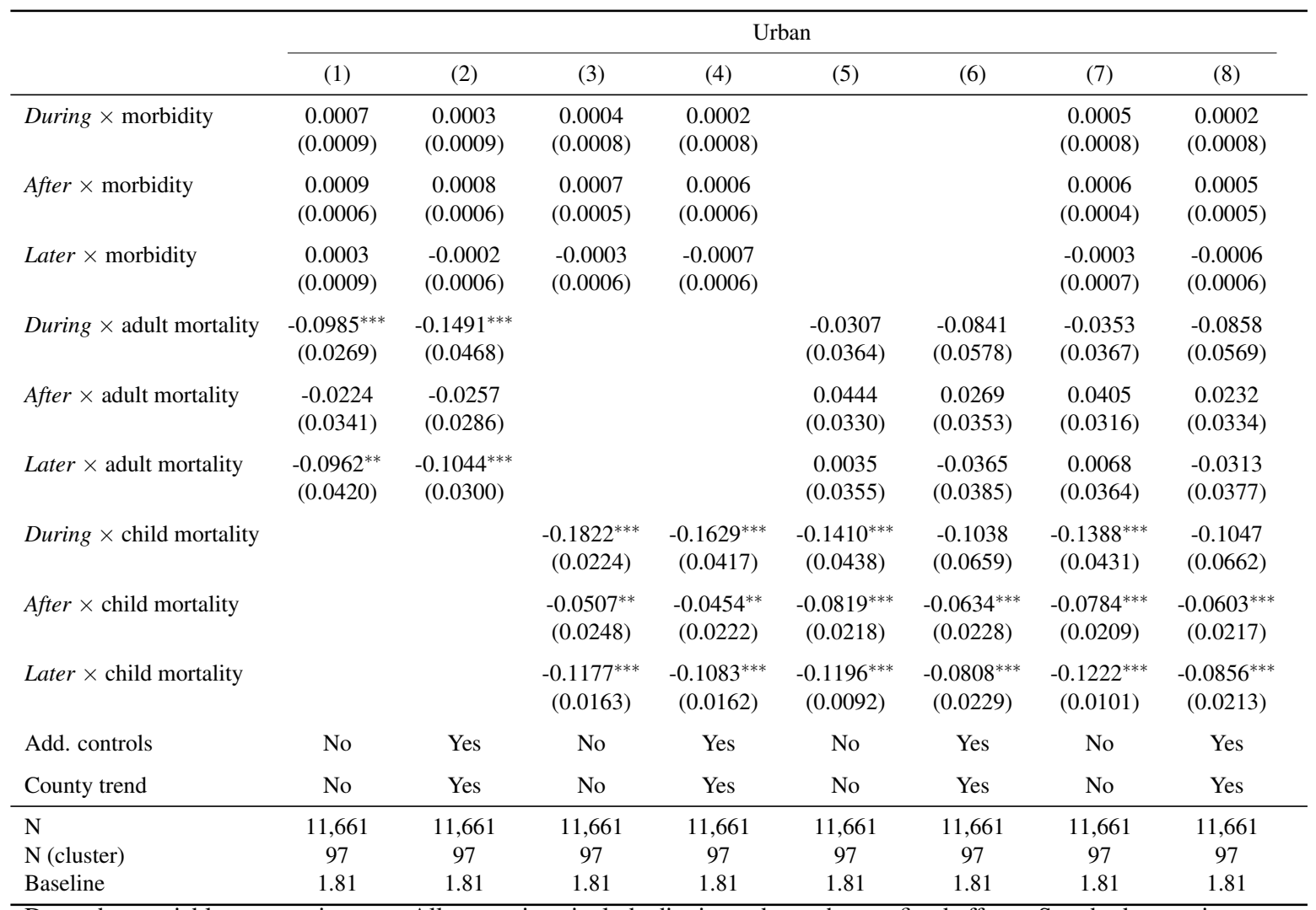

Dependent variable: conception rate. All regressions include district and month-year fixed effects. Standard errors in parentheses, clustered at the district level. Additional control variables include the current mortality rate, the log of the number of midwives, the log of earnings and the log of capital income in 1917 prices, the poverty share, and the labor supply of women and of children as a share of the labor force. The During period includes August 1918 to November 1918; After includes December 1918 to December 1920; Later includes January 1921 to December 1927. Morbidity and mortality rates are calculated as the cumulative sum of influenza cases/deaths occurring during the flu period, normalized by the district population in 1917. The stars represent significance at the following $\mathrm{p}$-values: $* \mathrm{p}<0.1 * * \mathrm{p}<0.05 * * * \mathrm{p}<0.01$ 


\section{F Effects by Mother Type}

Table F1 Effects by mother type

\begin{tabular}{|c|c|c|c|c|c|c|}
\hline & \multicolumn{2}{|c|}{ All } & \multicolumn{2}{|c|}{ Rural } & \multicolumn{2}{|c|}{ Urban } \\
\hline & (1) & & (2) & & (3) & \\
\hline & $\ln ($ married $)$ & $\ln$ (unmarried) & $\ln ($ married $)$ & $\ln$ (unmarried) & $\ln ($ married $)$ & $\ln ($ unmarried) \\
\hline \multirow[t]{2}{*}{ During $\times$ morbidity } & -0.004 & -0.016 & -0.006 & -0.008 & 0.010 & -0.017 \\
\hline & $(0.027)$ & $(0.021)$ & $(0.037)$ & $(0.026)$ & $(0.019)$ & $(0.034)$ \\
\hline \multirow[t]{2}{*}{ After $\times$ morbidity } & -0.005 & -0.026 & -0.010 & -0.028 & 0.019 & -0.002 \\
\hline & $(0.027)$ & $(0.021)$ & $(0.036)$ & $(0.026)$ & $(0.019)$ & $(0.035)$ \\
\hline \multirow[t]{2}{*}{ Later $\times$ morbidity } & $-0.076^{* * *}$ & $-0.061^{* * *}$ & $-0.085^{* * *}$ & $-0.053^{* *}$ & $-0.035^{* *}$ & $-0.070^{* *}$ \\
\hline & $(0.023)$ & $(0.018)$ & $(0.030)$ & $(0.022)$ & $(0.016)$ & $(0.029)$ \\
\hline \multirow[t]{2}{*}{ During $\times$ adult mortality } & 0.054 & 0.041 & 0.073 & 0.029 & -0.014 & -0.001 \\
\hline & $(0.037)$ & $(0.029)$ & $(0.051)$ & $(0.037)$ & $(0.025)$ & $(0.044)$ \\
\hline \multirow[t]{2}{*}{ After $\times$ adult mortality } & $0.067^{*}$ & 0.039 & $0.084^{*}$ & 0.048 & -0.023 & -0.056 \\
\hline & $(0.036)$ & $(0.028)$ & $(0.051)$ & $(0.036)$ & $(0.025)$ & $(0.044)$ \\
\hline \multirow[t]{2}{*}{ Later $\times$ adult mortality } & 0.026 & -0.021 & 0.048 & 0.003 & $-0.051^{* *}$ & $-0.115^{* * *}$ \\
\hline & $(0.030)$ & $(0.023)$ & $(0.041)$ & $(0.029)$ & $(0.021)$ & $(0.038)$ \\
\hline $\mathrm{N}$ & 4,237 & & 3,194 & & 1,043 & \\
\hline \multirow[t]{4}{*}{ Baseline } & 0.890 & 0.106 & 0.891 & 0.105 & 0.885 & 0.109 \\
\hline & \multicolumn{2}{|c|}{ All } & \multicolumn{2}{|c|}{ Rural } & \multicolumn{2}{|c|}{ Urban } \\
\hline & (1) & & (2) & & (3) & \\
\hline & $\ln$ (firstbirth) & $\ln$ (notfirst) & $\ln$ (firstbirth) & $\ln ($ notfirst $)$ & $\ln$ (firstbirth) & $\ln ($ notfirst $)$ \\
\hline \multirow[t]{2}{*}{ During $\times$ morbidity } & -0.010 & -0.005 & -0.001 & -0.010 & -0.016 & 0.016 \\
\hline & $(0.023)$ & $(0.027)$ & $(0.030)$ & $(0.036)$ & $(0.027)$ & $(0.019)$ \\
\hline \multirow[t]{2}{*}{ After $\times$ morbidity } & -0.008 & -0.007 & 0.000 & -0.015 & -0.012 & 0.025 \\
\hline & $(0.023)$ & $(0.026)$ & $(0.030)$ & $(0.035)$ & $(0.028)$ & $(0.019)$ \\
\hline \multirow[t]{2}{*}{ Later $\times$ morbidity } & $-0.065^{* * *}$ & $-0.074^{* * *}$ & $-0.057^{* *}$ & $-0.087^{* * *}$ & $-0.070^{* * *}$ & -0.025 \\
\hline & $(0.019)$ & $(0.022)$ & $(0.025)$ & $(0.029)$ & $(0.023)$ & $(0.016)$ \\
\hline \multirow[t]{2}{*}{ During $\times$ adult mortality } & 0.039 & $0.060^{*}$ & 0.050 & 0.075 & -0.020 & -0.006 \\
\hline & $(0.031)$ & $(0.036)$ & $(0.042)$ & $(0.050)$ & $(0.035)$ & $(0.024)$ \\
\hline \multirow[t]{2}{*}{ After $\times$ adult mortality } & 0.032 & $0.069^{*}$ & 0.049 & $0.084^{*}$ & -0.056 & -0.022 \\
\hline & $(0.031)$ & $(0.035)$ & $(0.041)$ & $(0.049)$ & $(0.035)$ & $(0.024)$ \\
\hline \multirow[t]{2}{*}{ Later $\times$ adult mortality } & -0.004 & 0.024 & 0.027 & 0.048 & $-0.088^{* * *}$ & $-0.068^{* * *}$ \\
\hline & $(0.025)$ & $(0.029)$ & $(0.033)$ & $(0.040)$ & $(0.030)$ & $(0.020)$ \\
\hline $\mathrm{N}$ & 4,237 & & 3,194 & & 1,043 & \\
\hline Baseline & 0.241 & 0.759 & 0.233 & 0.767 & 0.263 & 0.737 \\
\hline
\end{tabular}

Results for estimating SUR models for married/unmarried and first birth/not first birth separately, standard errors in parentheses. All regressions include district and year fixed effects. Additional control variables include the log of the current number of deaths in the age group 20-40 as well as the log of the total number of births. The During period includes 1918-1919; After includes 1920-1921; Later includes 1922-1927. Morbidity and mortality are calculated as the cumulative sum of influenza cases/deaths occurring during the flu period. The stars represent significance at the following p-values: $* \mathrm{p}<0.1 * * \mathrm{p}<0.05 * * * \mathrm{p}<0.01$ 


\section{G Robustness Checks}

\section{G.1 Migration}

Table G1 Fertility effects on county level

\begin{tabular}{|c|c|c|c|}
\hline & (1) & (2) & (3) \\
\hline During $\times$ morbidity & $\begin{array}{l}-0.0005 \\
(0.0010)\end{array}$ & & \\
\hline After $\times$ morbidity & $\begin{array}{c}0.0014 \\
(0.0011)\end{array}$ & & \\
\hline Later $\times$ morbidity & $\begin{array}{c}-0.0060^{* *} \\
(0.0028)\end{array}$ & & \\
\hline During $\times$ adult mortality & & $\begin{array}{l}-0.0671^{*} \\
(0.0391)\end{array}$ & \\
\hline After $\times$ adult mortality & & $\begin{array}{c}0.0415 \\
(0.0245)\end{array}$ & \\
\hline Later $\times$ adult mortality & & $\begin{array}{l}-0.1311^{*} \\
(0.0674)\end{array}$ & \\
\hline During $\times$ child mortality & & & $\begin{array}{r}-0.1245^{* *} \\
(0.0456)\end{array}$ \\
\hline After $\times$ child mortality & & & $\begin{array}{c}0.0759 \\
(0.0567)\end{array}$ \\
\hline Later $\times$ child mortality & & & $\begin{array}{c}-0.2451^{*} \\
(0.1281)\end{array}$ \\
\hline $\mathrm{N}$ & 3,732 & 3,732 & 3,732 \\
\hline $\mathrm{N}$ (cluster) & 25 & 25 & 25 \\
\hline Baseline & 1.62 & 1.62 & 1.62 \\
\hline
\end{tabular}

Dependent variable: conception rate. All regressions include district and month-year fixed effects. Standard errors in parentheses, clustered at the district level. The During period includes August 1918 to November 1918; After includes December 1918 to December 1920; Later includes January 1921 to December 1927. Morbidity and mortality rates are calculated as the cumulative sum of influenza cases/deaths occurring during the flu period, normalized by the district population in 1917. The stars represent significance at the following p-values: $* \mathrm{p}<0.1 * * \mathrm{p}<0.05 * * * \mathrm{p}<0.01$ 


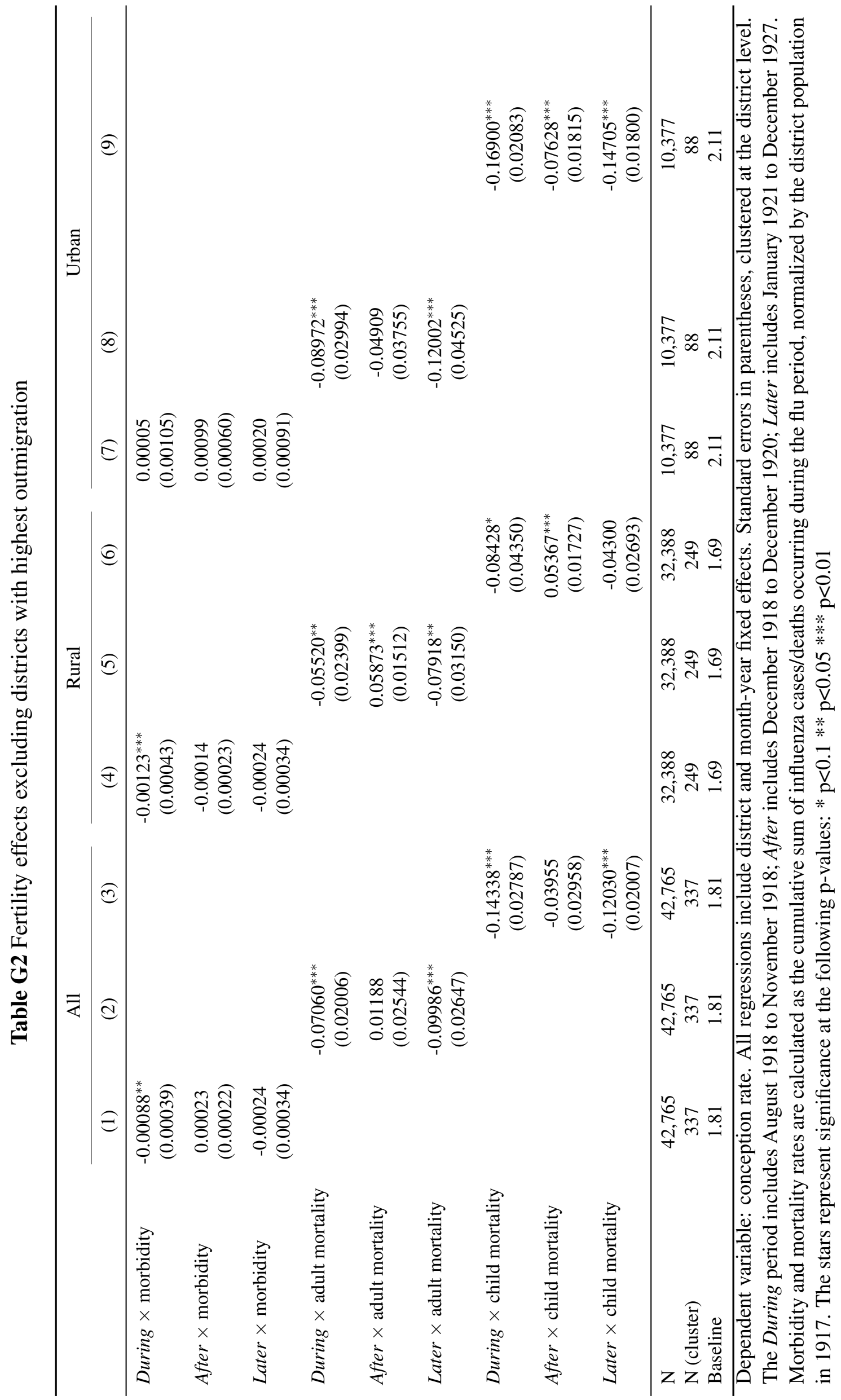


Table G3 Effect of flu intensity on migration

\begin{tabular}{|c|c|c|c|c|c|c|c|c|c|}
\hline & \multicolumn{3}{|c|}{ All } & \multicolumn{3}{|c|}{ Rural } & \multicolumn{3}{|c|}{ Urban } \\
\hline & (1) & (2) & (3) & (4) & (5) & (6) & (7) & (8) & (9) \\
\hline \multirow[t]{2}{*}{ During $\times$ morbidity } & $0.00063^{* *}$ & & & 0.00045 & & & 0.00034 & & \\
\hline & $(0.00029)$ & & & $(0.00056)$ & & & $(0.00023)$ & & \\
\hline \multirow[t]{2}{*}{ After $\times$ morbidity } & 0.00001 & & & 0.00001 & & & -0.00001 & & \\
\hline & $(0.00005)$ & & & $(0.00006)$ & & & $(0.00004)$ & & \\
\hline \multirow[t]{2}{*}{ Later $\times$ morbidity } & 0.00003 & & & 0.00001 & & & 0.00004 & & \\
\hline & $(0.00004)$ & & & $(0.00006)$ & & & $(0.00005)$ & & \\
\hline \multirow[t]{2}{*}{ During $\times$ adult mortality } & & $0.03467^{*}$ & & & 0.00282 & & & $0.04067^{* *}$ & \\
\hline & & $(0.02073)$ & & & $(0.04036)$ & & & $(0.01689)$ & \\
\hline \multirow[t]{2}{*}{ After $\times$ adult mortality } & & 0.00098 & & & -0.00004 & & & 0.00159 & \\
\hline & & $(0.00155)$ & & & $(0.00259)$ & & & $(0.00107)$ & \\
\hline \multirow[t]{2}{*}{ Later $\times$ adult mortality } & & $0.00310^{*}$ & & & $0.00522^{*}$ & & & -0.00008 & \\
\hline & & $(0.00177)$ & & & $(0.00266)$ & & & $(0.00107)$ & \\
\hline \multirow[t]{2}{*}{ During $\times$ child mortality } & & & 0.03461 & & & 0.04807 & & & $0.01399^{*}$ \\
\hline & & & $(0.02269)$ & & & $(0.04645)$ & & & $(0.00838)$ \\
\hline \multirow[t]{2}{*}{ After $\times$ child mortality } & & & 0.00179 & & & 0.00218 & & & $0.00119^{*}$ \\
\hline & & & $(0.00135)$ & & & $(0.00430)$ & & & $(0.00069)$ \\
\hline \multirow[t]{2}{*}{ Later $\times$ child mortality } & & & 0.00196 & & & $0.00709^{*}$ & & & -0.00043 \\
\hline & & & $(0.00135)$ & & & $(0.00362)$ & & & $(0.00070)$ \\
\hline $\mathrm{N}$ & 3,799 & 3,799 & 3,799 & 2,853 & 2,853 & 2,853 & 946 & 946 & 946 \\
\hline $\mathrm{N}$ (cluster) & 366 & 366 & 366 & 270 & 270 & 270 & 96 & 96 & 96 \\
\hline Baseline & 0.010 & 0.010 & 0.010 & 0.009 & 0.009 & 0.009 & 0.013 & 0.013 & 0.013 \\
\hline
\end{tabular}

Dependent variable: net migration. All regressions include district and month-year fixed effects. Standard errors in parentheses, clustered at the district level. The During period includes August 1918 to November 1918; After includes December 1918 to December 1920; Later includes January 1921 to December 1927. Morbidity and mortality rates are calculated as the cumulative sum of influenza cases/deaths occurring during the flu period, normalized by the district population in 1917. The stars represent significance at the following $\mathrm{p}$-values: $* \mathrm{p}<0.1 * * \mathrm{p}<0.05 * * * \mathrm{p}<0.01$ 
Table G4 Fertility effects excluding counties bordering Finland

\begin{tabular}{|c|c|c|c|c|c|c|c|c|c|}
\hline & \multicolumn{3}{|c|}{ All } & \multicolumn{3}{|c|}{ Rural } & \multicolumn{3}{|c|}{ Urban } \\
\hline & (1) & (2) & (3) & (4) & (5) & (6) & (7) & (8) & (9) \\
\hline During $\times$ morbidity & $\begin{array}{c}-0.001^{* *} \\
(0.000)\end{array}$ & & & $\begin{array}{l}-0.001^{* *} \\
(0.000)\end{array}$ & & & $\begin{array}{l}-0.000 \\
(0.001)\end{array}$ & & \\
\hline After $\times$ morbidity & $\begin{array}{c}0.000 \\
(0.000)\end{array}$ & & & $\begin{array}{l}-0.000 \\
(0.000)\end{array}$ & & & $\begin{array}{c}0.000 \\
(0.001)\end{array}$ & & \\
\hline Later $\times$ morbidity & $\begin{array}{l}-0.000 \\
(0.000)\end{array}$ & & & $\begin{array}{l}-0.000 \\
(0.000)\end{array}$ & & & $\begin{array}{l}-0.000 \\
(0.001)\end{array}$ & & \\
\hline During $\times$ adult mortality & & $\begin{array}{c}-0.057^{* * *} \\
(0.018)\end{array}$ & & & $\begin{array}{l}-0.039^{*} \\
(0.023)\end{array}$ & & & $\begin{array}{c}-0.073^{* * *} \\
(0.025)\end{array}$ & \\
\hline After $\times$ adult mortality & & $\begin{array}{l}0.042^{* *} \\
(0.019)\end{array}$ & & & $\begin{array}{c}0.065^{* * *} \\
(0.014)\end{array}$ & & & $\begin{array}{c}0.007 \\
(0.031)\end{array}$ & \\
\hline Later $\times$ adult mortality & & $\begin{array}{c}-0.076^{* * *} \\
(0.025)\end{array}$ & & & $\begin{array}{c}-0.081^{* *} \\
(0.032)\end{array}$ & & & $\begin{array}{l}-0.072^{*} \\
(0.039)\end{array}$ & \\
\hline During $\times$ child mortality & & & $\begin{array}{c}-0.128^{* * *} \\
(0.034)\end{array}$ & & & $\begin{array}{l}-0.070^{*} \\
(0.042)\end{array}$ & & & $\begin{array}{c}-0.179^{* * *} \\
(0.040)\end{array}$ \\
\hline After $\times$ adult mortality & & & $\begin{array}{c}0.047 \\
(0.033)\end{array}$ & & & $\begin{array}{c}0.074^{* * *} \\
(0.020)\end{array}$ & & & $\begin{array}{c}0.021 \\
(0.055)\end{array}$ \\
\hline Later $\times$ adult mortality & & & $\begin{array}{c}-0.111^{* * *} \\
(0.039)\end{array}$ & & & $\begin{array}{c}-0.080^{* *} \\
(0.032)\end{array}$ & & & $\begin{array}{c}-0.135^{* *} \\
(0.061)\end{array}$ \\
\hline $\mathrm{N}$ & 40,667 & 40,667 & 40,667 & 29,870 & 29,870 & 29,870 & 10,797 & 10,797 & 10,797 \\
\hline $\mathrm{N}$ (cluster) & 324 & 324 & 324 & 233 & 233 & 233 & 91 & 91 & 91 \\
\hline Baseline & 1.73 & 1.73 & 1.73 & 1.62 & 1.62 & 1.62 & 2.00 & 2.00 & 2.00 \\
\hline
\end{tabular}

Dependent variable: conception rate. All regressions include district and month-year fixed effects. Standard errors in parentheses, clustered at the district level. The During period includes August 1918 to November 1918; After includes December 1918 to December 1920; Later includes January 1921 to December 1927. Morbidity and mortality rates are calculated as the cumulative sum of influenza cases/deaths occurring during the flu period, normalized by the district population in 1917. The stars represent significance at the following p-values: $* \mathrm{p}<0.1 * * \mathrm{p}<0.05 * * * \mathrm{p}<0.01$ 


\section{G.2 Changes in health district borders}

Table G5 Fertility effects controlling for district changes

\begin{tabular}{|c|c|c|c|c|c|c|c|c|c|}
\hline & \multicolumn{3}{|c|}{ All } & \multicolumn{3}{|c|}{ Rural } & \multicolumn{3}{|c|}{ Urban } \\
\hline & (1) & (2) & (3) & (4) & (5) & (6) & (7) & (8) & (9) \\
\hline During $\times$ morbidity & $\begin{array}{c}-0.001^{* *} \\
(0.000)\end{array}$ & & & $\begin{array}{c}-0.001^{* * *} \\
(0.000)\end{array}$ & & & $\begin{array}{c}0.000 \\
(0.001)\end{array}$ & & \\
\hline After $\times$ morbidity & $\begin{array}{c}0.000 \\
(0.000)\end{array}$ & & & $\begin{array}{l}-0.000 \\
(0.000)\end{array}$ & & & $\begin{array}{c}0.001 \\
(0.001)\end{array}$ & & \\
\hline Later $\times$ morbidity & $\begin{array}{l}-0.000 \\
(0.000)\end{array}$ & & & $\begin{array}{l}-0.000 \\
(0.000)\end{array}$ & & & $\begin{array}{l}-0.000 \\
(0.001)\end{array}$ & & \\
\hline During $\times$ adult mortality & & $\begin{array}{c}-0.076^{* * *} \\
(0.019)\end{array}$ & & & $\begin{array}{c}-0.058^{* *} \\
(0.024)\end{array}$ & & & $\begin{array}{c}-0.093^{* * *} \\
(0.027)\end{array}$ & \\
\hline After $\times$ adult mortality & & $\begin{array}{c}0.022 \\
(0.024)\end{array}$ & & & $\begin{array}{c}0.058^{* * *} \\
(0.014)\end{array}$ & & & $\begin{array}{l}-0.021 \\
(0.037)\end{array}$ & \\
\hline Later $\times$ adult mortality & & $\begin{array}{c}-0.092^{* * *} \\
(0.027)\end{array}$ & & & $\begin{array}{c}-0.083^{* *} \\
(0.034)\end{array}$ & & & $\begin{array}{c}-0.097^{* *} \\
(0.043)\end{array}$ & \\
\hline During $\times$ child mortality & & & $\begin{array}{c}-0.152^{* * *} \\
(0.026)\end{array}$ & & & $\begin{array}{c}-0.181^{* * *} \\
(0.021)\end{array}$ & & & $\begin{array}{c}-0.152^{* * *} \\
(0.026)\end{array}$ \\
\hline After $\times$ child mortality & & & $\begin{array}{l}-0.024 \\
(0.036)\end{array}$ & & & $\begin{array}{l}-0.056^{*} \\
(0.031)\end{array}$ & & & $\begin{array}{l}-0.024 \\
(0.036)\end{array}$ \\
\hline Later $\times$ child mortality & & & $\begin{array}{c}-0.110^{* * *} \\
(0.023)\end{array}$ & & & $\begin{array}{c}-0.133^{* * *} \\
(0.019)\end{array}$ & & & $\begin{array}{c}-0.110^{* * *} \\
(0.023)\end{array}$ \\
\hline $\mathrm{N}$ & 46,756 & 46,756 & 46,756 & 35,109 & 35,109 & 11,647 & 11,647 & 11,647 & 46,756 \\
\hline $\mathrm{N}$ (cluster) & 367 & 367 & 367 & 270 & 270 & 97 & 97 & 97 & 367 \\
\hline Baseline & 1.81 & 1.81 & 1.81 & 1.68 & 1.68 & 1.68 & 2.14 & 2.14 & 2.14 \\
\hline
\end{tabular}

Dependent variable: conception rate. All regressions include district and month-year fixed effects. Standard errors in parentheses, clustered at the district level. The During period includes August 1918 to November 1918; After includes December 1918 to December 1920; Later includes January 1921 to December 1927. Morbidity and mortality rates are calculated as the cumulative sum of influenza cases/deaths occurring during the flu period, normalized by the district population in 1917. The stars represent significance at the following $\mathrm{p}$-values: * $\mathrm{p}<0.1 * * \mathrm{p}<0.05 * * * \mathrm{p}<0.01$ 